\title{
The Influence of Integration on the Remittance Behaviours of Diasporas
}

by

Dacia Douhaibi, BA

A thesis submitted to the Faculty of Graduate and Postdoctoral Affairs in partial fulfillment of the requirements for the degree of

\author{
Master of Arts \\ in \\ Carleton University \\ Ottawa, Ontario \\ (C) 2012 Dacia Douhaibi
}

The Norman Paterson School of International Affairs 
Library and Archives

Canada

Published Heritage

Branch

395 Wellington Street

Ottawa ON K1A ON4

Canada
Bibliothèque et

Archives Canada

Direction du

Patrimoine de l'édition

395 , rue Wellington

Ottawa ON K1A ON4

Canada
Your file Votre référence

ISBN: 978-0-494-94594-0

Our file Notre référence

ISBN: $978-0-494-94594-0$
NOTICE:

The author has granted a nonexclusive license allowing Library and Archives Canada to reproduce, publish, archive, preserve, conserve, communicate to the public by telecommunication or on the Internet, loan, distrbute and sell theses worldwide, for commercial or noncommercial purposes, in microform, paper, electronic and/or any other formats.

The author retains copyright ownership and moral rights in this thesis. Neither the thesis nor substantial extracts from it may be printed or otherwise reproduced without the author's permission.
AVIS:

L'auteur a accordé une licence non exclusive permettant à la Bibliothèque et Archives Canada de reproduire, publier, archiver, sauvegarder, conserver, transmettre au public par télécommunication ou par l'Internet, prêter, distribuer et vendre des thèses partout dans le monde, à des fins commerciales ou autres, sur support microforme, papier, électronique et/ou autres formats.

L'auteur conserve la propriété du droit d'auteur et des droits moraux qui protege cette thèse. $\mathrm{Ni}$ la thèse ni des extraits substantiels de celle-ci ne doivent être imprimés ou autrement reproduits sans son autorisation.
In compliance with the Canadian Privacy Act some supporting forms may have been removed from this thesis.

While these forms may be included in the document page count, their removal does not represent any loss of content from the thesis.
Conformément à la loi canadienne sur la protection de la vie privée, quelques formulaires secondaires ont été enlevés de cette thèse.

Bien que ces formulaires aient inclus dans la pagination, il n'y aura aucun contenu manquant. 


\section{Abstract}

Diasporas are known to be either promoters of peace or harbingers of conflict for their countries of origin. This study sought to investigate the claim that the host country environment is integral to supporting or constraining diasporic activity. The relationship between integration into a host country and remittance behaviours was chosen as the focus through which to illuminate that relationship. Canada and Kenya, both countries harbouring a large number of South Sudanese diasporas, were chosen as countries of comparison that would provide a clear difference on the independent variable, integration, due to their divergent treatments of refugees. The empirical evidence presented here suggests that higher levels of integration may not result in higher remittance levels. Diasporas in Canada and Kenya displayed similar levels of political and social remittances, and a small difference in financial remittances. The presence of transnational linkages and the presence of social capital may account for these findings. 


\section{Acknowledgements}

I am grateful to many people for the completion of this work. First, this research was made possible with generous funding from the Centre for Security and Defense Studies, Carleton Graduate Studies and the Bill McWhinney Memorial Scholarship. These awards enabled me to travel to complete my research, as well as undertake months of writing.

My Supervisor David Carment, and advisors Valerie Percival and Yiagadeesen Samy provided much support and ongoing feedback that was instrumental to my ability to complete this work, and certainly helped the end product become something more coherent and structured than I could have put together on my own. Other professors also provided extremely helpful feedback and advise as I progressed. Rima Berns-McGown from the University of Toronto graciously gave me her time and expertise in constructing the survey and interview questions that allowed me to collect the data for this study. James Milner from the Political Science department at Carleton and Awad Ibrahim from the University of Ottawa also met with me and gave me very useful advise on approaching the South Sudanese communities in Canada and Kenya. Thank you, thank you to all.

I am also extremely grateful to the South Sudanese communities in Canada and Kenya that welcomed me into their homes and their community gatherings and most importantly, allowed me access to personal and often difficult personal feelings and experiences. There were several people that I was fortunate to spend a lot of time with, and their willingness to give me so much of their time, and so much information about the history of their country, and the access they granted me to details of their lives, members of their family and events and activities that occurred within the community will never be forgotten. I learned so much more than I expected, far and above what is presented in this paper. I met wonderful, generous, strong, devoted people that fill me with hope for the future of the newly independent country of South Sudan.

Lastly, I am thankful for the friends and family that supported me through this process. There were some times of celebration, but there were certainly far more times of struggle, and there were people that have to be credited with pushing me towards the light at the end of the tunnel. First and foremost, Stacy - thank you so much for your unending support. You never stopped being supportive and championing me, and I will always remember that. Shannon - for the hours of writing together, bouncing ideas off each other, and supporting each other - you are almost at the end woman, keep pushing. Thanks for your time and your shoulder. Warren, thank you for reading drafts and learning about what I am writing about just so I could talk things through with you.

This thesis has been a part of big changes that occurred in my life over the past year, and I am so grateful to all of those who saw me through those things, and this paper, from beginning to end. 


\section{Table of Contents}

Abstract.........................................................................................................................................................ii

List of Tables ..............................................................................................................................................vi

List of Figures .................................................................................................................................................. vii

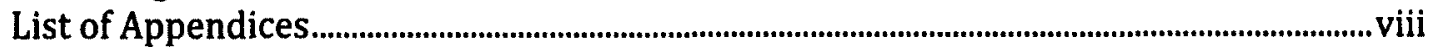

INTRODUCTION

CHAPTER ONE: A Literature Review: Determining Diaspora Behaviour ..........................................13

1.1 Ethnic Mobilization.............................................................................................................................14

1.2 The Role of the Host Country..................................................................................................19

1.3 The Influence of Individual Factors: Heterogeneity in Diasporic Communities ........34

1.4 The Country of Origin Dynamics ................................................................................................38

1.5 Other Motivations: Kinship, Personal Gain, Empathy, and Obligation ............................43

1.6 What About Distance? .........................................................................................................................4 46

1.7 Conclusion ................................................................................................................................................... 48

CHAPTER TWO: Integration Theory...........................................................................................................51

2.1 Establishing a Concept of Integration ……..................................................................................53

2.2 Indicators of Integration ....................................................................................................................54

2.3 The Importance of Integration into the Host Country .......................................................59

2.4 The Relationship between Integration and Diasporic Behaviour ......................................62

2.5 Transnationalism: An Intervening Force? ...................................................................................64

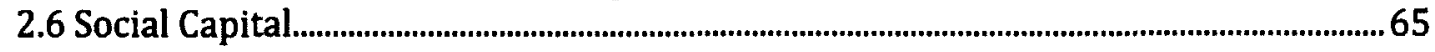

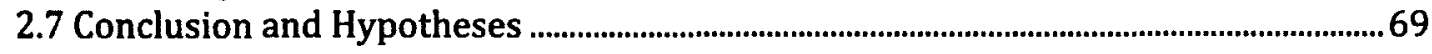

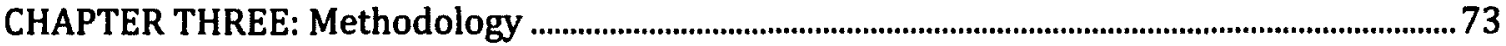

3.1 Study Design ……..............................................................................................................................73

3.2 Study Populations.....................................................................................................................................75

3.3 Data Collection Instruments ....................................................................................................... 77

3.4 Data Analysis ......................................................................................................................................

3.5 Limitations ...............................................................................................................................................

CHAPTER FOUR: Background .............................................................................................................. 84

4.1 Integration Experiences of South Sudanese Diasporas in Canada and Kenya ...........84

4.2 Conclusion: Integration Profiles of Canada and Kenya.........................................................91

CHAPTER FIVE: Evaluating the Data .......................................................................................................93

5.1 Integration Experiences.......................................................................................................................93

5.2 Host Country Opportunity Structures.......................................................................................... 100

5.3 Testing the Hypotheses.................................................................................................................... 105

5.4 Conclusions ........................................................................................................................................... 118

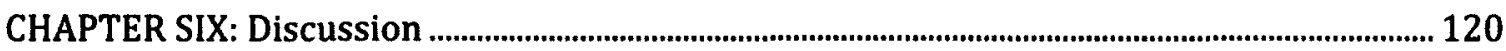

6.1 Emergent Themes .......................................................................................................................... 120

6.2 Research Questions: Asked and Answered.......................................................................... 131

6.3 Conclusion ............................................................................................................................................... 134 


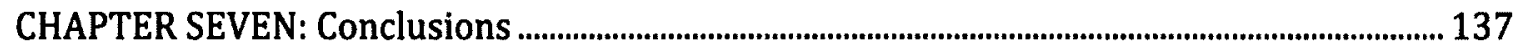

7.1 Summary of Findings .......................................................................................................... 137

7.2 Limitations and Contributions of this Study .................................................................... 140

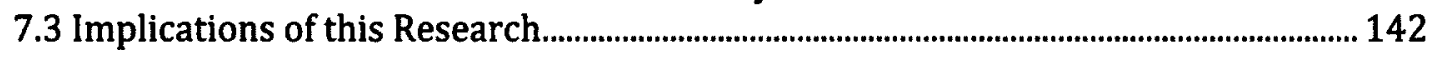

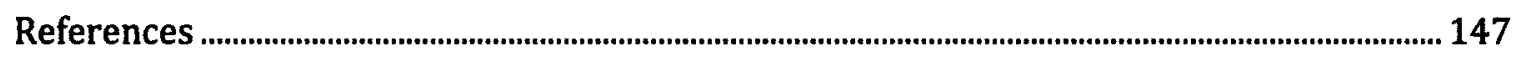

APPENDIX 1

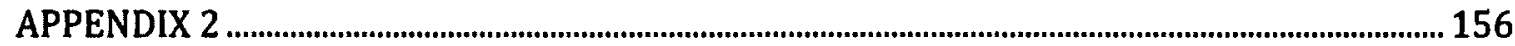

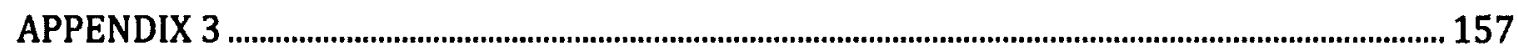

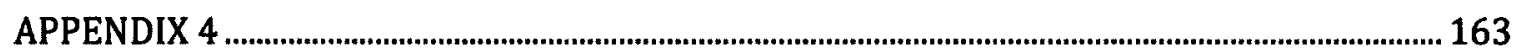




\section{List of Tables}

Table 1: Factors in a Host Country that Increase Capacity or Desire to Engage in Home-Country Oriented Activity .................................................................................... 25

Table 2: Summary of this section with Supporting Evidence............................................... 37

Table 3: Summary of factors in the country of origin that increase individual opportunity to engage with the country of origin, including examples.................. 40

Table 4: Summary of Motivational Factors with Examples.................................................. 45

Table 5: Summary of Indicators of Integration as Presented by Marrow...................... 56

Table 6: Summary of Section 3 with Example............................................................................ 61

Table 7: Summary of Section 4 with Example........................................................................... 63

Table 8: Summary of Section 3 with Examples........................................................................... 69

Table 9: Results of the Longitudinal Survey of Immigrants to Canada ...........................85

Table 10: Canada and Kenya compared across UNHCR description of integration .. 92

Table 11: Integration profile of diasporic communities in Canada and Kenya ........... 93

Table 12: Self reported feeling of integration of interview and survey participants 95

Table 13: Factors in a host country that Increase capacity or desire to engage in home-country oriented activity..........................................................................................100

Table 14: Correlation between host country and remittance behaviours.....................106

Table 15: Indicated presence of transnational networks by host country..................115

Table 16: Summary of hypotheses and results..........................................................................139 


\section{List of Figures}

Figure 1: Summary of Conclusions of Section 1.2............................................................... 23

Figure 2: Factors that Influence Individual Diaspora Activity ........................................... 35

Figure 3: Simplified model of the factors that contribute to diasporic activity........... 49

Figure 4: Predicted model of diasporic activity.......................................................................... 70 
List of Appendices

APPENDIX 1 ............................................................................................... Error! Bookmark not defined. APPENDIX 2 .......................................................................................... Error! Bookmark not defined.

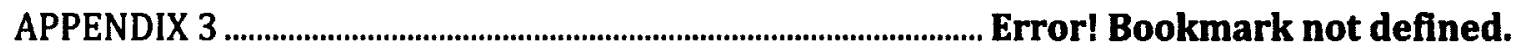
APPENDIX 4 ................................................................................... Error! Bookmark not defined. 


\section{INTRODUCTION}

Although migration has been an important part of contemporary world history, ${ }^{1}$ contemporary conflicts have also given rise to a vast increase in refugees, or forced migrants. This mobilization of people allows for the relatively rapid creation of large and influential diaspora communities (Demmers, 2007), formed when people migrate out of one area, whether by force or choice. Maintaining a connection to the homeland and to other members of a diaspora through discourse, encouragement, pressure, or manipulation supports the maintenance of a diasporic identity.

Although there is no common definition of diaspora, for the current study a working definition can be derived from the literature. ${ }^{2}$ A diaspora is a heterogeneous transnational collective whose members have unique personal histories that inform and shape an active connection with a country of origin. As a significant number of diasporas maintain these connections, their actions have increasingly important influences in homeland affairs. ${ }^{3}$ In addition, the ease of travel, new communication technologies, and the modern global media structure promote the persistence of strong connections between diasporas and homelands. This means that today, diasporic communities can play an increasingly influential role in the politics of their home and host countries (Adamson, 2008; Koinova, 2009; Collier and Hoeffler, 2000).

\footnotetext{
${ }^{1}$ Williamson (2006), of the International Monetary Fund, reports a boom in world mass migration since World War Two and indicates that the foreign-born share of mass migration increased by about a third in Oceania between 1965 and 2000 (from 14.4\% to 19.1\%), more than doubled in North America (from 6\% to $13 \%$ ), and more than tripled in Europe (from $2.2 \%$ to $7.7 \%$ ).

${ }^{2}$ A challenge of this term is that no agreed definition of diaspora exists and it has different meanings to different stakeholders. The definition provided here comes from consistent themes that emerge regarding the qualities of diasporas in current literature. See Koinova (2009), Adamson (2008), Ionescu and Geneva (2005), and Newland and Patrick (2004) for details.

${ }^{3}$ The University for Peace (2006) and Zunzer (2004) argue, for example, that diasporas can be a muscular force in the affairs of their home countries.
} 
It is increasingly common for academics, policy centres, and governments to consider the effect of diaspora communities on the social, political, and economic fabrics of their countries of origin, as well as the countries that become their temporary or permanent homes. In large part, this has happened as awareness of the relevance of the actions of transnational actors to national and international security has increased. ${ }^{4}$ Such concern over the consequences of diaspora community actions on security led Brinkerhoff to remark that "post-conflict governments and the international community ignore diasporas at their peril" (2009, p. 34).

One perspective in the ongoing debate concerning the effects that diasporas may have on the conflict dynamics in their countries of origin is that of Collier $(2000,2001$, 2006), who suggests that diasporas aggravate conflict by reinforcing factionalisation and by contributing to the capacity of opposing groups to continue fighting, hence undermining the potential for peace. Significantly, Collier and Hoeffler (2001) have suggested that support from diaspora groups is one of the biggest reasons for the continuation of protracted conflicts, because support provides the opportunity for conflicting parties to continue fighting. ${ }^{5}$

Although a view of diasporas as conflict mongers has been disputed in the literature, evidence suggests that diasporas can and do act in destabilizing ways, whether intentionally or not. ${ }^{6}$ On the other hand, it has been argued that the ability of these

\footnotetext{
${ }^{4}$ In a study of the relationship between diasporas and Haiti, the Dominican Republic, and Mexico, Shain (2000) claims that large diaspora populations from these countries live in the Unites States and play such a large economic and political role that they have become major factors in redefining national philosophies back home.

${ }^{5}$ Specifically, Collier and Hoeffler (2001) found that after five years of post-conflict peace, the presence of a large diaspora increased the likelihood of renewed conflict six fold. Their conclusions led them to argue that opportunities mean more in determining whether conflict will take place than do motives.

${ }^{6}$ Recent work by Brinkerhoff (2009) has suggested that even when diasporas are acting with the best intentions (i.e., to support stability, maintain peace, contribute to post-conflict reconstruction) their
} 
communities to contribute to peace building has been ignored, or at least given little attention (Cochrane, 2006; Mohamoud and Osman, 2008) ${ }^{7}$; accordingly, a new discourse has emerged where diaspora groups are viewed as partners in the peace process. Some cases demonstrate that diasporas have acted in ways that support peace, reconciliation, ${ }^{8}$ and post-conflict reconstruction and development. Turner (2008) outlines two major peace-building roles that diasporas play in their countries of origin. They have acted as external promoters of post-conflict peace, providing social, political, and economic support (what Turner calls the "moral economy of the diaspora" (p. 11)); and as internal promoters of peace-building when addressing personnel shortages and initiating development and governance programs. In sum, the literature currently supports the idea that, as Brinkerhoff states in regard to political developments in the country of origin, diasporas are neither "exclusively saints or sinners, but their significance to these process and outcomes can no longer be ignored" $(2009$, p. 36).

\section{Statement of the Problem}

Because diasporas are increasingly influential, with an influence further bolstered by technological innovation, empirical work that deciphers diaspora behaviour is vital. This is particularly important in light of the fact that diasporas both destabilize and stabilize home communities. Clearly, some diasporas support peace, some undermine

actions can have unintended negative consequences due to asymmetrical support for particular groups at home. This may result in destabilization rather than support.

${ }^{7}$ See also Adamson (2008). Adamson notes a danger in making too close a link between security and migration: it causes states to overreact. She argues that the policy tightening that occurred in the United States after the events of September 11, 2001 led to alienation of immigrant groups, destruction of public diplomacy efforts, dismantling of civil liberty institutions, and weakening of diaspora civil society networks that could have supported political liberalization in emergent democracies.

${ }^{8}$ The potential for diasporas to act in a mediating capacity is increasingly noted in the literature. Using Zartman and Touval's (1996) concept of leverage, Shain and Barth (2008) argue that in many instances diasporas have more potential than other actors to push a conflicting party in a certain direction through threat of withdrawal of much needed support--particularly in terms of remittances and investment. 
peace, and yet others do little or nothing. We may classify this behaviour as (a) no action or engagement with the country of origin; (b) negative action or engagement with the country of origin; or (c) positive action or engagement with the country of origin. It is yet to be conclusively determined why any individual diaspora may follow any one of these avenues. This puzzle underlies the research presented in this study.

Because of the potential influence of diasporas on conflicts at home, this area of inquiry is particularly important for diasporas that come from conflict-affected states. The host country environment has been identified as a factor affecting diaspora engagement with the country of origin. ${ }^{9}$ More specifically, it has been pointed out that integration into the host country is an important factor affecting diaspora engagement. ${ }^{10}$ The nature of the relationship between integration and engagement is not well understood, however, and little empirical evidence is available to use to generate theories.

In light of this puzzle, and in consideration of literature that suggests a relationship between integration and engagement, the overarching question asked in this study is: Does integration into a host country affect the engagement choices of diasporas? Within this question, a more specific research question was asked: Does access to political, economic, and social opportunity structures increase or decrease the remittance behaviours of conflict generated diasporas?

\footnotetext{
${ }^{9}$ Brinkerhoff (2009) and Smith (2007) theorize that the host country environment is a critical consideration in the determination of diaspora action, but do not undertake empirical work to qualify their positions. Newland and Patrick (2004) of the Migration Policy Institute have indicated that very little is known about the link between diaspora communities of refugee origin and engagement with countries of origin; or about the relationship between successful integration of emigrant communities and their engagement with the country of origin.

${ }^{10}$ Integration here is understood to be a process that involves the host state driven provision of rights and access to what I will here describe as opportunity structures (see Chapter One). Integration, contrary to assimilation does not result in the loss of all previously held identity markers or cultural practices, but rather is an adjustment both on the side of the immigrant and the new society (see Chapter Two).
} 


\section{Main Arguments}

In the spirit of a behavioural model created by Starr and Most (1976) to explain political behaviour, Shane and Barth (2003) and Turner (2008) state that motive and opportunity condition diaspora engagement with a country of origin. Al-Ali, Black, and Koser (2001) argue for the particular importance of capacity and access to opportunity structures provided by the host country in prompting behaviour. Cioffi-Revilla and Starr (1995) also argue that the opportunity to act is constrained or allowed depending on one's structural context. In this paper, I will first argue that capacity (environmental factors creating possibilities and constraints, i.e., the structural context) and desire (the motivation behind choices people make) are two critical components of the decision making process for diasporas. Consequently, understanding both the capacity of diasporas and their motivations are important in understanding why diasporas have acted in certain ways and in predicting how they may act.

Access to opportunity structures has been cited as an important intervening environmental factor in determining diaspora behaviour (Al-Ali, Black, and Koser 2001a; 2001b). If this is the case, whether a diaspora has access to social, political, or economic opportunity structures, that is, to legitimate structures with which to achieve a desired outcome for a conflict in a country of origin, is a critical factor in determining behaviour.

The second argument presented in this paper is that integration is an important consideration in a model of diasporic activity. While the relationship between integration and the engagement of diasporas with a country of origin is not clear from the literature, Brinkerhoff (2009) suggests a relationship. In questioning whether integration is necessarily a determinant of engagement, she predicts that if it is, low levels of 
integration will result in low levels of engagement. Guarinzo et al. (2003) similarly predict that high levels of integration will result in high engagement levels. This is perhaps reasonable, given the first argument made here: Integration affects access to political, economic, or social opportunity structures through which a diaspora can act directly or indirectly in the affairs of a country of origin, and may relate to identity, which underlies the motivation for the engagement of a diaspora. As a result, the level of diasporic integration will have consequences on the level of social, political, or financial remittances transferred from a diaspora to the country of origin.

In Chapter One, I present the argument, as indicated by the literature, that the host country, through its ability to control capacity, is critical in determining the ways diasporas engage with the host country. This engagement is visible and measurable in the remittance behaviours of diasporas. In Chapter Two, I present literature that indicates that a critical factor in determining access to host country structures is a diaspora's ability to integrate in to the host society. Based on the literature, I hypothesize that integration affects the engagement of diasporas with their country of origin. Specifically, I suggest that diasporas that have integrated into a host environment should demonstrate higher levels of remittance behaviours than those that have not integrated. ${ }^{11}$

In the chapters that follow, the methodology used to collect data to explore the arguments presented in this study will be detailed, the results presented, and the implications discussed. The final chapter, Chapter Seven, will address conclusions based on the findings presented and recommend avenues for further research.

\section{Objectives}

\footnotetext{
11 Remittances are transnational activities, categorized as political, economic or social. Remittances represent the social ties of solidarity, reciprocity, and obligation that bind migrants and their kin and friends across state-controlled national borders. See Chapter One and Appendix 1 for more detail.
} 
This study has three objectives. The first objective is to create a model that describes diaspora behaviour while delving into how integration into a host country contributes to engagement with the country of origin, as evidenced by the presence of remittance activities. This is important on the road to determining ways of encouraging positive intervention of diasporas. The second objective is to collect data on diaspora behaviour in two different host environments, one that has allowed diaspora integration, and another that has not, in order to analyze the differences caused by these differing host environments. The third objective is to identify whether host country policy has the potential to affect the engagement of diasporas with their country of origin.

\section{Methodology}

This report begins with a comprehensive literature review that investigates how diasporas behave; the available evidence of the ways in which diasporas engage with a country of origin; the different forces that affect and shape diaspora behaviour; and behavioural theories that could explain the choices that diasporas make. From the literature, a model was created that summarizes the factors contributing to the actions of diasporas. Significant gaps in the literature were identified, such as the role of opportunity structures in the host country in allowing or constraining diaspora behaviour; the relationship between integration and access to these opportunity structures; and the intervening role of transnational linkages on the power of the host country to constrain behaviour. Based on the literature, a framework was created that incorporates integration and the factors of desire and capacity that underpin behaviour.

This study adopts a comparative framework in which the opportunity structures for diasporas in Canada and Kenya (countries with distinct immigration policies and sharp 
differences in the political culture) are analyzed to provide indications of the consequences these structures have in disparate host country environments. Evidence for these opportunity structures was derived from immigration policies, statistics, and examples of diaspora collaboration in the host countries. This allowed for insight into the nuanced ways in which host country opportunities structure diaspora action, which will have broad implications for the study of post-conflict states. The use of this framework advances and refines what is known about factors that contribute to diaspora action. This study is unique in research on diasporic communities as it provides empirical data on the affect of integration, with consideration of the role of opportunity structures, on action directed towards a country of origin.

Evidence was gathered in Canada and Kenya through surveys and interviews conducted with 62 South Sudanese respondents to provide answers to the research questions presented above. A multi-strategy research design was chosen, as this strategy allows for the collection of qualitative data, which shows the general perspectives of subjects, and for the collection of quantitative data, which explores specific issues. ${ }^{12}$ Utilizing this research strategy allows for the bridging of a post-positivist approach, which seeks to predict, control, and generalize data, with a constructivist approach, which describes and interprets data and seeks to understand the phenomenon under study (Denzin and Lincoln, 2000). King, Keohane, and Verba (1994) second this methodology and argue that most research does not fit clearly into one category (quantitative or qualitative) alone, and that the best research combines elements of each to understand

\footnotetext{
${ }^{12}$ This strategy is recommended by Bryman and Teevan (2005) in their presentation of social science research methods.
} 
accurately the social world. ${ }^{13}$ In addition, utilizing this research strategy allows for consideration of observed, measurable outcomes and appreciation of reasons why those outcomes occur and the meaning behind them--valuable when exploring relationships that have not previously been addressed empirically (Merriam, 2009). More information on the methodology used in this study will be provided in Chapter Three.

\section{Sudanese Diasporas in Canada and in Kenya}

The 2006 Census (Statistics Canada, 2006) reported that 12,640 residents of Canada self-identified their ethnic background as "Sudanese."14 The majority of the Sudanese diaspora in Canada and Kenya has arrived in the last two decades, seeking asylum from state repression, economic collapse, and the escalation of conflict. In Canada, they came principally as Government Assisted Refugees (GAR), privately sponsored refugees, or members of the Family Class (The Mosaic Institute, 2009). Most have settled in Toronto. For many, the flight from Sudan was prompted by the advent of the National Islamic Front (NIF) and Lieutenant General--now President--Omar Al Bashir, who, in 1989, usurped control of the government and began a systematic crackdown on internal dissenters. Those who identify as "southerners" in the diaspora are mainly Dinka, Nuer, and Bari. On the other hand, the majority of refugees and asylumseekers in Kenya live in designated camps, although they often seek to make their way to urban areas to escape the harsh living conditions in the camps and in search of better

\footnotetext{
${ }^{13} \mathrm{King}$, Keohane, and Verba (1994) also suggest that qualitative research is valuable in explaining ambiguous causal findings and that qualitative research is made stranger with consideration of the strict methodology used in quantitative research.

${ }^{14}$ An organization called Diverse Hamilton suggests that a more accurate estimate of that number would be 40,000 , while some Southern Sudanese organizations in southern Alberta have estimated that as many as 80,000 individuals of Sudanese origin now live in Canada. The authors of a report commissioned by the Sudan Task Force of the Department of Foreign Affairs and International Trade from the Mosaic Institute (2009) claim that the true size of the Sudanese diaspora in Canada may be somewhere between the "official" census count of 12,640 , on the low end, and Diverse Hamilton's 40,000 -person tally on the high end.
} 
opportunities (UNHCR, 2011). The United Nations High Commissioner for Refugees indicates that in 2011, 32,000 refugees from Sudan were living in Kenya, the majority of whom came from the south (UNHCR, 2011). Thousands of Kenya's refugees now live illegally and largely undocumented in Nairobi, including many South Sudanese. An official count of urban refugees in Nairobi has never been made, but estimates range between 15,000 and 100,000 (Human Rights Watch, 2002). ${ }^{15}$ In Kenya, urban refugees are commonly subject to harassment and violence from police and government officials. Since independence, the South Sudanese refugees that have moved into cities and towns experience less harassment than other nationalities, although they are still excluded from integrating into the formal economy and experience poor access to many services (Jaji, 2009). To survive, urban refugees in Kenya typically run businesses, live by means of remittances from family members, or work as casual labourers.

\section{Summary}

Through an analysis of the behaviour of South Sudanese diasporas in Canada and Kenya, this study addresses the question of whether integration has an influence on the capacity and desire of diasporas to engage in remittance behaviours.

In evaluating the data collected, I did not find support for hypothesis one. The empirical evidence presented here did not support the overall hypothesis that integration into a host country environment will facilitate a higher degree of remittance behaviours through the permission of access to opportunity structures. The one exception to this was financial remittances, which I did find to be correlated with integration. Future studies may need to increase the subject pool to determine whether a correlation may be

\footnotetext{
${ }^{15}$ Some of the most vulnerable and high-profile refugees are granted limited protection and assistance and affluent refugees may also persuade the immigration department to give them some legal status to stay in the towns (Gitari, 2000).
} 
determined for social or political remittances. I did find support for hypotheses two and three. It would appear that limited capacity may not restrain diasporas who are highly motivated from acting in ways they wish, evidenced by the high degree of political and social remittance behaviours of the South Sudanese diaspora. This suggests support for hypothesis two. The presence of transnational networks, and the significant number of diasporas that are part of these networks, with the high level of political and social remittances found by diasporas in both Kenya and Canada, led me to conclude that these networks might facilitate transnational activities. The presence of transnational linkages and the presence of social capital are argued to explain the unexpected level of remittances from the South Sudanese diaspora community in Kenya. These factors may stand in place of opportunity structures and provide platforms from which motivation to engage in activities can be enacted.

There are both international and national benefits to better understanding what underlies the behaviour of diasporas. Diasporas do affect the trajectory of conflicts in their countries of origin, and they have enough force to be considered an interest group with the potential to spoil a fragile peace or undermine negotiations. It is in the best interests of the international community to work towards understanding the factors that push a diaspora towards action, or hold them back from acting. On a national level, there have been growing concerns around the relationship between migration and security, and particularly the consequences of diaspora groups on Canadian national security. This has resulted in an increase in political interest in diasporas, and questions of whether Canada needs to develop diaspora policy. Adamson (2008) argues that the key to managing the relationship between migration and security is state policy. Here I argue that host 
governments should engage with resident diasporas in ways that support and enhance their sense of identification with the host country, their ability to build working interethnic relationships and their capacity to support development contributions to the country of origin.

Little is known about how the South Sudanese diaspora is engaging with South Sudan since the country has gained its independence. While South Sudan has achieved its long-awaited independence, the nation-building process is just beginning. As South Sudan addresses challenges posed by a massive influx of returnees, threats from rebel militia, the accommodation of ethnic and tribal diversity and the strengthening of state institutions, its people are working towards a more peaceful future. The large body of Southern Sudanese diasporas suggests that the role of diasporas in these processes is a key point for consideration, research and policy prescription. Conversations about the involvement of the South Sudanese diaspora in the affairs of South Sudan are critical today as the country faces two conflicts: the precarious balance on the brink of interstate war with Sudan over unresolved issues of border demarcation and oil revenue sharing and as South Sudan struggles with internal ethnically driven conflict.

As South Sudan remains in a precarious economic and political position, understanding the motivations and constraints of diaspora engagement is valuable for the country. Canada hosts a large diaspora population and has expressed the desire to find new ways of adding to its international presence in conflict mediation and peace promotion. Understanding how the choices of diasporas are influenced by their host environment may contribute to our ability to move forward with these goals. 


\section{CHAPTER ONE: A Literature Review: Determining Diaspora Behaviour}

If, as Shane and Barth (2003, p. 451) suggest, "diasporic activities and influences in the homeland, despite their international location, expand the meaning of the term domestic politics to include not only politics inside the state, but also inside the people," factors which influence and shape diasporic activities are important considerations to domestic policy makers. Relying on a review of current literature, here present literature that supports the argument that a host country environment is crucial in determing di aspora behaviour. A host country plays a definitive role in determining if and how diasporic communities act by constraining or supporting capacity and shaping motivation. As this chapter progresses, factors presented in the literature (see Table 1) will provide a starting point from which to determine the capacity of diasporas to act.

Several authors (Shain and Barth, 2003; Koser, 2007; Turner, 2008) who concern themselves with the actions of diasporas point to two broad forces underlying decisionmaking behaviour: the capacity to act and the desire to actually do so. For example, Shain and Barth (2003) state that for a diaspora to exert influence on a homeland's foreign policy, motive and opportunity must exist. Diasporas must both want to exert influence and they must have the capacity to do so.

Capacity, otherwise termed opportunity, names the possibilities and constraints, or structural context, that affects behaviour. Desire, or willingness, describes the choices people make in light of those possibilities and according to other motivating factors such as a sense of obligation, empathy, kinship, or coercion (Cioffi-Revilla and Starr, 1995). As well, Al-Ali, Black, and Koser (2001a, 2001b) argue that the capability of individuals and communities to become involved may depend on the skills and resources available to 
them, which, in turn, rests on the opportunity structures in their countries of destination.

Cioffi-Revilla and Starr (1995) argue that opportunity and willingness, as jointly

necessary conditions, provide the fullest account for any behavioural phenomenon. ${ }^{16}$

Because of the complexity of factors that underpin opportunity and desire, understanding diaspora behaviour is a challenge. The host country, country of origin, and the broader international environment supports or constrains the ability of diasporas to act. A meagre literature base addresses these factors. In this chapter, I will address the arguments that are presented and establish a framework for studying the intervening role of the host country on the capacity and desire of diasporas to become actively engaged with the affairs of the country of origin. I will also identify other factors that play a significant role in determining diasporic activity. The latter is important in establishing other variables for consideration and to demonstrate the significance of the host country environment above other factors. The result of this chapter will be the construction of a model of diaspora behaviour that emphasizes the relative importance of the host country.

As a precursor to the development of a model of diaspora behaviour, it is important to address the question of why diasporas act in collectives towards the country of origin. Without some consideration of this issue, I have no basis to continue my argument regarding what influences such ethnic mobilization.

\subsection{Ethnic Mobilization}

To address adequately the idea of ethnic mobilization, we first will consider the theoretical roots of ethnic mobilization. Then it will be essential to relate ethnic

\footnotetext{
${ }^{16}$ Most and Starr (1976) developed the 'opportunity-willingness' framework to analyze behaviour in the context of international conflict. This model identifies opportunity and willingness as the components that underpin a decision to act.
} 
mobilization theory to a discussion of diasporic behaviour. The importance of ethnic identities, to both individuals and groups has been powerfully reasserted over the past three decades as the belief that incoming ethnic groups would simply assimilate into the dominant culture of a host country has faded. National interethnic competition for resources or power has led to increased salience of the ethnic self and ethnic affiliation. Ethnic identities encourage the support of co-ethnics, or a shared ethnic identity is created for the purpose of political mobilization. As ethnic politics have increased in the decades since World War Two and intrastate conflicts have become far more common, the importance of understanding the role of ethnicity in determining collective behaviour cannot be understated.

The study of ethnicity has roots in sociology, first introduced as a comparative category by Barth (1969). Barth and his collaborators observed how the boundaries between two ethnic groups are maintained with reference to in- and out-groups ${ }^{17}$ and proposed that for boundaries to be actively maintained they need to be continually validated and this requires regular interaction with members of out-groups. In his thinking, Barth assumes that ethnic boundaries are the outcome of negotiations of classification between actors situated in a social field. Three characteristics of a field--the institutional order, distribution of power, and political networks--determine the strategy that actors adopt in ethnic boundary making.

17 The differentiation of in-group from out-group membership, discussed within anthropological literature, is important to this discussion as it points to another factor underlying the unity of members within a collective-- an addition or complement to purposeful construction or social mobilization. Within anthropological literature, the phenomenon of in-group favouritism or bias is accepted as one of the most reliable findings in intergroup behaviour. In-group favouritism results from a group's efforts to achieve positive group distinctiveness or evaluation relative to other groups. This model also claims that to achieve this distinction, other groups must be derogated. In creating an ethnic group, or a diasporic community, capitalizing on the existence of this phenomenon can be a tool for uniting and mobilizing stagnant or fragmented groups. See Levin and Sidanius (1999) for a comprehensive discussion of this phenomenon and an empirical test of in-group effect, out-group derogation, and social dominance orientation. 
The focus on bounding ethnic groups, however, implies that the collectivity shares common views, outlooks, and behaviours and obscures the variation or heterogeneity that may be present within groups in modern societies. It obscures the myriad different ethnic identities that may be chosen by any individual in a modern nation and the factors that increase the salience of certain identities at any given time.

Barth's original position is similar to the traditional treatment of diaspora groups as homogenous entities. Later theorists took up the issue of homogeneity. Wimmer (2008), for example, proposed a multi-level process theory to explain why the characteristics of ethnic identity vary dramatically across cases, displaying different degrees of social closure, political salience, cultural distinctiveness, and historical stability. Since Barth's original theory presumes that ethnic boundaries are the outcome of negotiations of classification between actors in a social field, Wimmer also discusses the conditions under which these negotiations will lead to a shared understanding of the location and meaning of boundaries. Different actors will pursue different strategies of boundary making depending on their position in the hierarchies of power and the structure of their political networks. If they want others to accept their preferred ethnic classification and the associated boundaries of inclusion and exclusion, they have to convince others of their view of society.

In addition to his focus on the boundaries that define and distinguish ethnic groups, Barth (1969) pioneered a constructivist perspective: that ethnicity is the product of a social process, made and remade rather than taken for granted, chosen depending on circumstances rather than on birth. ${ }^{18}$ However, at this point Barth did not explore the

\footnotetext{
${ }^{18}$ Constructivism has become the principle theoretical lens in the study of ethnicities in anthropology, sociology and political science: ethnic identities are neither singular nor fixed. Constructivism refutes
} 
reasons why certain ethnic categorizations became salient while others did not. Recent work by sociologists Nagel and Olzak (1984) on ethnic mobilization provides some insight into this.

Current ethnic mobilization literature focuses on ethnicity as a social construct used to encourage groups to organize in support of some prescribed common goal. Defined by Nagel and Olzak (1982) as "the process by which a group organizes along ethnic lines in pursuit of political ends" (p. 154), ethnic mobilization may threaten the stability and legitimacy of a state and is considered critical in understanding contemporary politics. In later work, Nagel (1994) construes ethnic identity as the result of both structure and agency--a relationship played out between ethnic groups and society. Ethnicity is the product of actions undertaken by ethnic groups as they shape and reshape their selfdefinition and culture; however, external social, economic, and political processes and actors also construct ethnicity in shaping and reshaping ethnic categories and definitions. Nagel particularly emphasizes the fact that ethnic identity formation and transformation is a process, fed by the creation of collective meaning, by the construction of community through mythology and history, and by the creation of symbolic bases for ethnic mobilization.

For any individual, ethnic identity is both optional and mandatory: individual choices are circumscribed by the ethnic categories available at a particular time and place (Nagel 1994). While individuals may choose from a set of ethnic identities, the set that is available to them is limited to socially and politically defined categories with varying degrees of attached stigma or advantage. An individual selection may be restricting. For

earlier essentialist or primordial views that saw ethnicity as fixed by nature. This paradigm has been valuable in broadening understanding about the interplay between collectivities and their environment. 
example, governments routinely shape their decisions regarding ethnic groups through information provided by immigration agencies, census taking, and constitutions.

Consequent targeting of certain groups for special treatment can shape or construct ethnic boundaries by providing incentives for ethnic group formation or ethnic mobilization. In such an environment, ethnicity may become a strategy to gain personal or collective advantage.

International relations theory also considers ethnicity as a social construct. "Imagined" communities, often discussed in reference to diaspora collectivities (see Shane and Barth, 2003), are presented as constructed through discourse, manipulation, or processes of political mobilization. ${ }^{19}$ They are capable of growth and maintenance through mobility and communication. ${ }^{20}$ In addition, the experience of mobilization and exile provides new political categories that may transform passive or weak social networks into activated diasporic movements (Adamson, 2008).

Another international relations theorist, Sanders (2002), adds that ethnic identities may be fluid across time and social contexts. This suggests that diasporas may identify with a host identity, but continue to hold on and return to a previous national identity. Sanders also suggests that integration into a host country tends to occur in two or three generations, causing pluralistic identities to be constructed both as a product of attachment to country of origin and host country elements. This integration may result in a growing or shrinking interest in the affairs of the country of origin from one generation to the next. Zunzer (2008), also in the international relations field, similarly sees identity

\footnotetext{
${ }^{19}$ Adamson (2008) describes the essentialist vs. constructionist debate in the diaspora literature and argues that diaspora politics can be described as transnationalism that aims to construct and reinforce a transnational imagined community.

${ }^{20}$ See Vervotec (1999) for a comprehensive discussion of the role of modern modes of communication and transportation in supporting transnational linkages and communities.
} 
as fluid and believes that when a duality of belonging is adopted, it provides the perfect circumstance for diasporas to act as bridges between their home and host states for peacebuilding initiatives.

To summarize what the literature suggests regarding ethnicity as a social construct, the concept of ethnic mobilization provides insight into the reason why co-ethnics act together. Social mobilization theory accounts for the methods groups, or leadership elements within a group, use to create a sense of common goal within a constructed ethnic group. Strong motivational pressures resulting from ethnic identity affect the desire of diasporic communities to act in certain ways. Thus, mobilized groups can transcend physical borders, as people unite under common identity rather than proximity.

While theories of ethnicity and social mobilization acknowledge the mediating role of the environment in shaping available ethnic categories, a discussion of the role of the environment in conditioning actions taken by ethnic groups is largely missing. When coethnic individuals become mobilized, given the potentially constraining force of the policies of countries in which they reside, their capacity to carry out desired actions may be limited. This brings into focus the strength of the host country in shaping both capacity and desire.

\subsection{The Role of the Host Country}

How a diaspora group affiliates with and works through a host country are critical factors in understanding diasporic activity. The formulation posed here, based on the work of Cioffi-Revilla and Starr (1995), posits that access to opportunity structures in the host country is a significant determinant of support or constraint to diasporic action. The desire or willingness to act is also influenced by the possibilities framed by that context. 
In their discussion of the transnational behaviours of Eritrean and Bosnian

diasporas in Europe, Al-Ali, Black, and Koser (2001a) suggest a distinction that supports that of Cioffi-Revilla and Starr (1995). They distinguish between observable and measurable transnational activities and transnational capabilities, which include both the willingness, or desire, and ability, or capacity, of migrant groups to engage in activities that transcend national borders. As transnational activities are a crucial part of diaspora behaviour, these need to be further defined. Al-Ali, Black, and Koser (ibid) identify various categories of transnational activities. Some are political (e.g., lobbying), some economic (remittances and investment), others social (such as promotion of human and other rights), and cultural (e.g., placing articles in newspapers). Based on similar categorizations in the literature three categorical themes emerge: diasporas act economically, politically, and socially towards their countries of origin. Levitt (1998), among others, calls these actions remittances and that terminology will be employed here. Remittances represent the social ties of solidarity, reciprocity, and obligation that bind migrants and their kin and friends across state-controlled national borders (Ghedi, 2007). See Appendix 1 for a thorough description of diasporic activities across these remittance categories. These categories will be used in Chapter 5 to evaluate diasporic activity in the case study presented. Al Ali, Black and Koser argue that consideration of the capabilities of migrant or exile groups to participate in activities that transcend national borders is important in a discussion of diasporic activity. They further state that the capability of individuals, families, and communities to become involved may depend on the skills and resources available to them, which in turn depends on opportunity structures in host countries. 
Davis and Moore (1997) also provide insight into the importance of the role of context. In their investigation of the influence of transnational ethnic alliances on the international relations of states, they suggest that a host country may provide the context for diasporas to prompt action in their country of origin, often indirectly through influence on foreign policy. Thus, transnational ethnic alliances can serve as conduits of support from "advantaged" co-ethnics in one country to disadvantaged parties in other countries. In more detail, Davis and Moore propose that "states respond to domestic pressure from groups incorporated into the polity" (p. 173) and that members of an ethnic group are concerned with the status and well being of co-ethnics across borders. Based on these propositions, they further suggest that in states where members of an ethnic group are incorporated into the power structure, and where their ethnic brethren are disadvantaged in another state, the former will place demands on their national government to pressure the other to address inequities there.

Davis and Moore (1997) also suggest that transnational ethnic linkages will have a greater influence on the interactions of states if the members of the ethnic group in the target state are politically active in modifying their status. A politically active ethnic group is more likely to attract the attention of ethnic brethren since supporting them will be viewed as a worthwhile investment. Davis and Moore conclude that dyads containing an advantaged ethnic alliance should be monitored, particularly with regard to the mobilization level of the disadvantaged co-ethnic, as they are likely to demonstrate higher than average levels of international conflict. This supports the fact that context matters in providing opportunity; co-ethnics in advantaged positions are targeted for support due to the fact that they are in a position to make meaningful contributions. 
Other studies support the idea that differing access to opportunity structures results in disparate capabilities. King and Melvin (2000), for example, have argued that older diasporas in the West have become powerful actors within their countries of origin because they have the ability to develop internal organizations and extensive financial resources. These authors suggest that well-organized diasporas have been effective in challenging the leading role of indigenous elites within the homeland; these organizations have often become powerful, independent actors both within the home state and in the international arena. This may be because the host country regime determines the ability of diasporas to organize and interact. ${ }^{21}$

In the same vein, Wayland (2004) suggests that individuals who migrate from a closed society to an open one can capitalize on newfound freedoms to accumulate financial resources, to organize, and to publish in ways previously denied to them. The opportunity to gain political and economic foothold in a host country, through access to the political and economic structures present, increases diaspora capacity.

In sum, the transnational capabilities of diasporas translate into transnational activities, or remittances. Opportunity structures in the host country are a significant determinant of support or constraint to transnational capabilities. The desire or willingness to act is also influenced by the possibilities framed by the host country context. Figure 1 outlines the conclusions that I make concerning capacity and host country structure.

\footnotetext{
${ }^{21}$ In addition, see Shane and Barth (2003), who argue that capacity depends on the ability of co-ethnics to organize influence, which, in turn, depends on the regime type of the host country. In non-democratic regimes, civil societies, for example, are discouraged, if not completely prohibited, from functioning. Shane and Barth argue that this is even truer of those diaspora groups seen to have an erosive effect on national unity. In contrast, in "permeable" democracies, diasporas have two advantages: they can organize and apply direct pressure on home country politics, and they can push for indirect change by lobbying to influence host government foreign policy.
} 
Figure 1: Summary of Conclusions of Section 1.2

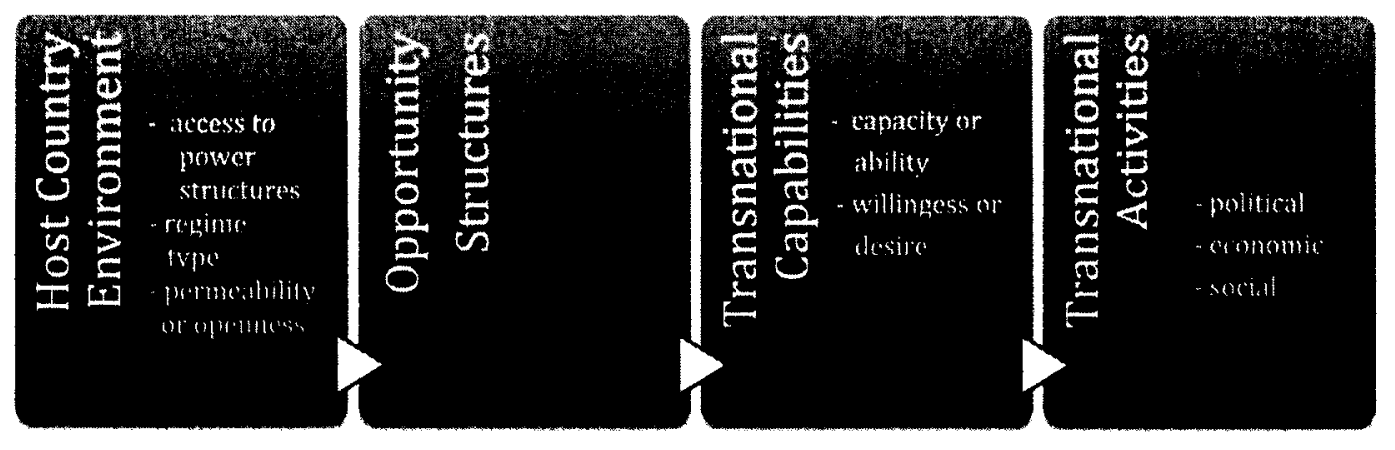

\subsubsection{Opportunity Structures in the Host Country}

Although I have concluded that, based on the literature, in a general way, opportunity structures shape the capacity and willingness of diasporas to act, we have no specific information or speculation on how this occurs. Here, I will focus specifically on the role of opportunity structures in shaping the capacity and willingness of diasporas to act. Although much of the literature points to the particular importance of access to political opportunity structures, access to economic and social structures is also significant. Koser (2007), for instance, found that employment was the most significant factor contributing to diaspora capacity in relation to remittances or philanthropic actions. As well, Ionescu (2005) suggests that opportunity is related to whether the host country is a high, middle, or low-income country. In poorer host countries, the potential of diasporas to support their home countries will be more limited.

Al-Ali, Black, and Koser (2001a, 2001b) considered political, social, and economic forms of capacity in their study of Bosnian and Eritrean refugees in Europe. Thirty refugees from Eritrea living in the United Kingdom and Germany and thirty refugees from Bosnia living in the United Kingdom and the Netherlands were interviewed to give insight into the role of the state in transnational behaviour 
development and the potential for and limitations to the national role in such practices. The authors found significant variation between individuals in terms of both ability and willingness. Eritrean respondents were reportedly engaged in more transnational activities than were Bosnians respondents, in part because most of the former enjoyed permanent residence rights, while many of the latter did not. Bosnian respondents indicated a sense of anxiety around their status in the host countries, which the authors interpreted as hindering the space within which transnational practices could occur. Insecurity about status and lack of access to channels for transnational activities limited the capabilities of this group. Their findings led Al-Ali, Black, and Koser to stress the importance of social, political, and institutional factors in providing constraints to transnational behaviour. They suggest that these constraints, established by the structures and policies of a host country, produce highly uneven patterns of transnational activities between diaspora groups in different host countries. ${ }^{22}$

As a part of their study, Al-Ali, Black, and Koser (2001b) tabled the factors that they observed to affect a diasporas' capacity and desire to act. These factors are divided into three categories: economic, political, and social. ${ }^{23}$ This table (Table 1) summarizes the factors within a host country that increase the opportunity or capacity of diasporas to engage in activities aimed at a country of origin. These factors resemble those previously introduced by other scholars, demonstrating support for their inclusion. In Table 1, the

\footnotetext{
22 An additional finding was that gender, age, education, place of origin, and political affiliation all appeared to affect levels of transnational engagement. This finding is not a surprise, given the fact that these researchers intentionally chose samples that differed across these points to provide variation. In future studies, these elements could be controlled to limit their influence on the economic, political, and social factors under the host country's purview.

${ }^{23}$ In a later case study of the contributions of diasporas in the United Kingdom to development and poverty reduction, Van Hear, Pieke and Vertovec (2004) point to factors that increase diaspora capabilities to participate in reconstruction in their countries of origin. These factors are likewise divided into the economic, political, and social categories drawn from those created by Al-Ali, Black, and Koser.
} 
factor suggested by Ionescu (2005) has been added in italics under those by Al-Ali,

Black, and Koser to provide a complete overview.

Table 1: Factors in a Host Country that Increase Capacity or Desire to Engage in Home-Country Oriented Activity

\begin{tabular}{|c|c|c|}
\hline & Capacity & Desire \\
\hline Economic & $\begin{array}{l}\text { - Employment } \\
\text { - Savings } \\
\text { - Access to information } \\
\text { - Access to banking facilities } \\
\text { - High/low/middle income status of host country }\end{array}$ & - Financial stability in host country \\
\hline Political & $\begin{array}{l}\text { - Secure legal status in the host country } \\
\text { - Positive attitude of host government and } \\
\text { population towards ethnic-national diasporas } \\
\text { - Ability to lobby/hold demonstrations }\end{array}$ & - Secure legal status in host country \\
\hline Social & $\begin{array}{l}\text { - Freedom of movement within the host country } \\
\text { - } \text { Gender equality } \\
\text { - Successful social integration in the host } \\
\text { country }\end{array}$ & $\begin{array}{l}\text { Links with family and friends in host } \\
\text { country/other host countries } \\
\text { Integration within the diaspora in the host } \\
\text { country }\end{array}$ \\
\hline
\end{tabular}

Al-Ali, Black, and Koser (2001a) indicate that the absence of political, economic, and social structures prevents both the capacity and desire of diasporas to act. It is further indicated that better integration of a diaspora into a host country will increase capacity to participate by providing access to these structures. Al Ali, Black and Koser's study gives valuable insights into factors that influence diasporic activity and provides a basis for exploring the factors that influence the capability of diasporas. The comparison between two different refugee groups limits the potential of this study to focus on the consequences of integration in a host country on transnational capabilities because in these cases there are many other factors that could account for the difference in transnational activity observed: history, relationship with the country of origin, relationship with the host country, time of arrival in the host country. Limiting these factors in future studies would allow for a clearer analysis. 


\subsubsection{Case Studies: Tamil and Kurdish Diasporas in the West}

The following case studies provide insight into the relationship between host country structures and diasporic capabilities. Evidence from these cases provides support for the argument that access to opportunity structures in a host country facilitates diasporic activity. The Tamil diaspora supports the importance of economic structures in particular, while the Kurdish diaspora indicates support for access to political structures in particular. The following cases are important. They provide examples of the reality of diasporic activity, and demonstrate that, as argued here, access to opportunity structures, or a lack of access to formal structures, influences transnational capabilities and activities.

\section{The Tamil Diaspora}

The Tamil diaspora is a highly politicized and influential transnational community (International Crisis Group, 2010). The persistence of the Tamil insurgency is unusual, since a lack of support for the rebellion within Sri Lanka might suggest that it would have been short-lived and relatively unsuccessful. Instead, the militant separatist group, the Liberation Tigers of Tamil Eelam (LTTE), fought a protracted civil war with the Sri Lankan government from 1983 to 2009. Literature suggests that this success was due to the opportunity structures available outside Sri Lanka, in countries that hosted Tamil refugees, and the capabilities garnered by the diaspora through access to those structures.

Wayland (2004) conducted a case study of the transnational dimension of the LTTE and the consequences of transnational networks for the conflict in Sri Lanka. Her results indicate that greater political freedom, the ability of communities to organize, and access to financial resources and communication technologies in receiving states 
increased diasporic activities. Wayland attributes these capabilities to the fact that the diaspora took advantage of political opportunity structures and concludes that discussions of political opportunity structures must include the role of transnational actors operating from liberal democratic states. ${ }^{24}$

The Tamil diaspora is large, between 600,000 and 800,000 people, the largest proportion of which resides in Canada (Statistics Canada, 2006). This diaspora is often represented as a monolithic group; however, several waves of migration began as early as the 1950s, with different characteristics (Fair, 2007). The diaspora is credited with being the backbone of the LTTE operation and a financial lifeline for the insurgency (Fair, 2007). The diaspora transferred a huge amount of financial remittances to the insurgents each year, both through coercion and voluntarily. ${ }^{25}$ In addition, Tamil networks have been reinforced by demonstrations and lobbying efforts, primarily in Canada and Britain. Funding for Tamil websites and newspapers comes largely from the diaspora, and access to communication technologies has allowed for instant communication and information transfer between diasporas, all of which strengthened the Tamil movement. While Tamils in Sri Lanka had limited opportunities to accumulate wealth, travel, assemble, or express themselves politically, members of the diaspora have had those opportunities through structures in host countries, and, consequently, could assist those in Sri Lanka (Wayland, 2004; Fair, 2007).

\footnotetext{
${ }^{24}$ Wayland (2004) describes opportunity structures as consistent dimensions of the political environment that provide incentives for collective action by affecting expectations for success or failure. Wayland remarks that political opportunity structures help explain why a challenger's chances of engaging in successful collective action vary over time and why similar challenges may meet with very different results in different places.

25 The International Crisis Group (2010) suggests close to $\$ 1$ million per month from the Canadian diaspora alone, and $\$ 200$ million per year worldwide in the last years of the insurgency.
} 
Fair (2007) further notes that the ability of the Tamil diaspora to work through opportunity structures was constrained in the late 1990s as Western countries began to add the LTTE to lists of terrorist organizations. The thought of being labeled as terrorists pushed the Tamil diaspora to encourage the LTTE to pursue diplomatic solutions; the consequences of losing contributions from the diaspora were so important to the LTTE that it could not disregard the interests of the diaspora and turned towards diplomacy.

This case demonstrates that capabilities, as provided through opportunity structures in a host country, affect the presence and activities of political groups in a home country. Despite unfavourable conditions in the homeland, factors abroad allow individuals or groups to attain objectives they would otherwise not have been able to do. In the case of Sri Lanka, these objectives may have protracted what might have been a brief insurgency. This case reinforces the argument made here: that, as an environment that can either allow or constrain, a host country plays an intervening role in diasporic activity that may influence the dynamics of political situations in the country of origin.

\section{The Kurdish Diaspora}

The actions of the Kurdish diaspora further highlight the critical role of the host country environment and of access to opportunity structures within that environment. In addition, this diasporic community provides evidence that the "form of participation in the diaspora is linked to the political opportunity structures available to different group members at home and abroad" (Natali, 2007, p. 196). Natali (2007) reviews the history of engagement of the Kurdish diaspora with Iraq between 1998 and 2004, when the United States and United Kingdom were intervening in Iraq and Kurdish nationalist interests were at stake; she also discusses the migration experiences of the Kurdish diaspora, 
originating in Iran, Iraq, and Turkey, and now scattered across Europe. This scattering results in differential access to host country opportunity structures and in asymmetrical policies for diasporas coming from different countries. For example, Kurds from Iraq experienced legitimization of their nationalistic claims in many European countries, while the claims of leftist Kurds from Turkey were largely ignored or discounted. Natali (2007) indicates that Iraqi Kurds were legitimized as victims of Saddam Hussein and had generous support from the international community and their host governments, while Turkish Kurds were viewed with disinterest because of the criminalized status of the Kurds in Turkey. As a result, the political opportunity structures available to the Iraqi Kurds were not available to the Turkish Kurds. As a result, an antagonistic relationship developed between Kurdish nationals from Turkey, moderate diasporas from Turkey, and Kurds from Iraq. The leftist Kurds from Turkey disagreed with the other Kurdish diaspora groups on methods to approach the war in Iraq and, due to their being prevented from working with intervening governments, a transnational anti-war movement developed and Turkish Kurds formed partnerships with interest groups to create platforms for lobbying the broader leftist community. Efforts by these three diaspora groups were peace promoting rather than peace-preventing until the diaspora communities felt that negotiations occurring during times of conflict escalation did not sufficiently protect Kurdish interests in Iraq. Also of significance was that during increasing Kurdish autonomy in post-Saddam Iraq, along with continued discounting of other Kurdish problems in the region, the Kurdish leftists from Turkey became less willing to maintain passive mobilization and neutrality. Natali's (2007) study concludes 
that the form of participation in the diaspora was linked to the political opportunity structures available to different group members.

Natali (2007) presents the idea that the more access diasporas have to a national political system, the more diasporic activities are channeled into that system and shaped accordingly, rather than taking place outside the system, perhaps in more confrontational forms. She also concludes that diasporas linked to legitimate leaders and organizations are more likely to pursue strategies based on negotiation than are diasporas that are delegitimized in the international arena. ${ }^{26}$

Despite a common goal, to protect the Kurdish identity and fight for Kurdish autonomy, the Kurdish diaspora community is very diverse. Individuals have different histories, different political experiences across host countries, and differing experiences of integration and access to host country structures based on their political histories. Added to this is the empirical challenge of evaluating the distinct impact of political opportunity structures in diaspora behaviour due to the other intervening factors in the chosen case. While these challenges are noted in terms of evaluating the distinct impact of political opportunity structures on diaspora behaviour, Natali's conclusions are important to the discussion here. Not only is inclusion in a host society and access to its political channels important in directing diasporic capability, lack of access to a political system may impede the opportunity for diasporas to act peacefully and channel behaviour into more aggressive or rogue activities. Motivation to act, in this case, seems to supersede opportunity, and the crucial intervening factor of access to political opportunity structures results in a change in the nature of the behaviour. Another interesting point

\footnotetext{
26 Natali (2007) also points to changes in the conflict cycle as affecting the behaviour of diasporas, examining Kurdish diasporic interventions during different phases of the Iraq war to identify conditions that prompt them to act as either peacemakers or peace wreckers.
} 
suggested by Natali's discussion is that diasporic communities frame their nationalistic claims relative to the political opportunity structures that exist in the host country; the way in which a community adapts activity rests on the political institutional environment. A side effect of this is that different aspects of a diaspora's identity may become salient due to this adaptation. Natali's case also points out the relevance of integration in establishing capacity to act; opportunity structures influences motivation to act. These last links will be expanded in Chapter 2.

\subsubsection{Transfer of Values: the Diffusive Power of the Host Country}

Diaspora literature often includes reference to the "hybridity" that occurs as people move into new environments (Wahlbeck, 1998). For example, Brinkerhoff (2009) suggests that diasporas frequently adopt hybrid identities that combine features of the homeland with the civil and cultural values of the host country. Levitt (1998) similarly notes that a number of "blending scenarios" (p. 930) occur when migrants interact with the host society. The result is a creolization, where the mixing of migrant and receiving country qualities creates new social relations and cultural patterns. These hybrid identities then inform the political considerations and action agendas directed to the country of origin. In fact, Brinkerhoff (2009) points out that exposure to and internalization of liberal values may give rise to a belief in basic freedoms and empowerment, and may instil the belief that diasporas can effectively promote and transfer these rights to the country of origin. Pérez-Armendáriz and Crow (2010) similarily argue that international migrants are at times agents of democratic diffusion, spreading attitudes and behaviours absorbed in democratic host countries to their less democratic home countries. They describe three processes in which this might occur: migrant returns, cross-border 
communication between migrants and their friends and family back home, and migrant information networks in high-volume migration-producing communities. ${ }^{27}$

Pérez-Armendáriz and Crow (2010) provide empirical evidence supporting this theory. In a study of transnational linkages between Mexican migrants in the United States and contact back home, migration was determined to lead to higher rates of nonelectoral political participation, greater tolerance of political and social difference, and critical evaluations of both democracy and observance of rights in Mexico. PérezArmendáriz and Crow explain that Mexican migrants and their communities establish connections because of the transfer of family remittances. They also facilitate crossborder diffusion of ideas, identities, beliefs, knowledge, and behaviour. This supports Diamond's (1994) earlier claim that socialization and participation within a wellfunctioning democracy leads migrants to learn and adopt the values, skills, and commitments of democratic citizenship.

In conclusion, a diasporic community can transmit ideas and values from the host country to the country of origin. What this point suggests is that a host country has the ability to shape diasporic behaviour in indirect ways, and that the influence of hostcountry values can be far reaching. The connection between exposure to certain values and transmission of them as a form of social remittance will be explored in Chapter Two.

\subsubsection{Directionality of Influence: Diasporas and their Role in the Host Country}

It is important to note that the stream of influence between diasporas and host countries flows both ways. Certainly, the values and policies of a host country affect

\footnotetext{
${ }^{27}$ Drawing on the results of Desencanto Ciudadano en México [Citizen Disenchantment in Mexico], a Mexico-wide public opinion poll conducted in June 2006, Pérez-Armendáriz and Crow (2010) argue that through one or another of these processes, migration has altered the political participation and behaviour of Mexicans living in Mexico.
} 
diaspora identity, action, and influence; equally, diasporas affect the domestic or foreign policy of a host country. ${ }^{28}$ When a host country's foreign policy is important to a country of origin, and the host country is receptive to diasporic influence, the diaspora's ability to influence the homeland's foreign policy is enhanced (Shain and Barth, 2003). The influence of large diaspora groups on Canada's foreign policy, for example, has been noted. ${ }^{29}$ Presumably after discussion with Jewish immigrant groups, Prime Minister Harper has indicated that the Conservative government will stand with Israel and has also pandered to a large group of Indo-Canadians to secure the support of this large interest group. The potential of diasporas to pressure domestic and foreign policy through their ability to win seats in ridings densely populated by individuals from the same country or ethnic group is increasing as numbers grow. Concerns may grow from this regarding whether priorities espoused by these groups are in a host country's interest, and whether those priorities will stabilize or destabilize events in the country of origin.

\subsubsection{Conclusion}

It seems clear at this point that social, economic, and political opportunity structures of a host country contribute to the capacity of diasporas to act. Social structures include support networks, knowledge of the local language, citizenship, and integration into society. Economic opportunity structures refer largely to the ability to remit financially; hence, employment opportunities, financial security, and access to education come into play. Political opportunity structures include the ability of diasporas to lobby,

\footnotetext{
${ }^{28}$ Shain and Barth (2003) point to the relative "weakness" or permeability of a state as a significant element in determining the influence a diaspora can have on host country policy. Shane and Barth spelling suggest that the United States is an example of a weak, or permeable and country. The implication of this is that the presence and activities of a diaspora can affect United States foreign policy towards a country of origin. ${ }^{29}$ Embassy magazine recently published an article that discussed the influence of large diaspora groups on Canada's foreign policy (Gurzu 2011).
} 
to put political pressure on governments, and to mobilize. In particular, because diasporas can act as both peace-makers and peace-breakers at the same time (due to differences within a diaspora population) and within different periods, ${ }^{30}$ Smith (2007) recommends an analysis of host-country political opportunities that either promote or discourage diaspora involvement in conflict in the country of origin. In conclusion, the importance of the host country in determining diaspora action and the need to consider the input of the host country in understanding a diaspora's potential role generates the need for further research in the intervening influence of the host country environment. However, Smith (2007) and Turner (2008) note that the capacity and desire of a diaspora to contribute to activities in countries of origin is also dependent on factors within the diasporas themselves.

\subsection{The Influence of Individual Factors: Heterogeneity in Diasporic Communities}

Individuals within a diasporic community are not alike. Their different histories and experiences, generation of exit, conflicts between different waves of exit, and their cultures and religions mark them as unique (Spear 2006). Van Hear, Pieke, and Vertovec (2004) bring to our attention that currently, and much more than in the past, diasporas include complex mixes of people who have arrived at different times, through different channels, through different means, and with very different statuses. In this context, Orjuela (2006) claims that the immense diversity within a diaspora community must be carefully considered when attempting to understand diaspora behaviour because diversity conditions the various manners with which individuals engage a country of origin.

\footnotetext{
${ }^{30}$ Brinkerhoff (2009) indicates that the policy environment in host countries can create incentives and disincentives for diaspora participation in both peace and conflict.
} 
Newland and Patrick (2004) explain that diaspora communities often reproduce the divisions of class, ethnicity, religion, political affiliation, language, and region found in their countries of origin. They further suggest that such differences within and among diaspora groups will influence the nature and scale of their opportunities and willingness to act, making these important considerations in understanding diaspora behaviour. These factors are summarized in Figure 2.

Figure 2: Factors that Influence Individual Diaspora Activity

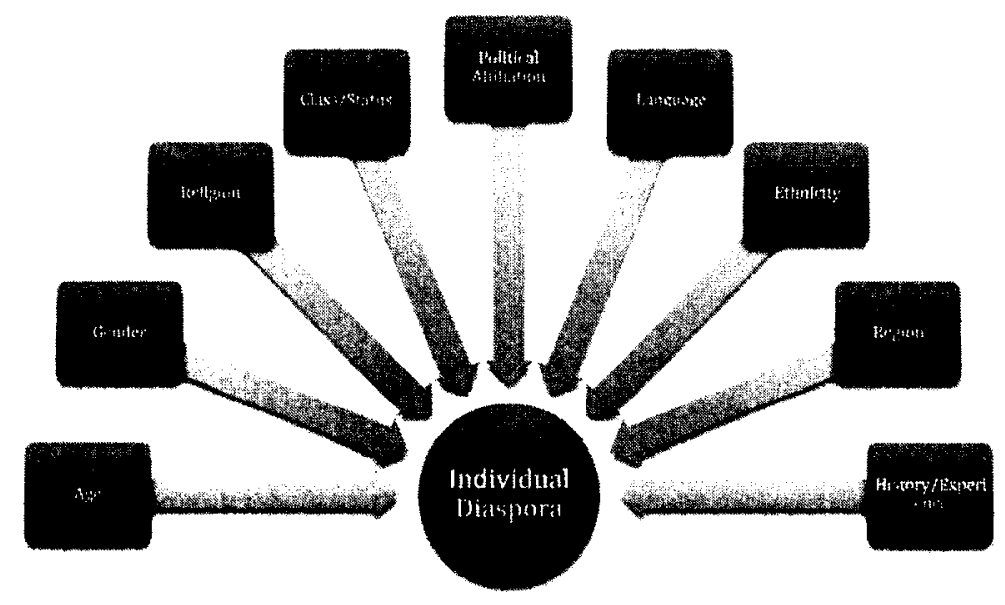

As both Spear (2006) and Brinkerhoff (2009) claim, it is important to note that because diasporas are internally heterogeneous, a challenge arises in analyzing diasporic communities if treated as single units. Indeed a community may be operating at crosspurposes with itself and one must be alert to this dynamic. Although controlling for intervening variables is a challenge in any diaspora research, the choice of study population and the parameters of the study can help mediate individual factors and isolate other variables of interest, such as host country opportunity structures, to some degree. An additional variable, often not controlled for in case studies involving diasporic communities is the reason for migration. The reason for migration may also have a strong influence on the decision to engage in certain activities. 


\subsubsection{Reason for Migration}

As individuals migrate, whether they are forced as asylum seekers, or chose to leave for educational or economic opportunities, or for family reunification, the reason for their migration will affect the nature of their engagement with countries of origin. For example, Kunz (1973) states: "it is the reluctance to uproot oneself, and the absence of positive original motivations to settle elsewhere, which characterises all refugee decisions and distinguishes the refugee from the voluntary migrants" (p. 130).

Conflict-generated diasporas in particular have been underscored as more likely to maintain strong connections with a country of origin and to engage in high levels of remittance activities. Terrence Lyons (2009), a researcher in this field, states: "Conflictgenerated diasporas--with their origins in violent displacement and their identities linked to symbolically important territory--often play critical roles with regard to political struggles in the homeland" (2009, p. 589). Diasporas forced to leave their country of origin have often been found to make little attempt to integrate into the host society, still considering themselves citizens of a home to which they will return as soon as circumstances allow.

A link between conflict-generated diasporas and actions that perpetuate conflict in their countries of origin has been acknowledged. Lyons $(2004 ; 2008 ; 2009)$ proposes that conflict-generated diasporas were created by violent conflict and their positions are sustained by memories of disturbance and suffering. Thus, they are less willing to compromise and more likely to reinforce and exacerbate conflicts in countries of origin. In reference to the Ethiopian diaspora, Lyons (2008) believes that "due to the nature of their attachment to the homeland, many in the diaspora have framed conflicts 
categorically and have supported the most militant and uncompromising leaders back

home. The Ethiopian diaspora, therefore, has the capacity to make conflict resolution more difficult and the conflict more protracted" (p. 594).

In her discussion of secessionist conflicts, Koinova (2009) states that the distress behind the displacement becomes fixed in the memories of such diasporas and limits their ability to see the conflict in interactive terms or to desire a resolution of the conflict (see also Shain, 2002; Adamson, 2006). Koinova further supports the thesis that diasporas act to support continuation or resurgence of conflict; she indicates that conflict-generated diasporas often support warring factions in their country of origin through lobbying and fundraising activities and through recruiting soldiers within their own communities. ${ }^{31}$ In many cases, the leaders of political opposition groups are among those who have been forced to leave the country of origin and their links to the unfolding events remain strong, as does their influence.

Table 2: Summary of this section with Supporting Evidence

\begin{tabular}{|c|c|}
\hline $\begin{array}{c}\text { Behaviour of Conflict-Generated } \\
\text { Diasporas }\end{array}$ & $\begin{array}{l}\text { Evidence: Ethiopian Diaspora } \\
\text { (Lyons 2004; 2009; 2011) }\end{array}$ \\
\hline $\begin{array}{l}\text { - Maintain strong connections } \\
\text { - Engage in higher levels of } \\
\text { remittance activities } \\
\text { - Engage in actions that perpetuate } \\
\text { conflict in their countries of origin }\end{array}$ & $\begin{array}{l}\text { - Key players in homeland conflicts by providing financial support } \\
\text { - Many diasporas support opposition parties (e.g. the Oromo Liberation } \\
\text { Front) } \\
\text { - Frame conflict through their control over Ethiopian media outlets and } \\
\text { other institutions } \\
\text { - Played a fundamental role in the political opening in } 2005 \text { and the } \\
\text { subsequent crises } \\
\text { - Insurgent groups operate in exile }\end{array}$ \\
\hline
\end{tabular}

A conclusion that can be drawn from the theorization of these scholars is that individual differences influence the integration of diasporas into a host country; the integration further compounds the effect of these individual factors. The reason why a

\footnotetext{
${ }^{31}$ Contrary to the position of Collier (2001), Koinova (2009) considers that diasporas do not usually cause conflicts in their homelands, becoming involved in a conflict spiral once a conflict erupts. Koinova points to two specific moments in the events of a country of origin that promote radical action by diasporas: grave violations of human rights and the loss of legitimacy among moderate actors.
} 
diaspora left the country of origin is also an important consideration. Forced departure may result in a diaspora that is more engaged with a country of origin, but also more uncompromising and militant in its position towards that country. Studies of diasporic communities must pay careful attention to the individuals that make up a diasporic community and take into consideration the reasons why that community migrated. ${ }^{32}$

\subsection{The Country of Origin Dynamics}

The relationship a diasporic community has with its country of origin also provides constraints or points of access for diasporic activity. It remains necessary to explore the significance of the country of origin in determining diasporic engagement and I will argue that although access to the country of origin is important, its relative importance is less than that of host country opportunities. It is important to discuss, however, given the close contact maintained with the homeland, the continuous struggle to maintain one's identity and the complexity of diasporas' loyalties to their homelands and host countries as well as their contributions to them (Sheffer, 2003).

States and regimes from which a diaspora originates adopt various stances towards their diasporic communities; these stances vary according to the national philosophy of the country of origin. Many factors condition the relationship between a country of origin and a diaspora. These factors include the official and societal perception of emigration in general; reliance on economic investments and remittances of the diaspora; and the makeup of the diaspora (emigrants, refugees, or exiles) and its general attitude toward the home regime. Other factors also come into play: the political role assigned by the home regime to the voice of the diaspora in domestic or international

\footnotetext{
${ }^{32}$ In this study, the South Sudanese diaspora community was chosen because the South Sudanese diasporic community consists almost entirely of conflict-generated migrants.
} 
affairs of the home country; and citizenship laws, especially the possibility of holding dual citizenship (Shain, 2000). Recently, countries of origin have acknowledged that the size of a diasporic community and the affluence of its members may transform diasporas into a major force in the economies and politics of their countries of origin (Shain, ibid; Lieber, 2008). As (Al-Ali, Black, \& Koser, 2001) indicate, the strength of the relationship between diaspora and country of origin often rests on the degree to which the country of origin needs diasporic resources. Newly democratized countries in Eastern Europe, for instance, have looked to their United States-based counterparts as a source of economic investment and as players in mediating and improving relations between the United States and the country of origin. Shain and Barth (2003) add that policy making is more susceptible to diasporic influence the more democratically permeable the homeland. If a country of origin is receptive to diasporic input, the ability of the diaspora to influence the country of origin's foreign policy is increased.

In some cases, a group may be strategically labeled a "diaspora" by a country of origin either to ensure that the population remains abroad or to create a privileged relationship with that group and capitalize on economic benefits. Shain (2000) discusses the growing trend of states to regard the acquisition of American citizenship by members of diasporas in terms of the advantages such citizenship can bestow. Lieber (2008) suggests that the relationship between a country of origin and a diaspora consists of a "push and pull," where financial remittances "pull" politicians to court diasporas. The financial remittances of diasporas, which are critical to many economies, are translated into political rights that allow diasporas to act in country-of-origin politics. On the other hand, King and Melvin (2000) suggest that a country of origin may utilize the term 
"diaspora" to ensure that the population remains abroad, since a diasporic identity "is both a normal and permanent feature of its members sense of self and community" (p. 136). According to King and Melvin, a homeland's attempt to define a group as a diaspora and to create a privileged relationship with that group is a tricky endeavour--it depends on the ability of the state to distinguish between membership in a transnational community and membership in the internal community defined by citizenship. It is important to note that diaspora contributions, particularly economic ones, are not always the result of encouragement but a more formal arrangement. In this case encouragement to remit is more accurately described as coercion.

Shain (2000) declares that efforts to keep diasporas close by allowing dual citizenship is a departure from the past when a change in citizenship was seen as a shift in loyalty and allegiance by countries of origin. A diasporic community consisting of refugees and exiles may have been considered enemies of the home regime and may have suffered from intimidations from abroad. That diasporas left a site of conflict and hardship while others stayed behind and endured the hardships of war could create a divide between those who stayed and those who did not. Orjuela (2006) has found that official and civil communities in a country of origin may prefer not to work with or develop ties with diasporas as a result of these negative feelings, depriving diasporas of legitimacy as advisors.

Table 3: Summary of factors in the country of origin that influence individual opportunity to engage with the country of origin, including examples

\begin{tabular}{|c|l|}
\hline $\begin{array}{c}\text { Factors that facilitate } \\
\text { diasporic activity in a country } \\
\text { of origin }\end{array}$ & \multicolumn{1}{|c|}{ Example } \\
\hline $\begin{array}{l}\text { - Need for diasporic } \\
\text { resources leads countries of } \\
\text { origin to court diasporas for } \\
\text { remittances }\end{array}$ & $\begin{array}{l}\text { Mexico has begun to acknowledge publicly the value of diasporic culture and } \\
\text { reward Mexican-American intellectuals and activists as its guardians. Mexico has } \\
\text { courted continued diasporic financial support by affording its diaspora dual } \\
\text { citizenship, intended to empower Mexican Americans as individuals and as } \\
\text { members of an interest group able to lobby American politicians on behalf of }\end{array}$ \\
\hline
\end{tabular}




\begin{tabular}{|l|l|}
\hline $\begin{array}{l}\text { - Coercion/pressure from } \\
\text { home government to remit }\end{array}$ & $\begin{array}{l}\text { Newland and Patrick (2004) noted that since independence, adult Eritreans overseas } \\
\text { have been asked to pay a contribution equivalent to 2\% of annual income. Efforts on } \\
\text { the part of the Eritrean state to increase contributions substantially to fund the 1998- } \\
2000 \text { border war with Ethiopia stirred considerable resentment among the diaspora } \\
\text { because they felt overburdened financially. Newland and Patrick also refer to the } \\
\text { relationship between the Tamil diaspora and the LTTE in Sri Lanka. Financial and } \\
\text { other contributions to the LTTE from the Tamil diaspora come from an obligation to } \\
\text { donate placed on Tamil diasporas and enforced by local branches of the LTTE. }\end{array}$ \\
\hline $\begin{array}{l}\text { Animosity because of the } \\
\text { sense that diasporas }\end{array}$ & $\begin{array}{l}\text { The Eritrean Popular Liberation Forces (EPLF) leadership, one of the opposition } \\
\text { groups responsible for Eritrean independence, fearful of outside influence and loss } \\
\text { of power, erected barriers to marginalize many of the professionals who returned } \\
\text { from countries all over the world. Most of them returned to where they came from } \\
\text { disillusioned and with their morale sapped (Kibreab, 2007). This was further } \\
\text { exacerbated by the EPLF elite ex-combatant fear of competition from diaspora } \\
\text { professionals. The EPLF commonly stated that the returning diasporas were coming } \\
\text { to take advantage of opportunities that they had not helped to create and the phrase } \\
\text { "where were you when the stones were burning?" was a common cliché repeated by } \\
\text { many former combatants (Kibreab, ibid, 133). }\end{array}$ \\
\hline
\end{tabular}

We have not yet considered how diasporic behaviour changes in time. A number of studies demonstrate that changes that occur in a conflict play a large role in encouraging diasporas to become active when they otherwise might not be.

\subsubsection{Transitions in the State of Affairs in the Country of Origin}

The potential of a diaspora to contribute to post-conflict development and reconstruction has been noted, as has the risk that diasporas will undermine a state of fragile peace and contribute to a resurgence of conflict. During state transitions such as secession, state-building, and democratic reform diaspora action is flexible and can be unpredictable. However, studies that trace the responses of diasporas to transitions in their countries of origin are few. It appears that the kind of action taken during times of transition depends on what is happening in the country of origin. According to Koinova (2009), moderate and radical mobilization of diasporas is linked to the domestic political context in the original homeland and relates to periods of sustained violence and postconflict reconstruction. She cites the Kosovo diaspora as an example of a group that radicalized in step with the transformation of the conflict in Kosovo. Koinova suggests 
that the level of aggressive action paralleled that of action in Kosovo.

In more detail, Koinova (2009) states that by gradually rendering support to secessionism, these diasporas entered into the conflict spiral, but did not initially engage in violent methods. In the early stages of the conflict, the diasporas engaged in economic and political transactions, including fund-raising and lobbying. However, they soon changed from moderate, external actors to direct participants, employing radical methods, because of human rights violations in the homeland. Initially, diasporas provided support (requested at the level of $3 \%$ of annual income) to the moderate Democratic League of Kosovo (LDK) party, but as the conflict grew, so did support for the insurgency. Albanians in the diaspora increased their support for the Kosovo Liberation Army, which advocated violent methods to achieve secession (see also Spear, 2006).

In Eritrea, a similar pattern emerged. The outbreak of the second war between Ethiopia and Eritrea led to political and economic re-mobilization of the Eritrean diaspora (Kibreab, 2007). In addition to financial support, diaspora communities lobbied the international community to pressure Ethiopia to cease its aggression and later to accept the decision of the Eritrean Ethiopian Boundary Commission regarding the border (Kibreab, ibid).

Koinova (2009) argues that diasporas have an incentive to act moderately to achieve the goal of sovereignty when peaceful activities dominate domestic politics. She distinguishes periods of acute violence and oppression in the homeland, when diasporas are prone to engage in radical activities, from periods of relative peace and post-conflict reconstruction, when other concerns dominate diaspora circles. 


\subsubsection{Conclusion}

What Section One demonstrates is that the receptivity of a country of origin to its diaspora will condition the ability of the diaspora to influence the political, economic, or social fabric of the country. The policies of the country of origin, as well as the overall feeling towards expatriates, are very relevant to such change. We must note, however, that, in many cases diasporic communities include a large number of people who left their countries out of necessity rather than choice--necessity resulting from opposition to the ruling regime. Hence, many of the actions diasporas take to influence the social or political events at home occur in spite of, rather than as a result of, attempts by the official channels in the country of origin to encourage or prevent those activities. This suggests that opportunity structures in the country of origin become less important in a discussion of the behaviour of diasporas in some cases because diasporas can utilize opportunity structures in their host countries instead. The cases of Eritrea and Sri Lanka demonstrate that in times of conflict when one political group has an interest in encouraging support from a diaspora, it can successfully obtain resources by engaging diasporic motivation to participate. A range of motivations, including those based on kinship, personal gain, empathy, and obligation, beyond the opportunity structures provided by a host country and country of origin, exist.

\subsection{Other Motivations: Kinship, Personal Gain, Empathy, and Obligation}

As stated in the opening of this chapter, partnered with the ability to act is desire. Other motivations than those directed by access or a lack thereof to opportunity structures in the country of origin or host country act on diasporas. Here, I address those 
motivations and reflect on whether simply being motivated is enough to support or prompt diasporic activity without capacity.

In their study of Eritrean diasporas in the United Kingdom and Germany, Al-Ali, Black and Koser (2001a) found that kinship was one of the principal motivations for sending home remittances. Of the forty-four Eritreans they interviewed in the United Kingdom and Germany, forty-two had close relatives living in Eritrea. Besides kinship, another motivation the authors found for making remittances was related to social status. By contributing, Eritreans in the diaspora raised their status within their diasporic community and in their "home" communities. Work by Shain and Barth (2003) also points to selfish motives by diasporas--diasporas may try to affect policies in countries of origin to suit their own priorities. They suggest that the diaspora community sometimes adopts a foreign policy of its own and pressures policy makers in their country of origin for support. The desire to return to a secure country of origin has been noted by Shain and Barth $(2003 ; 2008)$ to play a significant role in diaspora behaviour. This may motivate diasporas to promote stability and development as an investment in their own future.

Empathy is another important motivating factor for behaviour. Shain and Barth (2008) claim that empathy for a country of origin--specifically regarding economic development and financial support for other members of one's group--originate from an emotional connection. Due to this attachment, diasporas have become a crucial link between immigrant-receiving countries and the political climate in countries of origin.

Closely related to empathy and kinship is a felt sense of obligation, which may encourage or force diasporas to act when they otherwise would not have the desire to, or when limited opportunities are present either due to restraints in the country of origin or 
the host country and the perception of costs may outweigh benefits. Parekh (2003)

defines obligations as "social actions that the moral agent ought to undertake and his

failure to do which reflects badly on him and renders him liable to social disapproval" (p.

5). Recent work concerning pressures felt by diasporas to financially remit to family or

friends provides an example of obligation in action. Examples of cases that cite

obligation as a motivating force for action are found in Table 4, which summarizes the

motivations addressed in this section and provides examples of each.

Table 4: Summary of Motivational Factors with Examples

\begin{tabular}{|c|c|}
\hline Motivation & Example \\
\hline Kinship & $\begin{array}{l}\text { For most public projects in Eritrea, members of the local community, or other direct } \\
\text { beneficiaries, are required to contribute, and they in turn often turn to relatives abroad for } \\
\text { support in meeting their payments (see Al Ali, Black, and Koser, 200la). } \\
\text { - Mohan (2006) describes several elements important in Ghanaian culture: that the kin } \\
\text { group is provided for; that future generations are given an education; and that physical } \\
\text { infrustruture exists to symbolically demonstrate ones success. These values created a sense } \\
\text { of obligation in Ghanaian diasporas to financially remit to ensure that these criteria were } \\
\text { met for them and their families.Mohan (ibid) found kinship and community to be the the } \\
\text { two axes around which obligations were negotiated and constructed. }\end{array}$ \\
\hline Personal Gain & $\begin{array}{l}\text { - Al Ali, Black, and Koser (2001a) interviewed an Eritrean woman living in Saudi Arabia } \\
\text { who paid about } £ 70,000 \text { for the construction of a new mosque in Eritrea. When } \\
\text { interviewed, her status within the village was apparent, and she reported that she had also } \\
\text { earned the respect of both Eritreans and Arabs in the community in Eritrea where the } \\
\text { mosque was built. }\end{array}$ \\
\hline Empathy & $\begin{array}{l}\text { - In January 1999, President Bill Clinton, with the backing of many Cuban-Americans, } \\
\text { modified anti-Cuba legislation. The initiatives increased the number of Americans } \\
\text { permitted to send money to Cuba (Shane, 2000). Shane notes in a study of diaspora } \\
\text { remittance behaviours that Cuban-Americans were eager to send money home to better the } \\
\text { situation of those living there. Shane notes that although the Castro regime saw these } \\
\text { measures as a subversive attempt to bribe the Cuban people to change their perspectives, } \\
\text { the regime permitted some measures over which Cuba had control because the regime was } \\
\text { anxious to have the infusion of cash. }\end{array}$ \\
\hline Obligation & $\begin{array}{l}\text { Mohan (2006) suggests that remittances may serve as a repayment for the cost of } \\
\text { education and transportation of diasporas and that migration is viewed as an investment in } \\
\text { human capital, presumably by the family members that stayed in the country of origin and } \\
\text { supported the diaspora to migrate elsewhere. Mohan describes the burden felt by the } \\
\text { diasporas and the frustration that they felt. He quotes one participant as saying "they think } \\
\text { England is a pot of gold you've been there everything is easy as soon as you walk in } \\
\text { money is everywhere" (p. 271). } \\
\text { - In Al-Ali, Black, and Koser's (2001a) study, closer analysis of remittance behaviour of the } \\
\text { Eritrean diasporas revealed that remittances were similarly dispatched in response to } \\
\text { specific requests from family or friends, ranging, for example, from requests for help to } \\
\text { meet the costs of school uniforms or books, to requests to help repay outstanding debts. }\end{array}$ \\
\hline
\end{tabular}

Many motivational factors influence a diaspora's decision to behave in a certain

way. However, as Al-Ali, Black, and Koser (2001a; 2001b) note, opportunity structures 
in the host country still matter. Desire and capacity work together to create behaviour, and while the motivation to behave is important, the opportunity to take that motivation and direct it into meaningful action is necessary.

\subsection{What About Distance?}

The ease with which diasporas can interact with a country of origin may be affected by the physical distance separating them. As noted in the introduction to this study, the advent of advances in communication and transportation technologies has enabled diasporas to act with greater ease than before, from great distances. Here, I address the role of distance in diasporic activity and will argue that in an increasingly mobile transnational world, it is not as relevant as it once was.

Much of the work on distance and borders has been within the context of state-tostate relations and interethnic conflicts that cross borders. Drawing on the work of Boulding (1962) on projection of military power, Starr (2000) discusses the issue of distance within a conflict approach. He examines borders within an opportunitywillingness framework and concludes that borders affect both the willingness of conjoined countries to interact and the interaction opportunities of states, and of groups within states, by expanding or constraining the possibilities for interaction. Starr and Most (1978) further indicate that simple geographic proximity as indicated by borders affects the amount of interaction that takes place and the probability of various kinds of peaceful or conflictual interactions. Starr (2000) argues that states that share borders will have an easier time interacting with one another. Borders also have consequences for those who choose policy options because they act as indicators of areas of importance. 
Within literature that discusses the role played by proximity in determining levels of interaction, the work by Lemke (1996) is also relevant. Lemke (1996) believes that structural features such as paved roadways and the railways are vital in the determination of strength gradients. This is relevant here because it indicates that structures joining two bordering countries permit or restrain interaction.

The influence of a shared border on interaction can also be viewed through its affect on the willingness or desire of one or both parties. Starr (2000) explores this and suggests that willingness is associated with the value of territory behind the border. The more important something is on the other side of the border, the more willing one party will be to protect it. This includes co-ethnics. Siverson and Starr (1990) second this and explain that because states are likely to be interested in the political situation on their borders, they may have tendencies to shape the range of willingness of one of the parties involved, giving the state some control.

Physical borders may not be central to interaction. Within the diaspora literature, for example, one can find considerable discussion on the transnational qualities of diasporas. Mohan (2006) argues that a discussion of the relationships between political communities and territory involves de-centralizing the role of physical states as the definitive point of interaction. He points to studies on cosmopolitanism, which focus on the political community beyond national borders, and suggests that this body of work may easily replace discourse that views the "bounded territory of the state as the preeminent political community" (p. 868). Mohan argues that diaspora communities are territorialized in a dynamic way, and multi-level networks become bound by a shared morality and attachment to home. He concludes that distance is not a significant factor in 
the opportunity or willingness of a diaspora group to act--those elements are provided through trans-border diffusion.

The modern ease of travel and communication also serves to increase the strength and longevity of transnational ties between migrants. Demmers (2007), for instance, maintains that high mobility combined with the ease and speed of communication has enabled kin groups to create and sustain strong social linkages with their homelands. Whether the links facilitated by communication and transportation technologies provide interaction and engagement equal to or greater than that which would occur between neighbouring countries is a question that warrants further study. A consideration of transnational linkages may have significant relevance to this study. If, as Mohan (2006) and Demmers (ibid) suggest, transnational linkages are becoming more significant than physical space and that political communities are becoming borderless, this may result in a lessening of the influence of a host state on diaspora behaviour. Access to opportunity structures in one locality may not have significant consequences for diasporic activity, capacity, or desire if the use of transnational linkages mitigates barriers. The ability of diasporas to form transnational communities and to capitalize on structures that exist in one area or another, or exist outside the influence of the host state, may become the new direction of study. Transnational linkages will be further explored in Chapter 2.

\subsection{Conclusion}

It is clear from this review that a myriad of factors influence diasporic activity. These factors are complex and, thus far, pertinent literature has neither addressed them as a whole nor attempted to determine the relative influence of each in conjunction with others. Additionally, the literature does not clarify how these factors interact, and it does 
not open the question of whether some factors are more significant in prompting certain behaviours than others. This chapter has attempted to make progress on clarifying both of these points of inquiry (see Appendix 2 for the full model based on the contributing factors to diasporic capabilities and the outputs of diasporic activities). The results of this study should lend further insights into these relationships.

Further to this, this chapter has argued that one cannot overlook the importance of the role of structures in a host country in contributing to diaspora capacity and desire. Regardless of encouragement or discouragement by the country of origin, exclusive of individual factors and independent of distance, diasporas can be permitted or constrained from acting by a lack of access to political, economic, or social structures in the host country. Because of the important influence of the host country, this particular relationship was chosen for further exploration in this study. Figure 3 presents a simplified version of the model that was developed through this chapter and found in Appendix 2. This model will be used to analyse the role of the country of origin and, in particular, the capabilities afforded by the country of origin, in determining diasporic activity.

Figure 3: Simplified model of the factors that contribute to diasporic activity

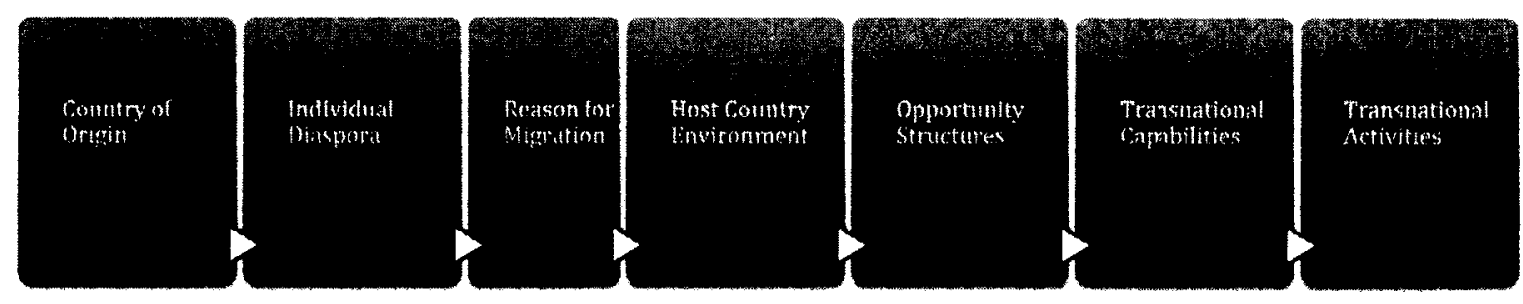

Based on the importance of the host country environment in determining diasporic, transnational activities, this study will focus on this determinant of diaspora behaviour and, particularly, on the political, social, and economic factors that contribute to transnational capabilities. The factors provided by Al Ali, Black, and Koser (2001b) 
(presented in Section 1.2) will be used as constructs to determine the capability profile of the country of origin. Levels of diasporic activity of populations living in distinct host countries that vary on these constructs will be measured to determine the effect of these constructs on these activities (see Appendix 1 for the tool that will be used to determine diasporic activity across the political, social, and economic spheres). The reason for migration will be taken into consideration as a factor to be controlled, given the findings presented here regarding the proclivity of conflict generation in promoting increased diasporic activities. To limit the effect of this variable, the chosen study population should be uniform on this factor. Attempts will also be made to limit the influence of the individual factors introduced in this chapter by identifying them in individual diasporas and by addressing any effect found related to these factors. In terms of the influence of a host country, two strategies will be employed to account for the affect of the country of origin on diasporic behaviour. First, a diaspora population from a single country of origin will be studied to limit the influence of factors arising from different countries of origin. Second, the three factors introduced in Section 4 will be addressed in the diasporic community, further isolating the role of the host country.

As was suggested in this chapter, a critical component of the system of which diasporas are part is integration, specifically, whether diasporas are integrated into the host country environment. Integration is an important consideration because it conditions a diaspora's transnational capability through mediating access to the host country and to the opportunity structures within that environment. The next chapter will address the role of integration in permitting diasporas to act through opportunity structures in the host country. 


\section{CHAPTER TWO: Integration Theory}

In this chapter, I highlight the role of diaspora integration in a host country in an analysis of diasporic activity. In the previous chapter, I presented considerations regarding a host country environment as a critical determinant of diasporic behaviour. I argued that access to opportunity structures within a host country affects diaspora engagement with its country of origin, constraining or allowing remittance behaviours. In this chapter, I will argue that integration of a diasporic community into a host country is vital for three reasons.

First, norms and policies of the host country can promote or frustrate diaspora integration. The last chapter demonstrated that for a diaspora to engage with a country of origin it must have legitimacy within a host country and it must have financial, social, and political wherewithal to remit from that country. Al-Ali, Black, and Koser (2001) framed this ability in terms of capabilities based on opportunity structures. This chapter will argue that integration of a diaspora into a host society is a critical precursor to accessing and acting on the foundation of the political, social, and economic structures available to them.

The second reason for which diasporic integration is vital is that integration permits exposure to political and social norms that may be internalized and transferred to the country of origin. In the previous chapter, I discussed the existence and importance of such social remittances; they are significant in terms of encouraging diasporas to support peaceful negotiations and peace building processes.

Third, we have reason to believe that diasporic communities may act in certain ways depending on whether they have legitimate access to formal channels through 
which to operate. I will argue that when these channels are not available, because of barriers to integration, their behaviour may be dramatically different than it would be otherwise. This point has particular relevance to a discussion of the factors that prompt peace "wrecking" behaviours by diasporas.

Initially, I will establish a working concept of integration. Next, indicators of integration will be formulated, based on the literature. These indicators will be used here to confirm the integration levels of individual diasporas. Following this, I discuss social capital as a potential confound to the effect of integration on engagement, as it is an important consideration for evaluating the findings presented here. Then, I will argue the importance of integration in remittance behaviours. Finally, I present in detail hypotheses regarding the affect of integration on diaspora engagement, specifically in terms of remittance behaviours. These hypotheses will also allow consideration of the consequences of integration for the capacity or desire of diasporas to engage with their country of origin.

To date, little empirical research has been conducted that addresses the affect of integration on remittance behaviours; however, the studies presented in this chapter suggest that a relationship exists between integration and engagement of diasporas with their country of origin and with their use, we can provide a framework from which this relationship can be empirically tested. To conclude, in this chapter, (a) I will answer the question of why integration is a critical consideration in shaping diaspora behaviour, and (b) I will provide a framework through which to establish whether a diasporic community is integrated into a host environment. A significant part of this framework will be the elicitation of specific indicators to evaluate the presence of integration. 


\subsection{Establishing a Concept of Integration}

Before discussing integration, it is worthwhile to establish what this concept means, particularly in terms of this study. Integration is used in both analytical and normative fashions. Several working definitions provide some clarity and will provide a definition for the term as used in this study. The United Nations High Commissioner for Refugees (UNHCR) defines integration as the product

of a multi-faceted and on-going process, of which self-reliance is but one part. Integration requires preparedness on the part of the refugees to adapt to the host society, without having to forego their own cultural identity. From the host society, it requires communities that are welcoming and responsive to refugees, and public institutions that are able to meet the needs of a diverse population (de Costa, 2006, p. 8).

The UNHCR further describes the process of integration as:

a legal, economic and socio-cultural process whereby refugees are granted a progressively wider range of rights and entitlements by the host State that are broadly commensurate with those enjoyed by its citizens. These include freedom of movement, access to education and the labour market, access to public relief and assistance, including health facilities, the possibility of acquiring and disposing of property, and the capacity to travel with valid travel and identity documents (de Costa, ibid, p. 8).

Although referring explicitly to refugees, the explanation provided has broader application and includes critical points from both the side of the incoming individual and the receiving society. Important for the study here, integration is a process that involves the host state driven provision of rights and access to what we have here described as opportunity structures. McGown (1999) similarly defines integration as a "two sided process of an immigrant's adjustment to a new society without loss of what they consider essential to their identity and simultaneously of the adoptive society's accommodation of them" (p. 43). McGown further differentiates between external and internal integration. She explains that external integration is achieved when members of a group can move 
laterally and vertically within the economic, social, and political spheres in the absence of barriers between group members and have ready mobility in social, economic, and political fields. Internal integration is the process by which immigrants weave together and balance their birth and adopted culture. McGown's definition affirms the role of the host country in facilitating integration, particularly in regard to what she calls external integration. It is notable that this definition is quite different from that of assimilation and that the two are not synonymous. The term "assimilation" suggests giving up one's cultural identity being absorbed into or adopting the culture of the host community to the extent that refugees become indistinguishable from local populations (Kuhlman, 1991). Integration, on the other hand, involves interaction between immigrants or refugees and locals without absorption of the former (Nagel, 1994; McGown, 1999). This definition is provided explicitly for the purpose of explanation and theorization.

\subsection{Indicators of Integration}

A number of indicators allow one to evaluate diaspora integration into a host country. A study of current literature allows the formulation of these factors and the creation of a model through which the validity of diaspora integration into a host country can be confirmed.

In a study of the contextual and structural factors that affect immigrant integration, Marrow (2005) argues that although individual characteristics of migrants affect their integration, greater attention must be paid to the reception of immigrants and to factors under the influence of the receiving country. Marrow (2005) (as well as Phalet and Swyngedouw, 2003) proposes classification of integration along three spheres: social or cultural, political, and economic, allowing an analytical framework through which to 
evaluate the presence of integration.

Marrow defines social and cultural integration as the "process by which immigrants accumulate social and cultural experience in ... society as their tenure in the host country increases" (p. 784). She further breaks this category into structural integration, measured by residential location, intergroup contact, local language ability, and intermarriage rates; and cultural integration, measured by ethnic identification and feelings of social distance from other groups. Marrow similarly defines political integration as the process by which immigrants "accumulate political experience ... as their tenure in the host country increases" (p. 784). She recommends investigating this through indications of electoral participation, non-electoral participation, affect on the political resources and standing of established groups, and affect on the political structure of their host country. Electoral participation can be determined through voter turnout, financial contributions, and employment in political parties or by candidates. Nonelectoral participation is measured by occurrences of lobbying, litigation, petitioning, protesting, civil disobedience, and contacting public officials and the media. Economic integration is "the process by which immigrants accumulate job experience in the ... labour market as their tenure in the host country increases" (p. 787). Marrow suggests that economic integration can be evaluated using a human capital approach, which focuses on employment status, level of education, language skills, and time spent in the host country. ${ }^{33}$ The identified indicators, which Marrow, as well as Phalet and Swyngedouw (2003) argue provide evidence of the presence of integration, are tabulated in Table 5.

${ }^{33}$ Length of residence in a host society relates positively to successful integration, according to Yang and Abu-Laban, et al. (1999). 
Table 5: Summary of Indicators of Integration as Presented by Marrow

\begin{tabular}{|c|c|}
\hline Type of Integration & Criteria \\
\hline Social/Cultural Integration & 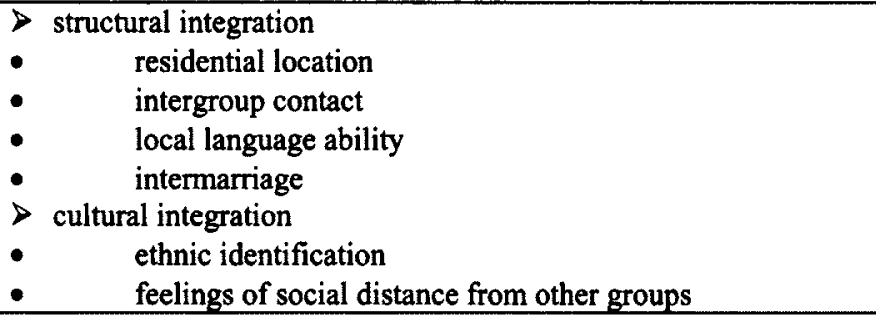 \\
\hline Political Integration & $\begin{array}{l}\text { electoral participation } \\
\text { voter turnout } \\
\text { - } \quad \text { financial contributions } \\
\text { employment in political parties or by candidates } \\
\text { - } \quad \text { lobbying } \\
\text { - litigation } \\
\text { petitioning } \\
\text { protesting } \\
\text { - } \quad \text { civil disobedience } \\
\text { contacting public officials and the media } \\
\text { affect on the political structure of their host country } \\
\text { affect on the political resources and standing of established groups }\end{array}$ \\
\hline Economic Integration & $\begin{array}{ll}\text { employment status } \\
\quad & \text { level of education } \\
\text { time spent in the host country }\end{array}$ \\
\hline
\end{tabular}

Although Marrow's work did not empirically study whether these structures play a large role in determining immigrant integration, and did not come to any definitive conclusions about the strength of the influence of these factors on integration, Marrow did achieve the objective of creating an analytical foundation for further research on this issue. This study will move this objective forward.

Other factors that affect integration have been identified. Yang (1994), for instance, indicates that social dynamics have been found to solidify or weaken integration into a host country, but also suggests that individual characteristics matter. According to Yang, five characteristics influence an individual's propensity to integrate: (a) successful economic adaptation; (b) age; (c) gender; (d) family make-up; (e) and marital status. Successful economic adaptation occurs with the acquisition of an occupation, with higher 
education, with a decent income, and with home ownership, ${ }^{34}$ which are factors congruent with economic indicators of structural integration suggested by Marrow (2005). Yang claims that working-age immigrants, men, ${ }^{35}$ and married immigrants with children (particularly young children) are more likely to integrate because they tend to settle into the host country. The factors of age, gender, and marital status provide additional variables that affect integration on an individual basis.

McGown (1999) has also looked closely at factors governing integration. She explains that each group brings with it specific characteristics that will affect how it integrates with a host society. Her comparative study of the integration of Somali diasporas in Toronto and London found a number of variables including the existing host country institutions to condition integration. She argues that of these, the political culture of a host country most significantly affects integration of immigrants. Specifically, McGown states that a political culture that emphasizes the ability of immigrants to participate as full members of society and that accords immigrants respect as political and social actors leads to harmonious integration.

McGown made several observations relevant to a discussion of access to opportunity structure. She found that political culture determined the level of legitimacy that diasporas were accorded in a host country. Taking political culture as "the pattern of individual attitudes and orientations towards politics" (p. 43) or the "set of attitudes, beliefs and sentiments that inform the political process and provide its underlying

\footnotetext{
${ }^{34}$ See also Abu-Laban, et al. (1999). Moghissi, Rahnema, and Goodman (2009) found that barriers to employment and equal wages contribute to a sense of isolation from the host state and result in a lower propensity to integrate.

35 A study by Ataca and Berry (2002) of Turkish diasporas in Canada found that males were more likely to assume an integrative attitude (supporting Yang (1994)). Alvarez (1987), however, suggests an opposing scenario, where women have stronger motivations to acquire membership as a strategy to escape repressive relationships or jobs. Recent research indicates that women tend to be less divided on ethnic lines and more flexible on identity aspects tied to ethnicity (Koch 2006), which also suggests that women would more readily integrate.
} 
assumptions" (p. 43), she asserts that political culture modulates the degree to which external integration can occur in shaping public attitudes towards immigrants and towards their acceptance as legitimate members of the collective. It also affects internal integration because decisions are not often made without awareness of the public aspect.

As an example, McGown found that Somalis in Canada felt inclusion into Canadian society, whereas they did not in the United Kingdom. To account for this difference, she identifies two ways in which Canada differs from the United Kingdom: a difference in the legal statuses of Somali refugees and political culture. In Canada, refugees and immigrants are afforded certain rights and protections, and McGown argues that Canada has been relatively successful at creating political cultural conditions that permit the inclusion of all its resident voices, including recent immigrants. McGown's study points to the fact that official structures can and do affect integration and legitimacy within a host society. Legitimacy allows diasporic communities access to social, economic, and political structures through which to act. The studies by Marrow (2005) and McGown (1999) reflect official or institutional structures that condition integration, and can be used to design policy to facilitate successful integration. Unofficial channels also operate to assist integration, and will be addressed below.

It is worthwhile to note that whether diasporas integrate into a host state also depends on the agency of individual diasporas. ${ }^{36}$ Yang (1994) argues that the costs, benefits and meaning of integration are the most immediate considerations in immigrant decisions to integrate. Costs include the process of gaining citizenship in a new country, the loss or reduction of rights as a citizen of the homeland, and inherent obligations to the

\footnotetext{
${ }^{36}$ Another consideration is the relationship dynamics that transfer from origin to host countries along with diasporas. Demmers (2007), for instance, states that cultural and political boundaries that delineate diasporas are reproduced in their host countries, making integration into new societies much more difficult.
} 
host country such as loyalty and upholding the laws and values (Yang, 1994). Benefits include rights of citizenship in the host country. Lyons (2006) also argues that diaspora groups will always maintain close ties to their country of origin that will override any attempt at integrating members of a diaspora into a host society. This is particularly true for conflict-generated diasporas, those forced to leave their countries of origin. Since symbolic attachment is paramount to these communities, many conflict-generated diasporas oppose bargains that trade off some portion of the sacred homeland for some other goal (Lyons, 2006).

I conclude that it is possible to assess integration through objective (or "hard"), quantifiable, and often structural, measures such as employment, access to housing, health, and education, as well as through subjective (or "soft") indicators such as sense of well-being and inclusion in the host society (Griffiths, Sigona and Zetter, 2005). Social interaction; the formation, expansion and nurturing of social relationships with locals; and participation in social life are essential elements of integration (Griffiths, Sigona and Zetter, ibid). These interactions often result in the accumulation of "social capital," discussed below.

\subsection{The Importance of Integration into the Host Country}

In Chapter One, I began to highlight the importance of integration into a host country on diaspora behaviour. Here, I drive that point home by emphasizing two points.

First, integration facilitates transnational capability. Integration implies the selective extension to non-nationals of legal, social, and political rights and opportunities that were once the exclusive entitlements of nationals. Thus, newcomers attain access to formal structures through which to promote their interests or accumulate and send 
economic, social, or political remittances to their homelands.

The second noteworthy effect of integration is that it creates opportunity for the transmission of social remittances. Levitt (2008) defines social remittances as the behaviours, ideas, values, identities, and social capital that flow from countries receiving a diaspora to those sending them. Levitt studied the formation of social remittances by countries receiving diasporas and the mechanisms by which diasporas return remittances to sending communities. Levitt concludes that integration results in exposure to political institutions such as democracy, whose governing ideas return to the homeland through contact between the diaspora and the homeland. By investing time and money, and by visiting their home countries, diasporas disseminate social remittances.

Levitt (2008) asserts that social remittances merit attention for three reasons: (a) they play an important role in transnational collectivity formation; (b) they bring the social affects of migration to the forefront; and (c) they are a potential community development aid. Levitt also believes that most migrants arrive strongly attached to their country of origin, which heightens the intensity of social remittance flows. ${ }^{37}$

Levitt identified three types of social remittances: (a) normative structures (ideas, values, and beliefs); (b) systems of practice (actions based on normative structures: religious practices, patterns of civil and political participation, leadership styles and strategies); and (c) social capital. Levitt indicates points of communication such as return trips home, telephone calls, and the exchange of other forms of communication as the sites of transmission of social remittances.

\footnotetext{
${ }^{37}$ In earlier work regarding social remittance creation, Levitt (1998) posits that a number of blended scenarios result when migrants interact with a host society. In some cases, existing ideas and practices may go unchallenged, while in others new elements are grafted onto existing ones. Finally, new relations and cultural practices are created through the intermingling of diaspora and host country forms.
} 
This transmission of social remittances has been discussed as a key method for changing norms, which is particularly relevant in diaspora remittance behaviours because of the potential for such changes to impact peace perspectives and conflict issues.

Crucially, Portes and Zou (1993) argue that the degree to which diaspora's interpretive frames are restructured depends on the degree of interaction and integration of a diaspora to the host country. Portes and Zou indicate that this restructuring is affected by the socioeconomic characteristics and opportunity structures available to diasporas in the host country. This further affirms a relationship between integration into a host country and the behaviour of diasporas and provides a critical window of opportunity for a host country to affect diasporic behaviours that can either promote or frustrate peace building in countries of origin.

In sum, integration is an important component of a model of diasporic behaviour and activity. It has been included here for two reasons: integration facilitates transnational capability through the provision of access to formal structures through which to promote diasporic interests, and integration creates the opportunity for the transmission of social remittances - remittances that have the potential of frustrating or supporting peace. These points are summarized in Table 6.

Table 6: Summary of Section 3 with Example

\begin{tabular}{|c|c|c|}
\hline Summary & Example & Relevance \\
\hline $\begin{array}{l}\text { Integration is vital because } \\
\text { it: } \\
\text { 1. Facilitates } \\
\text { transnational } \\
\text { capability } \\
\text { 2. Facilitates the } \\
\text { transmission of } \\
\text { values through social } \\
\text { remittances }\end{array}$ & $\begin{array}{l}\text { The study byPérez-Armendáriz and Crow (2010) on } \\
\text { Mexican diasporas in the US underlines the } \\
\text { importance of integration into a host country and } \\
\text { presents several findings. Migrants observe how } \\
\text { politics and society work in their democratic host } \\
\text { countries, operate under that country's institutions } \\
\text { and economy, and interact with citizens of the host } \\
\text { country and with other migrants. The economic well- } \\
\text { being and efficiency of most migrants' host countries } \\
\text { constitute a powerful incentive for migrants to } \\
\text { emulate what they observe. Migrants also have } \\
\text { opportunities to participate politically in their host } \\
\text { countries. }\end{array}$ & $\begin{array}{l}\text { Integration is critical to the } \\
\text { study of diasporic behaviour } \\
\text { because it facilitates access to } \\
\text { structures in the host } \\
\text { environment that contribute to } \\
\text { diasporic capability, which } \\
\text { then results in differing levels } \\
\text { of diasporic activity. }\end{array}$ \\
\hline
\end{tabular}




\subsection{The Relationship between Integration and Diasporic Behaviour}

The nature of the relationship between integration and active engagement with, or activity in, the country of origin is not clear due to the scant amount of information on the subject. However, Brinkerhoff (2009) proposes that the degree of integration into a host society does not necessarily determine diaspora engagement with the homeland, but any relationship that exists may arise from the struggle that many diasporas face in integrating into a new society. She indicates that diasporas increasingly shift focus from the activities of a home country to improvement of quality of life in the host country. Diasporic communities that are not given an opportunity to integrate into a host country and which are, therefore, blocked from receiving certain rights within that country, tend to focus on fighting for and defending rights within the host country; this will inevitably detract from a focus on issues in the country of origin. This suggests a correlation between the level of integration in the host country and engagement (and correlative remittance behaviour) with the country of origin.

Thus, integration may push diasporas to focus the majority of their efforts on their position within a host country, rather than on what is occurring in the country of origin.

In this case, low integration results in low levels of diasporic activity. Brinkerhoff (2009) also suggests that the degree of integration in a host country is not the sole determinant of whether or the extent to which diasporas engage in activity on behalf of the homeland. She points to other contributing motivations: obligations, guilds, grievances, powerseeking, influence-seeking, and violence. What remains to be determined is the power of these motivations in the absence of opportunity: are they strong enough to compel action when opportunity in a host country to act on those motivations is lacking? The link 
between capacity and desire suggested by Cioffi-Revilla and Starr (1995) suggests that capacity constrains desire, and so it may be that without capacity desire wanes, or that a certain amount of desire or willingness is required to encourage a diaspora to look for ways to overcome structural barriers.

Describing the same relationship as Brinkerhoff (2009), Guarinzo et al. (2003) had suggested that the longer a diaspora is in a host country and the more integrated the diaspora becomes, the more likely it is actively to engage with the country of origin. Van Hear, Pieke, and Vertovec (2004) similarly argue that, as diaspora groups feel more settled as a community, their collective attention turns to their home and they increase their home-country-related activity. Hear, Pieke, and Vertovec believe that the longer a diaspora lives in a host country, the more it integrates, and the more familiar and comfortable its members become with social structures and institutions. This allows diasporas to use official channels to promote their overseas objectives.

In sum, a relationship between integration and diasporic activity is suggested. Table 7 summarizes the relationship outlined in this section: integrated diasporas should exhibit higher levels of transnational activity than diasporas that are not integrated. This relationship provides a key piece of the foundation underpinning diasporic behaviour.

Table 7: Summary of Section 4 with Example

\begin{tabular}{|l|l|l|}
\hline Summary & Example & Relevance \\
\hline $\begin{array}{l}\text { A relationship has been } \\
\text { suggested between } \\
\text { integration and diasporic } \\
\text { activity level. Integrated } \\
\text { diasporas should exhibit } \\
\text { higher levels of diasporic } \\
\text { activity than those who are } \\
\text { not integrated. }\end{array}$ & $\begin{array}{l}\text { Pérez-Armendáriz and Crow (2010) found that } \\
\text { Mexican migrants to the US faced many difficulties in } \\
\text { the host country-including language barriers, finding } \\
\text { employment and housing, and navigating social and } \\
\text { legal institutions. These barriers served as the } \\
\text { foundation for becoming politically active in ways } \\
\text { unimaginable at home, where they were full citizens. } \\
\text { Learning to become socially and politically active and } \\
\text { to navigate through associated structures and processes } \\
\text { give diasporas the knowledge and familiarity to use } \\
\text { these avenues to further causes related to the country of } \\
\text { origin, or to engage in actions directly targeted at social } \\
\text { or govemmental structures back home. }\end{array}$ & $\begin{array}{l}\text { This section } \\
\text { of integration and diasporic } \\
\text { activity. }\end{array}$ \\
\hline
\end{tabular}




\subsection{Transnationalism: An Intervening Force?}

Although the preceding section has provided evidence that integration, and through it access to opportunity structures that facilitate transnational capabilities, has an impact on remittance behaviours, competing factors must be addressed. The first of these is the presence of transnational linkages.

Phalet and Swyngedouw (2003) suggest that the concept of transnationalism is a paradigm competing with that of integration in migration studies. Transnationalism refers to processes that transcend international borders. These processes take place in transnational spaces, that is, they consist of "relatively stable, lasting and dense sets of ties reaching beyond and across borders of sovereign states. Transnational spaces comprise combinations of ties and their substance, positions within networks and organisations and networks of organisations that cut across the borders of at least two national states" (Faist, 2010, p. 13).

While diaspora studies tend to focus on the distinctiveness of a collectivity and its shared connection to a territorial place, transnational studies focus on mobility and the creation of networks. Transnational studies question the idea of territoriality and suggest instead that the increasingly common process of connecting people in different places results in a de-territorialisation, forcing investigators to re-think the affect of localities on identity and behaviour (Faist, 2010; Bruneau, 2010; Vertovec, 2011). Geography is a field that increasingly theorizes about the social construction of space as a result of transnational networks, however this trend has yet to firmly make its way into migration or diaspora literature. In this school of thought, Schiller (2010) argues against an over reliance on a "methodological nationalist" (p. 100) approach that accepts national borders 
as the borders of society; she maintains that if this can be set aside, migration can be discussed as part of a broader transnational process that includes, but is not focused on the boundaries of a nation state.

In sum, the presence of transnational linkages may serve as another factor facilitating diasporic activity, and may serve as a strategy that supersedes integration. The intervening affect of transnational linkages and spaces on behaviour, and how they influence the localized effect of the structures of a host state are questions that have yet to be answered. The results of the present study will lend some insight into that debate through an inquiry into the nature of the affect of host country structures.

\subsection{Social Capital}

The second factor which may provide an avenue for diasporic activity, regardless of the presence or absence of integration, is social capital. Marrow (2005) clarifies that even when a host country creates barriers to formal participation in political processes, other institutions such as labour unions, churches, and voluntary organizations create skills that enable active participation. This accumulation of skills has been termed "social capital." Social capital may allow diasporas an increased ability to act from within a host country where barriers may be present in formal structures. It may also facilitate more effective remittance transfer from diasporas to people in the country of origin.

Social capital addresses the role of informal relationships and channels in forming linkages that affect and effect integration. A concept introduced into sociology by James Coleman $(1988),{ }^{38}$ social capital comes about through changes in relationships between

\footnotetext{
${ }^{38}$ The concept was developed by Coleman (1988) to reconcile two existing streams that explain social action --one that saw individuals as socialized to act in certain ways because of norms, rules, and obligations (it focuses on the role of the social context) and another that viewed people as self-interested independent actors.
} 
people. Just as physical capital and human capital facilitate productive activity, social capital does so as well. According to Coleman, a group that has trust is able to accomplish more than a comparable group without trust. Trust can dramatically reduce what economists call transaction costs such as negotiation and enforcement and make forms of economic organization possible that otherwise would be encumbered by rules, contracts, and bureaucracy.

Another social capital theorist, Fukuyama (1995), argues that social capital forms the linkages between non-rational social factors such as religion, culture, and tradition that guarantee the success of modern societies. Social capital is related to traditional virtues of honesty, keeping commitments, reciprocity, and reliable performance of duties (Fukuyama, 2001). In describing the origin of social capital, Fukuyama relies on the idea of an iterated Prisoner's Dilemma game. A tit-for-tat strategy leads players to a cooperative outcome. Fukuyama suggests that while this explains spontaneously generated social capital, a strictly economic approach is limited because in many cases social capital is produced by hierarchical sources of authority, like religious institutions or large cultural systems. This point is important here because it demonstrates that social capital is the by-product of religion, tradition, shared historical experience, and other factors that lie outside the control of any government. States do not have many obvious levers for creating or influencing social capital, however the area where governments have the greatest direct ability to generate social capital is education. This limits the host government's role in intervening in this process, suggesting that there are avenues diasporas may take to access or utilize structures outside of those provisioned by the host country, reducing the importance of the host country in determining diasporic activity. 
Glaeser, Laibson, and Sacerdote (2002) investigate an individual's decision to accumulate social capital using a standard optimal investment model. These authors discounted previous models because during laboratory experiments conducted by Glaeser et al. (2000), it was found that subjects who report that they are trusting do not necessarily act more trusting in trust games. Here, Glaeser et al. (2002) define social capital as a person's social characteristics, including social skills, charisma, and the number of contacts which enables him or her to reap market and non-market returns from interaction with others. Utlizing Putnam's (1993) approach to collecting evidence of social capital--namely, organizational membership--Glaesar et al. (2002) describe an economic approach to investment in social capital and present some basic empirical evidence testing the implications of their framework. They found that social capital depreciates when an individual leaves his neighbourhood and that individuals with more sociable occupations invest more in social capital. In addition. results seems to indicate that human capital and social capital may be complements. Spatial proximity also influenced the cost of social capital investment; people who are spatially far apart are less likely to form social connections. They conclude that individual incentives and not group membership drives social capital accumulation and decisions.

Social capital is not always described as a positive component of interaction. Portes (1998) reviews the literature on social capital and extracts four negative consequences of social capital: (a) exclusion of others, where the same strong ties that bring benefits to members of a group can bar others from access; (b) excess claims on group members, where group closure may prevent the success of business initiatives by their members; (c) restrictions on individual freedoms, as group participation creates 
demands for conformity; and (d) downward leveling norms, whereby group solidarity is cemented by a common experience of adversity to mainstream society and individual successes undermine group cohesion.

In conclusion, integration in a country of resettlement offers challenges to refugees or other immigrants; they may face racism, discrimination, and language and cultural barriers. In addition, many refugees have few skills that can be transferred from a developing country of origin to a Western country of resettlement (Shandy, 2007). Relationships and support networks built within non-official channels can provide social integration and a cushion for a lack of social, political, or economic integration. Table 8 summarizes the arguments presented here for the role of social capital in creating these networks.

What a discussion of social capital suggests is that in environments with a lack of access to structures through official channels, people may still achieve much that they desire through informal networks based on trust and reciprocity. The presence of social capital is a consideration in the present study study because it may act as a confound to the affect of integration. However, we should keep in mind that the relationships provided through the exchange of social capital may not be enough to facilitate transnational activity. Pietrese (2003), a social capital theorist, acknowledges that social capital alone without access to resources will not lead anywhere. Pietrese argues that levels of integration influence access to formal structures in the host country, and access to formal structures by some or many individuals within a group is necessary for the production of social capital. Even if diasporas find a sense of community and connectedness through group membership, lack of access to institutions in the host country may still constrain 
their behaviour (Coleman, 1988).

Table 8: Summary of Section 3 with Examples

\begin{tabular}{|c|c|c|}
\hline Summary & Example & Relevance \\
\hline $\begin{array}{l}\text { Informal networks based on trust and } \\
\text { reciprocity form and may circumvent } \\
\text { lack of access to state structures } \\
\text { Trust within groups facilitates fruitful } \\
\text { economic and social organization, } \\
\text { aiding in the success of groups that } \\
\text { lack formal access }\end{array}$ & $\begin{array}{l}\text { For South Sudanese women, religion } \\
\text { is the main avenue for integration } \\
\text { into US society (Benesova, } \\
\text { 2004). Religious affiliation was an } \\
\text { asset in securing third country } \\
\text { resettlement and religious identity } \\
\text { connected South Sudanese to a wide } \\
\text { community of Christians. Churches } \\
\text { provided social support for this } \\
\text { community-- a sense of identity, } \\
\text { which ultimately helped individuals } \\
\text { integrate into society and gain access } \\
\text { to structures they would not have had } \\
\text { access to otherwise. }\end{array}$ & $\begin{array}{l}\text { Social capital may circumvent host } \\
\text { country structures, limiting the } \\
\text { potential for the host country to } \\
\text { constrain diasporic activity. } \\
\text { When a host country creates barriers } \\
\text { to formal participation in the host } \\
\text { society, other institutions such as } \\
\text { labour unions, churches, and } \\
\text { voluntary organizations create } \\
\text { opportunity and build capability. } \\
\text { The presence of social capital should } \\
\text { be considered in a study of diasporic } \\
\text { behaviour. }\end{array}$ \\
\hline
\end{tabular}

\subsection{Conclusion and Hypotheses}

In this chapter, I have presented theoretical and empirical evidence to support the thesis that integration facilitates access to the political, economic, and social structures in a host society, and that integration serves as an avenue for the transmission of social remittances that may influence political and social ideas in the country of origin. I have also argued that desire without capacity may not allow diasporas to act in ways they wish, because of lack of opportunity. Yet, some suggest that new ideas in transnational studies qualify that claim and suggest that the influence of localities may be something of the past. If this is the case, new research directions for the study of diasporas must be forged. The conclusions drawn from the empirical study undertaken here will take us further towards knowing what factors remain integral to diasporic transnational activity, and where we may have to direct our efforts in the future.

Continuing the investigation into the concept of 'diaspora' through a study of the impact of the host country environment on diaspora behaviour will further the knowledge 
base on mobility, interconnectedness and extra-national influences in the contemporary world.

Hypotheses regarding the influence of integration on diasporic activity, and regarding how opportunity structures might mitigate diasporic capabilities were developed based on the factors modeled here. Figure 4 provides a model summarizing the predicted relationship between the factors identified in Chapters One and Two.

Figure 4: Predicted model of diasporic activity
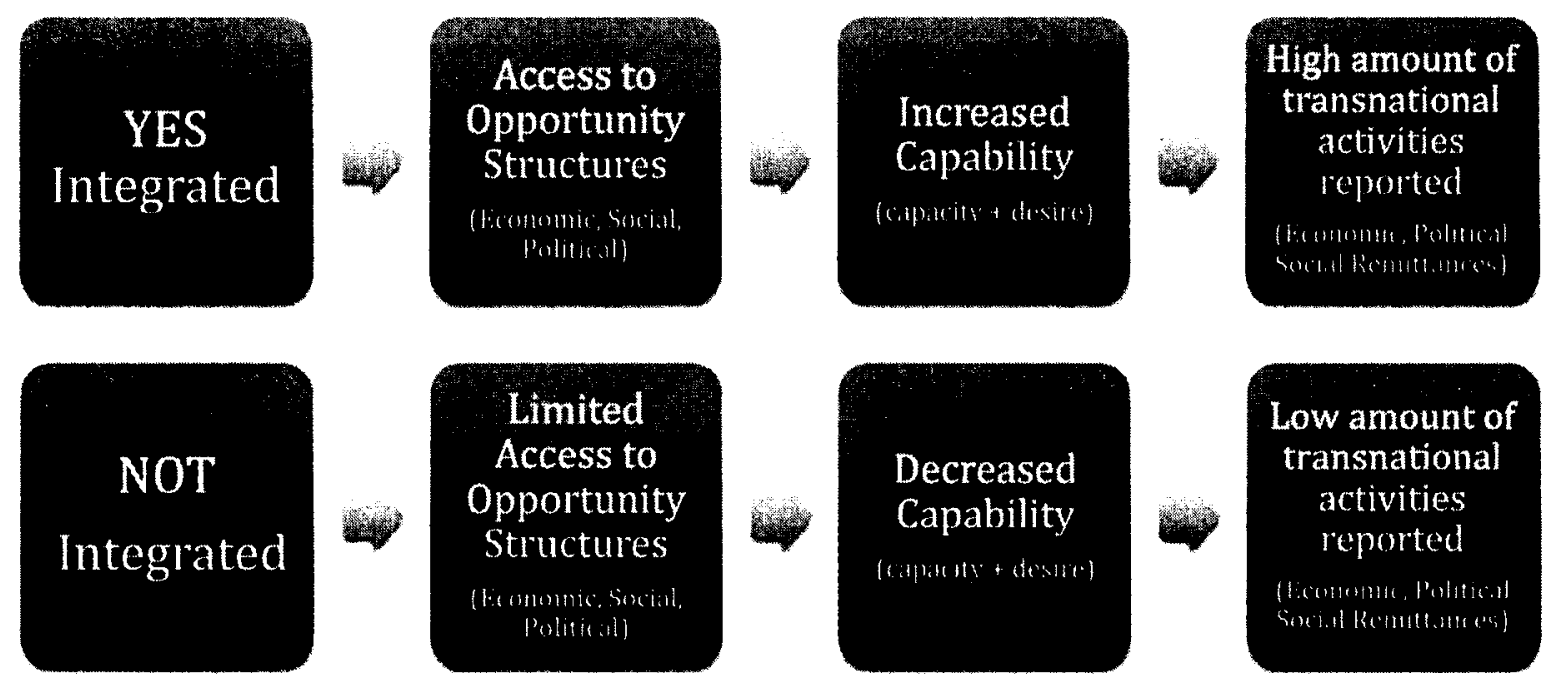

Based on the relationships predicted by Brinkerhoff (2009), Guarinzo et al. (2003), Van Hear, Pieke and Vertovec (2004) and Pérez-Armendáriz and Crow (2010), and based on the model above which incorporates the arguments presented in Chapters One and Two, the following hypothesis was formulated:

Hypothesis 1: If a diasporic community experiences high levels of integration then that community should demonstrate high levels of remittance activities.

This hypothesis operationalizes the argument that has been developed in this chapter: that we should expect to see a relationship between integration and remittance activities. A 
factor underpining this relationship is access to opportunity structures in the host country, which contribute to transnational capability.

Based on the relationship discussed by Binkerhoff (2009), who indicated that motivations independent of the influence of integration are significant factors in determining the desire or willingness of diasporas to engage in remittance behaviours, and the motivations outlined in Section 1.5, the following hypothesis was developed:

Hypothesis 2: The level of integration experienced by diasporas will not have an affect on the desire or motivation of diasporas to engage in remittance activities.

Because many of the motivations that underpin desire or willingness arise from factors internal to a diaspora (negotiation of identity, obligation, reciprocity) or pressures from the country of origin, it is hypothesized that the differences in desire or motivation between diaspora groups based on degree of integration will be insignificant. If a difference is found between integrated and non-integrated diasporic communities, it will suggest a strong constraining effect of capacity on desire. Information on remittance behaviour will be correlated with the presence of capacity and willingness to determine how remittance behaviour translates into actual activity.

The presence of transnational networks will also be considered as a factor that may limit the affect of integration into the host country and provide opportunity to engage in diasporic activities. Based on the arguments concerning the relevance of transnational linkages to remittance behaviour, presented by Faist (2010), Bruneau (2010), Dahinden (2010), and Vertovec (2007), the following hypothesis was developed:

Hypothesis 3: If strong transnational linkages are present in a diaspora, the difference between the remittance levels in diasporic communities in different host countries should be small. 
If, as suggested in section 5, transnational linkages provide avenues for diasporic activity to take place regardless of the host country a diaspora is located in, we should see a limited effect of integration on remittance activities. This will be demonstrated if there is an insignificant difference between diaspora groups in different host countries.

Three additional considerations arise from the information before us. First, it is interesting to consider whether integration into a host country facilitates the transfer of social remittances that could aid in the development of peace. Second, does integration affect whether diasporas act in a peace supporting or peace wrecking capacity? Third, does the presence of social capital create avenues through which diasporas can engage with a country of origin independently of their levels of integration into a host society? These questions are posed before an exploration of the findings of this case study begins so that they are kept in mind through the evaluation of the data collected.

As will be demonstrated throughout the remainder of this paper, a continuing investigation into the concept of diaspora through a study of the affect of the host country environment on diaspora behaviour will further the knowledge base on mobility, interconnectedness and extra-national influences in the contemporary world. As indicated in the introduction, in the modern world where diasporic activity has a strong effect on the politics, economics and social fabric of sending countries around the world, understanding the factors that influence transnational activities is increasingly important. 


\section{CHAPTER THREE: Methodology}

The themes that I have presented warrant further, detailed investigation to explore the motivations and experiences of diasporas. Studies in this area are few and many questions remain unanswered. This chapter will detail the methodology that was used here in the pursuit of answers to the research questions presented in the introduction: Does integration into a host country affect the engagement choices of diasporas? Does access to political, economic, and social opportunity structures increase or decrease the remittance behaviours of diasporas?

\subsection{Study Design}

I employed a multi-sited case study of South Sudanese diasporas living in Canadian and Kenyan urban centers. Both quantitative and qualitative research methods were used. Quantitative data collection allowed specific information to be gathered, and for the use of statistical analysis. Patterns and correlations were thus able to be determined. Qualitative data collection was determined to be of import since the richness, detail, and breadth of information collected through interviews is of great value and provides a foundation for further empirical research (King, Keohane and Verba, 1994).

The strength of qualitative research is its ability to provide complex textual descriptions of how people experience a given issue. It provides information about the "human" side of an issue--that is, regarding the behaviours, beliefs, opinions, emotions, and relationships of individuals, as well as intangible factors such as social norms (Merriam, 2009). The researcher is the primary instrument of data collection and 
analysis. ${ }^{39}$ The weakness of this methodology, exemplified here, was that only a small numbers of subjects were studied because data collection methods were labour intensive. King, Keohane, and Verba (1994) argue that the value of qualitative research, which involves few cases and allows subjects under study to provide descriptive answers to questions, is that it may suggest valuable insights that may be missed by other methods. In addition, with qualitative methods relationships between the researcher(s) and participant are often less formal than in quantitative research, giving participants the opportunity to respond in greater detail than is typically the case with quantitative methods. ${ }^{40}$ Thus, qualitative research serves as a valuable complement to quantitative methods (Patton, 2002; Merriam, 2009). With Yeung (1997), I would argue that the inclusion of qualitative methods, here interviews, are beneficial in helping us abstract the causal mechanisms obscured by quantitative and statistical methods. Quantitative methods have an important role to play in establishing the empirical connectivities between objects, and together these methodologies can lend strength or insight to the findings of one other. Another weakness of this methodology is the difficulty analyzing qualitative data rigorously. The analytical objectives of qualitative research, however, are to describe variation, relationships, individual experiences, and group norms; the data collected are used to develop concepts and theories that help understand phenomena in

\footnotetext{
${ }^{39}$ A qualitative approach provides the advantages of processing data immediately, clarifying and summarizing material, checking with respondents for accuracy of interpretation, and the ability to explore unusual or unanticipated responses. This came in handy in this study when interviewing subjects with varied levels of English comprehension.

${ }^{40}$ Generally, quantitative methods are fairly inflexible. With quantitative methods such as surveys and questionnaires, the response categories from which participants may choose are closed-ended. The advantage of this inflexibility is that it allows for meaningful comparison of responses across participants and study sites. However, it requires a thorough understanding of the important questions to ask, the best way to ask them, and the range of possible responses. Qualitative methods are typically more flexible--they allow greater spontaneity and adaptation of the interaction between the researcher and the study participant. Qualitative methods ask mostly "open-ended" questions, not necessarily worded the same way with each participant. Participants are free to respond in their own words, and these responses tend to be more complex than only "yes" or "no."
} 
the social world (Merriam, 2009). The subject matter of the study here is complex and firmly housed in the social world, rendering the use of qualitative methodology very appropriate.

\subsection{Study Populations}

In order to isolate the affect of integration and access to opportunity structures in the country of origin on remittance behaviours, a single diaspora group that has migrated to several distinct host countries was necessary. South Sudan was chosen as a case study based on two key qualities discussed in Chapter 1: reason for migration and relative homogeneity. First, the diaspora from South Sudan consists almost completely of conflict-generated migrants. Second, the majority of the diaspora left South Sudan around the same time, and members reached their host countries within 10 years of one another. These qualities contribute to the relative uniformity of this group and also make this population somewhat different from diasporas reported in case studies already published.

Canada and Kenya were chosen as countries of comparison because of distinct immigration policies and the sharp differences in the political culture of the two countries. ${ }^{41}$ South Sudanese diasporic communities in Canada and Kenya were also determined to be substantially different in terms of their structural integration, based on the indicators presented in Chapter Two. The selection of these two communities allows one to study whether integration affects the engagement level of diasporas with their

\footnotetext{
${ }^{41}$ McGown (1999) suggests that a comparison across countries with differing political cultures and immigration policies is a strategy for exploring integration. McGown chose Canada and England as countries to contrast experiences of integration and claims that as the largest and most central cities in their respective countries, London and Toronto exemplify their respective national political cultures and, accordingly, chose the two cities as sample populations in her research.
} 
country of origin. It also allows for consideration of the consequences of integration on the capacity desire of diasporas to engage.

\subsubsection{Sampling}

I used purposive sampling in this study. One of the most common sampling strategies in qualitative research, purposive sampling selects participants according to predetermined criteria relevant to a particular question (Patton, 2002). In particular, the snowball method aided me in finding and recruiting individuals that would have been not easily accessible through other sampling strategies (Patton, ibid). Participants or informants with whom contact had previously been made used their social networks to refer me to other people who could participate in or contribute to the study. The first participants were located through advertising in local settlement service agencies, churches, and refugee services. Informants found through this strategy pointed out other members of the South Sudanese community. The sample size for interviews was 15 individuals from Canada and 15 individuals from Kenya and for surveys 15 individuals from Canada and 17 individuals from Kenya. ${ }^{42}$

Ethics approval was obtained prior to conducting data collection to ensure the protection of participants during data collection. All participants provided informed consent before their participation and the researcher will withhold and protect all information that could identify participants. Participants were informed of the condition of strict confidentiality for this study and in the case of those respondents who completed online surveys, anonymity was assured. Participants were also informed of their right to refuse to answer any question and of their ability to remove themselves from the study at

\footnotetext{
${ }^{42}$ The majority of participants were above 30 years old. Out of survey and interview participants, 10/32 were under 30 years of age in Kenya and 8/30 participants in Canada were under 30 years of age.
} 
any point up to a specified date. This assurance of anonymity created trust between the

researcher and the respondents, allowed respondents to answer questions without concern for identification, and allowed respondents to answer questions without fear of repercussion. This was critical for South Sudanese respondents because of concerns over punishment for speaking out against the South Sudanese government or leadership.

\subsection{Data Collection Instruments}

Two data collection methods were used in this study: surveys and semi-structured interviews. The questions used are provided in Appendix 3. This combination of methods allowed collection of a larger amount of data than would have been possible using only one method. Participants who were reluctant to participate in an interview were more at ease completing a survey because their voices were not recorded.

Surveys by Canadian respondents were completed online through an online survey hosting program called Fluidsurveys. ${ }^{43}$ Participants were given the web address for the survey and told they could complete it anonymously at any time. Kenyan respondents completed surveys in person due to lack of access to computers and due to the need to have the researcher present to clarify questions when needed. The questions were largely closed-ended, with three open-ended questions that allowed for further elaboration of answers. ${ }^{44}$ Surveys gave participants the opportunity to participate in the study in a completely anonymous manner and provided an option better suited to those

\footnotetext{
${ }^{43}$ Fluidsurveys is an online survey tool hosted in Canada (www.fluidsurveys.com).

${ }^{44}$ As Rea and Parker (1992) note, several advantages accrue to the closed-ended question technique. The set of questions and alternative answers are uniform across participants, allowing comparisons between participants. Additionally, the fixed list of possibilities tends to make the questions clearer and less onerous for the respondent. The disadvantages are that the respondent may be unsure of the right answer and will pick the closest one, or randomly choose an answer without real thought. It also creates the potential for mistakes, such as a respondent ticking one box when they meant to choose the adjacent answer.
} 
respondents who had too little time for an interview. Surveys also allowed participants to respond quickly and easily to questions asked.

Those respondents completing the survey were not the same individuals as those who completed the interviews. This means that there is no duplication of information. Except for two cases where two participants were interviewed together, as per their request, participants were interviewed individually, in a place determined jointly by the subject and the researcher. This was normally a public place such as a café. Interviews are optimal for collecting data on individual personal histories, perspectives, and experiences, particularly when sensitive topics are explored, and encourage subjects to express their views at length. The interviewer is the primary instrument of data collection, which had its advantages in this case because it allowed me to make slight adjustments in each interview as it progressed. The specific interview format used was semi-structured interviews. I had a set of questions to ask, but some aspects of the interview were flexible--for example, the addition, exclusion, or wording of particular interview questions. As well, participant responses affect how and which questions the researcher asked next. If the interview schedule is too tight, the phenomena under investigation may not be explored in breadth or depth (Rea and Parker, 1992). Semi-structured interviews work well when the interviewer has identified a number of aspects he or she wants to address. The interviewer can decide in advance what areas to cover, but is open and receptive to unexpected information from the interviewee. Ensuring that interviewees felt as though they were participating in a conversation, rather than a formal question and answer situation was a successful strategy in creating a comfortable setting, and participants were willing to answer each question, many at length. 
Four types of questions were asked, based on Patton's (2002) recommendation:

1. Background/demographic questions

2. Experience and behaviour questions

3. Opinion and value questions

4. Feeling questions

The surveys and interviews included questions designed to elicit descriptive information about the respondents. Demographic information such as respondent age, gender, education level, ethnicity, employment status, and length of residency in the host country were collected to help understand the nature of the larger population represented by the sample. Questions about experiences of integration were asked to determine the integration level of each participant, as indicated by him or herself, important as this is the independent variable. Questions regarding connections with South Sudan and the level of frequency of economic, political and social remittances were asked to collect data on the dependent variable: remittance behaviour. This allowed me to evaluate hypothesis 1. Finally, questions about the factors that motivate diasporas to remit and about the presence of transnational networks were asked in order to evaluate hypotheses 2 and 3.

Open-ended questions were used in all interviews. Interviews were tape recorded, leaving the interviewer free to concentrate on listening and responding to the interviewees. Tape recording ensured that the whole interview was captured and provided complete data for analysis so cues missed the first time could be recognized when listening to the recording. Lastly, interviewees may have felt inhibited if the interviewer suddenly started to record what had been said in earnest: they may have wondered why what they had just said was of particular interest and it may have affected their answers. The same survey and interview questions and techniques were used in Toronto and Nairobi to assess the differences attributable to location. Rea and Parker (1992) indicate 
that this technique is effective. McGown (1999) has used this method to conduct comparative research with diaspora groups in two host countries.

\subsection{Data Analysis}

The data collected in Canada and Kenya will be presented in two ways: quantitative results and qualitative results. Interview transcripts were coded using content analysis, allowing for statistical analysis. Surveys were coded as well, also allowing for statistical analysis. This section will detail these strategies. In addition, key quotations from responses will be presented in Chapter Six to reinforce findings.

\subsubsection{Content Analysis}

Qualitative data from the interviews was analyzed using content analysis. Klaus Krippendorff formalized content analysis as a methodology in the late 1970s and early 1980s (Krippendorff, 1980). A central thesis of content analysis is that the words of a text can be classified into content categories. Weber (1990) notes that to make valid inferences from a text, the classification procedure must be consistent. However, no single method of content analysis is available; rather, a researcher must judge the methods appropriate for the problem addressed (Weber, 1990).

Commonly used in communications literature, content analysis permits the examination of media, documents, or texts and can be quantitative (when coding data into pre-determined categories in a systematic and easily replicable manner) or qualitative (when seeking deeper meanings). Neuendorf (2002) describes the use of latent constructs (the symbolic meaning behind messages) to integrate quantitative content analysis and qualitative message analysis. Latent construct analysis allows researchers some latitude to 
explore both the latent and the manifest content of text. Further interpretation can allow analysis of a text through the coding of ideologies, beliefs, or principals.

Two main elements determine a content analysis coding scheme: the design of a coding schedule, that is, a form that data are entered into; and the creation of a coding manual, a set of instructions for coding the text. The coding manual includes all possible categories for each coded dimension, the categories subsumed under each dimension, the codes (numbers) that correspond with each category, and information regarding the characteristics determining the allocation of a particular code to each dimension.

Advantages of content analysis applicable in this case include its transparency as a research method, the rigour introduced by allowing for analysis of quantitative elements, and its flexibility. Another benefit is that the content of the responses was a direct result of the questions asked, which were constructed to reflect the theoretical underpinnings of interest. Disadvantages include the element of interpretation present in coding, particularly in analyzing latent content, and the tendency of content analysis to focusing on what is measurable rather than what is theoretically significant. Regarding the survey questions, participant responses were coded to allow quantitative analysis. The content analysis performed on the interview transcripts used nominal or ordinal levels of measurement. Coded categories were mutually exclusive. Only one investigator coded the data, which removed the concern of inter-coder reliability, one of the main reliability concerns with this methodology.

Interview tapes were transcribed verbatim and the text was coded for thematic content. ${ }^{45}$ The interview questions asked are presented in Appendix 3 and the coding

\footnotetext{
${ }^{45}$ Merriam (2009) states that verbatim transcription of interviews provides the ideal database for analysis and that transcription done by the researcher her- or himself is preferable to hiring others because it allows
} 
schedule can be found in Appendix 4. As dictated by this methodology, the coding manual and coding schedule were designed before the data were analyzed. The units of analysis used in coding were the entire interview, or the responses to each question.

Quantitative analysis was conducted on several points of the manifest content of the interviews. Qualitative analysis provided detailed descriptions of the themes and responses, and data will be presented using brief quotations in the results chapter. The program SPSS was used to analyze the data coded from the surveys as well as the data coded from the interviews using content analysis.

\subsubsection{Statistical Analysis}

In statistically evaluating the data, the responses from the South Sudanese diasporas living in Canada were contrasted with those living in Kenya. These samples were naturally divided into test groups based on the level of integration experienced as a result of host country policies (Canada $=$ high integration and Kenya $=$ low integration). Variables identified to be confounds (age, gender, length of residence, race, and refugee status) were controlled. Correlations and multivariate regression isolated the effects of integration on remittance activities, and helped to evaluate the influence of other factors.

\subsection{Limitations}

Baser and Swain (2008) argue that studying the behaviour and attitude of diasporas is not an easy task. In fact, simply gathering accurate quantitative and qualitative data is a challenge because it implies defining diasporas. Defining a diaspora is perhaps a difficult endeavour for two reasons: the transnational quality of diasporas and

the researcher to gain intimate familiarity with the data. It also prevents errors or missed data during points of poor tape quality as the researcher could recall the conversation. 
their heterogeneity (Faist, 2010). ${ }^{46}$ The heterogeneous nature of diasporas raises the methodological question, how much can be generalized from a study of one group?

It would have benefited the present research to include more cases; this would have increased the variation of experiences of integration of South Sudanese diasporas and have strengthened the precision and validity of the findings presented here. Nonetheless, this study provides a foundation for further research in this area and offers insights into the relationship that exists between integration and diasporic activity. As the latter relationship is still poorly understood, there is value in the present contribution.

A barrier to data collection on diasporas is the reluctance of diaspora populations to respond to surveys and inquiries, which suggests having neutral bodies undertake such kinds of exercises (Ionescu and Geneva, 2005). I noticed some hesitation in several of the respondents included in this study, presumably due to concerns speaking out against the governing body of South Sudan. However, as time passed and the participants became more comfortable with the interviewer, this hesitation diminished. Three potential participants declined to participate in the study when the parameters of the questions were explained; but, overall, the majority of the participants felt comfortable completing an interview or survey.

\footnotetext{
${ }^{46}$ Faist (2010) also suggests that a methodological challenge occurs in studying issues of transnational actors due to the fluidity of relations, identities, and structures. Multi-sitedness may mitigate this issue, that is, research in the sites of agents' practices in various countries, paired with internet research as a complement to fieldwork. That was the approach used in this study.
} 


\section{CHAPTER FOUR: Background}

In this chapter, I provide the integration profiles of the host countries, Canada and Kenya, based on immigration and refugee policy in each country. This will demonstrate that the host environments indeed differ in regard to the integrative atmosphere for incoming migrants. Although brief, this chapter will provide a background that familiarizes the reader with the host country environments, and provide insights into the experiences of South Sudanese diasporas in each. This information will inform the presentation of data collected in Chapter Five.

\subsection{Integration Experiences of South Sudanese Diasporas in Canada and Kenya}

This section describes the integration process and experience of South Sudanese diasporas in the host countries As will be demonstrated, the integration experiences of South Sudanese diasporas have varied between the different host country environments. Section one will first present information on the Canadian environment for incomers, whether immigrants or refugees, and second describe the experiences of South Sudanese in Canada, as drawn from previous research. Section two will do the same for the Kenyan context. The information presented will be drawn from previous research in Canada and Kenya. Information on South Sudanese diaspora in each case is very limited.

\subsubsection{Canada}

In 2003, the Government of Canada (Statistics Canada, 2003) conducted the Longitudinal Survey of Immigrants to Canada (LSIC). The LSIC examines how immigrants in the 2000-2001 landing cohort assess their life in Canada and indicates that most respondents had positive assessments. This survey can be used to assess the 
immigrant experience in Canada and provide a foundation for comparison with the experience in Kenya.

Four years after landing, almost three-quarters were satisfied or very satisfied with their life in Canada. One-fifth said they were neither satisfied nor dissatisfied, while $7 \%$ said they were dissatisfied or very dissatisfied. In terms of expectations, $43 \%$ said that life in Canada was somewhat better or much better than they expected it would be, $33 \%$ said it was about what they had expected, and $24 \%$ said it was somewhat worse or much worse than they had expected. Finally, four years after landing, $87 \%$ of respondents said that if they had to make the decision again, they would still come to Canada. In terms of access to services, I looked at access to housing, health services, education and employment. The results are indicated in Table 9.

Table 9: Results of the Longitudinal Survey of Immigrants to Canada

\begin{tabular}{|c|c|}
\hline Service & Finding \\
\hline Housing & - $62 \%$ of the 125,100 immigrants who needed to look for housing did not encounter any problem \\
\hline Healthcare & $\begin{array}{l}\text { - } 97 \% \text { of newcomers obtained a health card within six months of their arrival in Canada } \\
\text { - Of the } 122,500 \text { immigrants who tried to access health care services, } 77 \% \text { did not encounter any } \\
\text { problems }\end{array}$ \\
\hline Education & $\begin{array}{l}\text { - Of the } 108,900 \text { newcomers who tried to obtain education or training after coming to Canada, } 40 \% \\
\text { reported at least one problem with the process } \\
\text { - For } 27 \% \text { language was the most significant barriers } \\
\text { - For } 25 \% \text { finding financing was the biggest barrier }\end{array}$ \\
\hline Employment & $\begin{array}{l}\text { - } 44 \% \text { (or } 72,100 \text { ) of newcomers had found employment within some six months of their arrival to } \\
\text { Canada } \\
37 \% \text { (or } 42,200 \text { ) newcomers who were looking for work had not found jobs yet at the time of the } \\
\text { interview } \\
\text { - Of the newcomers who were employed at the time of the survey, a high proportion were not } \\
\text { working in the same occupational field as they did prior to immigrating to Canada } \\
\text { For both women and men, } 6 \text { in } 10 \text { employed immigrants worked in a different occupational group } \\
\text { after their arrival } \\
\text { Of the } 116,700 \text { newcomers who looked for work, } 70 \% \text { reported at least one problem in the process } \\
\text { - The most common problem cited by immigrants who encountered barriers when looking for } \\
\text { employment was the lack of Canadian job experience }\end{array}$ \\
\hline
\end{tabular}

Source: Statistics Canada, 2003

Limited evidence addresses South Sudanese diasporas in Canada. This will be presented below with a particular focus on the integration experiences of the diaspora community. Because of the recent secession of South Sudan, no research is available that 
addresses South Sudanese diasporas since that time and much of the information available refers to all incomers from either Sudan or South Sudan as 'Sudanese.' The majority of Sudanese refugees in Canada, however, did arrive from the South during the second civil conflict so this information does provide insight into that community.

\subsubsection{South Sudanese Diasporas in Canada}

The 2006 Census of Canada (Statistics Canada 2006) reported that 12,640 residents of Canada self-identified their ethnic background as "Sudanese." In a report commissioned by the Sudan Task Force of the Department of Foreign Affairs and International Trade, however, the Mosaic Institute (2009) states that the actual number of Sudanese in Canada is somewhere between the official census count of 12,640 , on the low end, and 40,000, as indicated by Diverse Hamilton (n.d.) on the high end. ${ }^{47}$ Toronto, in particular, is a hub for the Sudanese diaspora in Canada and contains the largest concentration of Sudanese individuals in Canada. The Mosaic Institute found that a majority of the Sudanese immigrants who came to Canada came as Government Assisted Refugees, seeking asylum from state repression, economic collapse, and escalation of conflicts. ${ }^{48}$ The report also found that members of the Sudanese community living in Canada retained a knowledge of and concern for Sudan, its internal dynamics, and the crises that it and its people had faced. The Mosaic Institute also found that members of the Sudanese diaspora in Canada remained closely connected to Sudan, as demonstrated

\footnotetext{
47 The South Sudanese population in Canada has a unique history, since at least 200 South Sudanese sent to Cuba for medical training in the 1980s by the SPLM immigrated to Canada (Njoka 2007).

${ }^{48}$ The Mosaic Institute (2009) conducted research on the size, distribution, intra-community dynamics, and organizational structure of the Sudanese diaspora population in Canada. Although the information presented in this report predates the secession of South Sudan and refers to Sudanese diasporas in general, the majority of Sudanese refugees in Canada came from the South during the second civil war, making these findings relevant. Those who identified as "Southerners" were primarily from the Dinka, Nuer, and Bari tribes.
} 
by the regular and generous payment of financial remittances to both family members and friends in Sudan, and by return trips home. In between visits to Sudan, many members of the Sudanese diaspora in Canada stay abreast of current affairs, particularly political events, in Sudan through access to Sudanese media sources. These sources include digital cable stations, websites, and the Internet (Centre for Addiction and Mental Health, 2004). For some individuals this connection included ongoing participation in political organizations such as the SPLA, which still has chapters across Canada representing a sizable number of Southern Sudanese (Abd-El Aziz, 2005). In some provinces, members of the diaspora population have not involved themselves to any great extent in the political life of Canada and, instead, they have focused their energies on lobbying in regard to issues that affect Sudan (Abd-El Aziz, ibid).

The Culture, Community and Health Studies Program within the Centre for Addiction and Mental Health conducted a study of the Sudanese population in Ontario and found varying degrees of integration into Canadian life across the Sudanese diaspora. The Sudanese diaspora in Canada expressed challenges in finding employment for even the best-educated and professionally accomplished members of their community. Without Canadian experience or recognized credentials, immigrants typically struggled to regain that status and level of economic success for several years after their arrival in Canada (Centre for Addiction and Mental Health, 2004).

In sum, overall immigrants to Canada express satisfaction with life in Canada. The majority has access to housing, education, healthcare and employment, although there are barriers present that may cause some to have easier access than others. Although limited, the information on South Sudanese diasporas in Canada suggests that this diasporic 
community in particular maintains strong connections to the country of origin, and has experienced barriers to employment. Below the Kenyan environment will be presented.

\subsubsection{Kenya}

While the majority of Kenya's refugees reside in refugee camps, several thousand live illegally and without documentation in Nairobi. With no official count of urban refugees, estimates of their number across all Kenyan cities range between 15,000 and 100,000 (Human Rights Watch 2002; UNHCR 2004). Most urban refugees have little or no access to material benefits and do not announce their presence to UNHCR for fear of repatriation (Refugee Consortium of Kenya 2005). Their lack of legal status in the city leaves refugees subject to the xenophobic and violent tendencies of the local Kenyan population and unable to access the formal economy. To survive, urban refugees run businesses, receive remittances, or earn money through casual labour.

In spite of hosting large numbers of refugees for extended periods, the Kenyan government has not developed clear guidelines or policies to deal with refugees in Kenya (Hassan, 2002). Refugees International (2008) indicates that Kenyan citizenship law does not protect refugees and refugees are unable to naturalize, increasing the risk of statelessness. Gitari (2000) notes that it is not clear who is responsible for refugees: the government, UNHCR, or humanitarian rights organizations. At the time of Gitari's study, refugees had no legal rights in Kenya and had no effective redress for denial of rights. It would appear that the situation remains vague and haphazard. The police, immigration department, and the Ministry of Home Affairs deal with issues concerning refugees, with no clear definition of the role and functions of each (Hassan 2002; Barasa 2009). According to Gitari, refugees are typically at the mercy of the immigration and police 
departments and are often arrested during regular police sweeps and released at the whim of the officers in charge. Few of those arrested are ever taken to court and most buy a way out of police custody. More recent accounts support the continuation of such activities and note that allegations of corruption and bribery arise in the issuance of these visas or permits (Campbell 2005; Njanga 2011).

Kenya pursues a restrictive employment policy, prioritizing its own citizens, which deters refugees from entering the formal labour market (Jaji 2009). According to data collected by the Refugee Consortium of Kenya (2005), $21 \%$ of refugees in urban areas were employed, $43 \%$ of which were self-employed and $36 \%$ depended on remittances from relatives. Many of those who found employment were employed in the informal sector and lived in fear of harassment and extortion from local authorities. Despite the exclusion refugees encounter in the Kenyan labour market, refugees invest in education in the hope of repatriation or third country resettlement (Valtonen 1998; Shandy 2007). Campbell (2005) notes that urban refugees have managed to forge global social and economic relations that link together their countries of origin, countries of asylum, and countries of resettlement. Campbell suggests that these transnational networks have helped many urban refugees to become successful entrepreneurs and prominent businessmen, particularly in the informal marketplace, countering their exclusion from the formal labour market.

Addressing other rights and freedoms, the Refugee Consortium of Kenya (2005) notes that urban refugees do not enjoy basic rights: they lack freedom of movement due to the high incidences of harassment, extortion, and arrest; and since refugees living in urban areas do so unaided by government and UNHCR support, those in the lower 
income group are largely unable to access basic welfare services, including education for their children. Almost all refugees $(98 \%)$ responded in the affirmative to the question of whether the authorities caused insecurity.

What this information indicates is that refugees in Kenya experience discrimination and exclusion, and the lack of a coherent refugee policy leaves refugees that have migrated outside refugee camps open to harassment. From this, it seems clear that refugees are not permitted to integrate into Kenya. I next outline a study by Jaji (2009) that presents empirical data on South Sudanese refugees living in Nairobi.

\subsubsection{South Sudanese Diasporas in Kenya}

Historically, Kenya has ties with South Sudan and sympathized with South Sudanese during Sudan's second civil war. Little information is available on the current relationship between the Kenyan government, the Kenyan people, and the South Sudanese diaspora remaining in Kenya. A study of refugees in Nairobi conducted by Jaji (2009) provides some insight into the experiences of South Sudanese diasporas in Kenya.

Jaji (2009) states that Sudanese refugees tend to be conspicuous because of their reluctance to speak Kiswahili and their use of English. Communicating in English, which is associated with affluence, in a country where Kiswahili is an official language exposes Sudanese refugees to abuse and extortion. Jaji also states that visible physical and cultural markers also differentiate South Sudanese refugees in Nairobi.

Kenyan labeling of South Sudanese occurs, including the use of terms South Sudanese people find derogatory and demeaning; female respondents in Jaji's study indicated that they were often subjected to verbal abuse and labeled bush people-meaning primitive and uncivilized. In terms of subsistence, Jaji (2009) found that 
established diasporas in Western countries or relatives in South Sudan sustained their relatives in Kenya through remittances, either from South Sudan or abroad. Economically stable women reportedly denied that they came to Kenya as refugees, so that they might access the relative hospitality extended to non-refugee immigrants in Kenya and enjoy a degree of social integration into Kenyan communities. Some women who had money from remittances also indicated that they used the money to pay bribes for lacking identity documents. As a result of Kenya's restrictive employment policy, the majority of South Sudanese who had been in Kenya for more than three years were still unable to find formal employment.

\subsection{Conclusion: Integration Profiles of Canada and Kenya}

The information presented above provides a basis from which to understand the experiences of refugees in Canada and Kenya, and the barriers to integration and opportunities that are present. Although limited information is available regarding South Sudanese refugees in both host countries, what does exist allows us to gain an understanding of the host country environments, a profile of the South Sudanese communities in each, and access to opportunity structures within each environment. This information provides a foundation for the data collected in this study.

As indicated in Chapter 2, the UNHCR describes the process of integration as

a legal, economic and socio-cultural process whereby refugees are granted a progressively wider range of rights and entitlements by the host State that are broadly commensurate with those enjoyed by its citizens. These include freedom of movement, access to education and the labour market, access to public relief and assistance, including health facilities, the possibility of acquiring and disposing of property, and the capacity to travel with valid travel and identity documents (de Costa 2006, 8).

We can evaluate the information presented here on each host country against this 
definition to gain a preliminary integration profile of each host country. Below I break the process defined by the UNHCR into individual components, allowing us to evaluate whether South Sudanese diasporas have experienced integration in the host country environments studied here. Table 10 presents these components and evidence I have drawn from the studies described above.

Table 10: Canada and Kenya compared across UNHCR description of integration

Components indicating integration

Freedom of movement

Access to education

Access to the labour market

Access to public relief and assistance

Access to health facilities

The possibility of acquiring and

disposing of property

Capacity to travel with appropriate

documentation

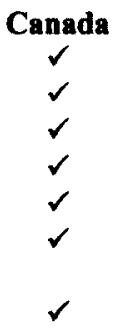

$\checkmark$

$\checkmark$

$\checkmark$

$\checkmark$

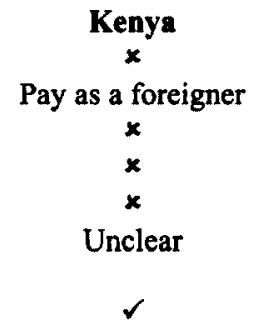

This would indicate that, as expected, South Sudanese diasporas experience a higher degree of integration in Canada than in Kenya. This finding provides support for the choice of these countries as cases of comparison, and suggests that differences in integration between these host countries should be substantial enough to create variation on the independent variable: integration. Chapter 5 will test this against the outcome of interest in Hypothesis 1, remittance activities, as well as provide the results of data analysis that allow us to evaluate Hypotheses 2 and 3. 


\section{CHAPTER FIVE: Evaluating the Data}

In this chapter, I present the results of the surveys and interviews that took place in Canada and Kenya and weigh these results against the hypotheses posed in Chapter Two. Initially, I provide the integration profiles of the host countries, based on the empirical work conducted in Canada and Kenya. This will demonstrate that the host environments indeed differ in regard to the integrative atmosphere for individual incoming migrants based on responses to survey and interview questions. I continue with a summary of access to opportunity structures in each host country in section two. In section three, I show the results of statistical analyses conducted on the data collected and evaluate these results against the hypotheses. Finally, I present conclusions and lead into Chapter Six in which I engage more fully with the qualitative data collected.

\subsection{Integration Experiences}

This section will present the individual responses of survey and interview participants to questions regarding integration. A clear understanding of integration in each case is an important part of this study as integration served as the independent variable. Based on the information provided by survey respondents and interview participants, Table 11 presents the integration profiles of South Sudanese diasporas using the categorizations described by Marrow (2005) in Chapter Two. This information is based on responses from 30 diaspora in Canada and 32 in Kenya.

Table 11: Integration profile of diasporic communities in Canada and Kenya

\begin{tabular}{|l|l|l|l|l|}
\hline \multicolumn{1}{|c|}{$\begin{array}{c}\text { Type of } \\
\text { Integration }\end{array}$} & \multicolumn{1}{|c|}{ Criteria } & \multicolumn{1}{|c|}{$\begin{array}{c}\text { Supporting Canadian } \\
\text { Evidence }\end{array}$} & \multicolumn{1}{c|}{$\begin{array}{c}\text { Supporting Kenyan } \\
\text { Evidence }\end{array}$} \\
\hline $\begin{array}{l}\text { Social/ } \\
\text { Cultural } \\
\text { Integration }\end{array}$ & $\begin{array}{l}\text { Structural } \\
\text { integration }\end{array}$ & residential location & $\begin{array}{l}\text { Dispersed between and within } \\
\text { cities }\end{array}$ & $\begin{array}{l}\text { Dispersed between and } \\
\text { within cities }\end{array}$ \\
\cline { 3 - 5 } & & intergroup contact & Yes & Some, but limited \\
\hline
\end{tabular}




\begin{tabular}{|c|c|c|c|c|}
\hline & & $\begin{array}{l}\text { local language } \\
\text { ability }\end{array}$ & Yes & $\begin{array}{l}\text { Some: about half of } \\
\text { respondents }\end{array}$ \\
\hline & \multirow[t]{3}{*}{$\begin{array}{l}\text { Social } \\
\text { integration }\end{array}$} & intermarriage & $\begin{array}{l}\text { All married respondents } \\
\text { married South Sudanese }\end{array}$ & $\begin{array}{l}\text { All married respondents } \\
\text { married South Sudanese }\end{array}$ \\
\hline & & ethnic identification & $\begin{array}{l}\text { Canadian, South Sudanese } \\
\text { Canadian }\end{array}$ & $\begin{array}{l}\text { South Sudanese, Tribal } \\
\text { group }\end{array}$ \\
\hline & & $\begin{array}{l}\text { feelings of social } \\
\text { distance from other } \\
\text { groups }\end{array}$ & $\begin{array}{l}\text { Some indication of feeling } \\
\text { "othered" }\end{array}$ & Yes \\
\hline \multirow[t]{10}{*}{$\begin{array}{l}\text { Political } \\
\text { Integration }\end{array}$} & \multirow[t]{3}{*}{$\begin{array}{l}\text { Electoral } \\
\text { participation }\end{array}$} & voter turnout & $\begin{array}{l}\text { The majority of those who are } \\
\text { citizens vote in Canadian } \\
\text { elections }\end{array}$ & $\begin{array}{l}\text { Do not vote: no } \\
\text { respondents were Kenyan } \\
\text { citizens }\end{array}$ \\
\hline & & $\begin{array}{l}\text { financial } \\
\text { contributions }\end{array}$ & No & No \\
\hline & & $\begin{array}{l}\text { employment in } \\
\text { political parties or } \\
\text { by candidates }\end{array}$ & $\begin{array}{l}2 \text { respondents indicated } \\
\text { working for the Government } \\
\text { of Canada }\end{array}$ & No \\
\hline & \multirow[t]{5}{*}{$\begin{array}{l}\text { Non-electoral } \\
\text { participation }\end{array}$} & lobbying & $\begin{array}{l}\text { Yes: the majority of } \\
\text { respondents indicated they } \\
\text { would lobby or have lobbied } \\
\text { the Canadian government } \\
\text { regarding South Sudanese } \\
\text { issues }\end{array}$ & $\begin{array}{l}\text { Limited: few respondents } \\
\text { indicated they would lobby } \\
\text { or have lobbied the Kenyan } \\
\text { government, and when they } \\
\text { have it was for South } \\
\text { Sudanese issues }\end{array}$ \\
\hline & & petitioning & $\begin{array}{c}\text { Yes } \\
\end{array}$ & No \\
\hline & & protesting & Yes & No \\
\hline & & civil disobedience & No & No \\
\hline & & $\begin{array}{l}\text { contacting public } \\
\text { officials and the } \\
\text { media }\end{array}$ & $\begin{array}{l}\text { Yes: a majority of } \\
\text { respondents indicated they } \\
\text { would contact or have } \\
\text { contacted public officials to } \\
\text { increase awareness of needs } \\
\text { in South Sudan. There is also } \\
\text { media contact }\end{array}$ & $\begin{array}{l}\text { Limited: few respondents } \\
\text { indicated they would } \\
\text { contact or have contacted } \\
\text { officials; when they have it } \\
\text { was for South Sudanese } \\
\text { issues. Contact with media } \\
\text { was more common }\end{array}$ \\
\hline & $\begin{array}{l}\text { affect on the } \\
\text { political } \\
\text { structure of } \\
\text { their host } \\
\text { country }\end{array}$ & & $\begin{array}{l}\text { Limited: evidence of lobbying } \\
\text { for South Sudanese interests, } \\
\text { but infrequent and weak } \\
\text { engagement was noted by } \\
\text { three respondents }\end{array}$ & $\begin{array}{l}\text { None: South Sudanese in } \\
\text { Kenya do not have access } \\
\text { to Kenyan political } \\
\text { structures }\end{array}$ \\
\hline & $\begin{array}{l}\text { affect on the } \\
\text { political } \\
\text { resources and } \\
\text { standing of } \\
\text { established } \\
\text { groups }\end{array}$ & & No & No \\
\hline \multirow[t]{3}{*}{$\begin{array}{l}\text { Economic } \\
\text { Integration }\end{array}$} & & employment status & $\begin{array}{l}\text { Most people employed: } 27 \text { of } \\
30 \text { respondents indicated that } \\
\text { they are currently working }\end{array}$ & $\begin{array}{l}2 \text { of } 32 \text { respondents } \\
\text { employed in Kenya: the } \\
\text { barriers to employment } \\
\text { were frequently discussed }\end{array}$ \\
\hline & & level of education & $\begin{array}{l}\text { Respondents indicated levels } \\
\text { ranging from undergraduate } \\
\text { to graduate. Most had } \\
\text { completed education and are } \\
\text { employed }\end{array}$ & $\begin{array}{l}\text { The majority of } \\
\text { respondents are taking } \\
\text { some form of education in } \\
\text { Kenya, most at the } \\
\text { undergraduate level and } \\
\text { several at the graduate level }\end{array}$ \\
\hline & & $\begin{array}{l}\text { time spent in the } \\
\text { host country }\end{array}$ & $5-20$ years & $5-20$ years \\
\hline
\end{tabular}

Evaluating integration experiences using Marrow's method allows us to consider 
integration experienced by diasporas across political, social, and economic categories.

This categorical evaluation suggests that diasporas in Canada experience increased integration across each category. A close comparison across host country environments points to the fact that South Sudanese diasporas in Kenya have experienced some degree of integration in each instance. In fact, a close reading of the self-reported responses to the question of whether or not each respondent feels integrated into their host country provides further evidence that individual feelings of integration vary within each host country. A summary of these results is indicated in Table 12.

Table 12: Self reported feeling of integration of interview and survey participants

\begin{tabular}{|l|l|l|l|l|}
\hline & Canada & Kenya \\
\hline & Integrated & Not integrated & Integrated & Not integrated \\
\hline Survey respondents & $100 \%$ & $0 \%$ & $47 \%$ & $53 \%$ \\
\hline Interview participants & $80 \%$ & $30 \%$ & $7 \%$ & $93 \%$ \\
\hline Total & $90 \%$ & $15 \%$ & $27 \%$ & $73 \%$ \\
\hline
\end{tabular}

As we see by looking at responses to both survey and interview questions, when given the opportunity to elaborate more on whether participants feel integrated, perceptions of integration again differ. ${ }^{49}$ As a result, the host country respondents live in is highly, but not perfectly, correlated with the expressed feeling of integration by individual diaspora respondents. $^{50}$

The qualitative responses gathered by interview participants in each host country gives further insight into the aspects of their experiences that lead diasporas to report feeling integrated or not. These responses allow us to appreciate the detailed answers provided by participants to this question. Including this question in the interviews also

\footnotetext{
49 These results are based on the results of content analysis performed on the interview responses of participants. Participants were asked the following question: Do you feel integrated in Canada/Kenya? When answers were not clearly "yes" or "no," the latent content of the response was evaluated to group the response. No responses were unclear enough to be discounted.

${ }^{50}$ Host country and expressed feeling of integration (yes or no) resulted in a correlation of 0.627 , significant at the 0.001 level.
} 
allowed an opportunity for participants to voice their frustrations and concerns regarding feelings of inclusion or exclusion.

\subsubsection{Canadian Participant Responses}

As indicated by the results above, the majority of participants in Canada reported feeling integrated - all fifteen survey respondents and twelve of fifteen interview respondents. Those indicating integration expressed feeling equivalent membership in Canada as any other person living here. For example, one participant stated: "This is a place that is my country" (Participant 15, Canada). Some expressed an ease integrating: "It was easy for me to blend in and begin my life, and it wasn't so hard" (Participant 14, Canada). Others shared meeting challenges upon first arrival: "The first year was difficult, but ... the adaptation was not big because I got support from the community, it wasn't that much of a problem ... integration was not that bad" (Participant 13, Canada). This suggests that the timescale is an important consideration in integration. ${ }^{51}$

While most participants expressed that they currently felt integrated, whether or not they did at first, others expressed a sense of exclusion that they expect will never go away. This sense of exclusion underpinned the responses of each of the interview participants that expressed that they did not feel integrated.

"It is very difficult for an immigrant to be completely connected because there is an element of foreignness for people that are not born here. . But I do not see integration as a necessity. What I see as a necessity is understanding the Canadian way of life and then balancing it with my own personal or cultural values so that I get along with any Canadian. You see that many South Sudanese live in Canada as if it was temporary" (Participant 3 , Canada).

"Most people that are here are going through hell. A lot of stress, a lot of things . . . they have to learn the English language to be able to function and most of them

\footnotetext{
${ }^{51}$ Most participants were young adults when they arrived in Canada (aged 21-35). Most have been in Canada for over ten years and return to South Sudan to visit when possible, usually every few years.
} 
begin to do manual job... they weren't able to integrate well. They are on the fringes of Canadian society." (Participant 2, Canada)

Hence, a sense of "otherness" is felt by at least some members of the South Sudanese community in Canada. Other barriers to integration included the challenge of learning English, for those who arrived without that ability, the loss of credentials and having to rebuild a career. These latter two points were expressed by several of the participants who indicated that they were integrated.

\subsubsection{Kenyan Participant Responses}

The majority of South Sudanese diasporas in Kenya expressed that they did not feel integrated. As with the Canadian diaspora, some variation occurred of feelings regarding inclusion and exclusion from the host country.

A majority of diasporas in Kenya did not indicate insecurity about their status in Kenya. This differs from the findings of studies presented in Chapter Four, which demonstrated that treatment by the government, police, and other official bodies in Kenya was discriminatory and abusive. This is something that has changed in recent years in Kenya. Two participants spoke directly to this. The first stated: "It took us years to be part of the 'good people' in Kenya--to be respected. It took us some years. It was not that easy. It was difficult in Nairobi. The police arrested us, life was really difficult . . at some point we were better incorporated into Kenyan society" (Participant 13, Kenya). The second indicated, "nowadays it is okay. Before there was a lot of discrimination of South Sudanese" (Participant 15, Kenya). The latter response indicated progressive changes in unofficial policy initiated by President Kibaki in 2002.

The inability to find work and the lack of access to Kenyan services were two commonly stated structural barriers to integration that persist for the community today. 
"It is very hard [to integrate]. One, you don't have a job here.... So you are not going to stay. The reason why people stay here, one of the most important things, is education. The reason why people are not in South Sudan is because the educational infrastructure is not there. The South Sudanese, they have known education is one of the key things that one can face in life, and so we all are here for our education and our children to be educated as we hope that the education system, the road system, in South Sudan improves, people will go back." (Participant 1, Kenya)

"Even though it is your right, if you go to the government who is supposed to assist you, at the end of the day they will tell you that you should know you are Sudanese. So you leave disappointed. You know that is your right. There are some schools now, if you go to those schools they do not admit foreigners. ... We are supposed to be Kenyan by residency, but it is not given to us by the Kenyan government." (Participant 12, Kenya)

In addition to this, diasporas in Kenya expressed feeling excluded from Kenyan society because they did not come from a Kenyan tribe, and their culture was too different to facilitate integration.

Ease of mobility, measuring themselves against other Kenyans in terms of access to education, and the comfort they felt interacting with Kenyans were factors that contributed to perceptions of integration by several of the South Sudanese diasporas interviewed in Kenya. Length of residency, knowledge of Kiswahili, and having been educated in Kenya were also commonly discussed. Several respondents expressed that until recently they were viewed very negatively by the Kenyan population, encountered barriers to accessing public services, and experienced harassment from civilians and government officials. Respondents who tended to indicate feeling integrated were often younger (under 30), and had attended school in Kenya for an extended length of time.

The lack of integration expressed by South Sudanese diasporas in Kenya affected their perceived identities. Because participants felt a clear separation from their host country, they expressed their identification as much more strongly tied to South Sudan. 
Whereas diasporas in Canada most commonly expressed that they felt like SouthSudanese Canadians, or dual citizens, or Canadians outright, diasporas in Kenya most commonly referred to themselves as South Sudanese, or by tribal designation. This connectivity to South Sudan through identity may contribute to a closer engagement with South Sudan through feelings of kinship, obligation, and connectedness to the country strongly perceived as home.

"Typically we know this is not our home ... no one can be recognized in two different societies--you have to have one. Your own society where you can be recognized. Especially your society where you are born, your place. Your clan. So in South Sudan we have that unity. And we teach our children too--that is a home for them. This is not home." (Participant 1, Kenya)

"I have been here long enough to be Kenyan, but I wouldn't want to be Kenyan." (Participant 2, Kenya)

Notably, individuals of the South Sudanese diaspora in Kenya were much more likely to associate wholly or mostly with other South Sudanese rather than Kenyans. In Canada, individuals spent time with a wide variety of people as well as with South Sudanese during community gatherings or events. This will be further discussed in Chapter Six.

\subsubsection{Conclusion}

The data presented above indicates that, on the whole, South Sudanese diasporas are more integrated in Canada than in Kenya. This supports the country profiles presented in Chapter 4. Data collected on an individual level, however, allows us to gain insight into the personal experiences of integration in each diasporic community, and into the considerations resulting in expressed feelings of integration. These conclusions prevent the assumption that every individual within the diasporic communities is or is not integrated based on the host country itself. The finding that there is variation within the host countries on the independent variable is significant because of the implications it has 
on the dependent variable. In the following section, we will see how these differing levels of integration translate into different degrees of access to political, social, and economic opportunity structures in the host countries.

\subsection{Host Country Opportunity Structures}

Here, I evaluate the opportunity structures accessible to South Sudanese diaspora in each host country. This information is important to note since I have argued, based on Black and Koser (2001) and Revilla and Starr (1995), that capacity (environmental factors creating possibilities and constraints, i.e., the structural context) and desire (the motivation behind choices people make) are two critical components of the decision making process for diasporas. Consequently, understanding both the capacity of diasporas and their motivations are important in understanding why diasporas have acted in certain ways and in predicting how they may act. In this section, I present a summary of opportunity structures and provide quotations from interviews that give us further detail on what supports or constrains transnational activity.

\subsubsection{Summary Table of Opportunity Structures in Canada and Kenya}

Table 13 presents the findings of this study in the tool presented in Chapter One and considers data collected from both interviews and surveys.

Table 13: Factors in a host country that Increase capacity or desire to engage in home-country oriented activity

\begin{tabular}{|c|c|c|c|c|c|c|}
\hline & Capacity & $\begin{array}{r}\text { Diaspora } \\
\text { in Canada }\end{array}$ & $\begin{array}{l}\text { Diaspora } \\
\text { in Kenya }\end{array}$ & Desire & $\begin{array}{r}\text { Diaspora } \\
\text { in Canada }\end{array}$ & $\begin{array}{l}\text { Diaspora } \\
\text { in Kenya }\end{array}$ \\
\hline \multirow[t]{5}{*}{ Economic } & Employment & $\checkmark$ & $x$ & \multirow{5}{*}{$\begin{array}{l}\text { Financial } \\
\text { stability in host } \\
\text { country }\end{array}$} & \multirow[t]{5}{*}{$\checkmark$} & \multirow[t]{5}{*}{$x$} \\
\hline & Savings & $\checkmark$ & $x$ & & & \\
\hline & Access to information & $\checkmark$ & $\checkmark$ & & & \\
\hline & $\begin{array}{l}\text { Access to banking } \\
\text { facilities }\end{array}$ & $\checkmark$ & $\checkmark$ & & & \\
\hline & $\begin{array}{l}\text { High/low/middle } \\
\text { income status of host } \\
\text { country }\end{array}$ & $\begin{array}{l}\text { High } \\
(\checkmark)\end{array}$ & Low & & & \\
\hline \multirow[t]{2}{*}{ Political } & $\begin{array}{l}\text { Secure legal status in } \\
\text { the host country }\end{array}$ & $\checkmark$ & $x$ & \multirow{2}{*}{$\begin{array}{l}\text { Secure legal } \\
\text { status in host } \\
\text { country }\end{array}$} & \multirow[t]{2}{*}{$\checkmark$} & \multirow[t]{2}{*}{$x$} \\
\hline & Positive attitude of & $\checkmark$ & $\checkmark$ & & & \\
\hline
\end{tabular}




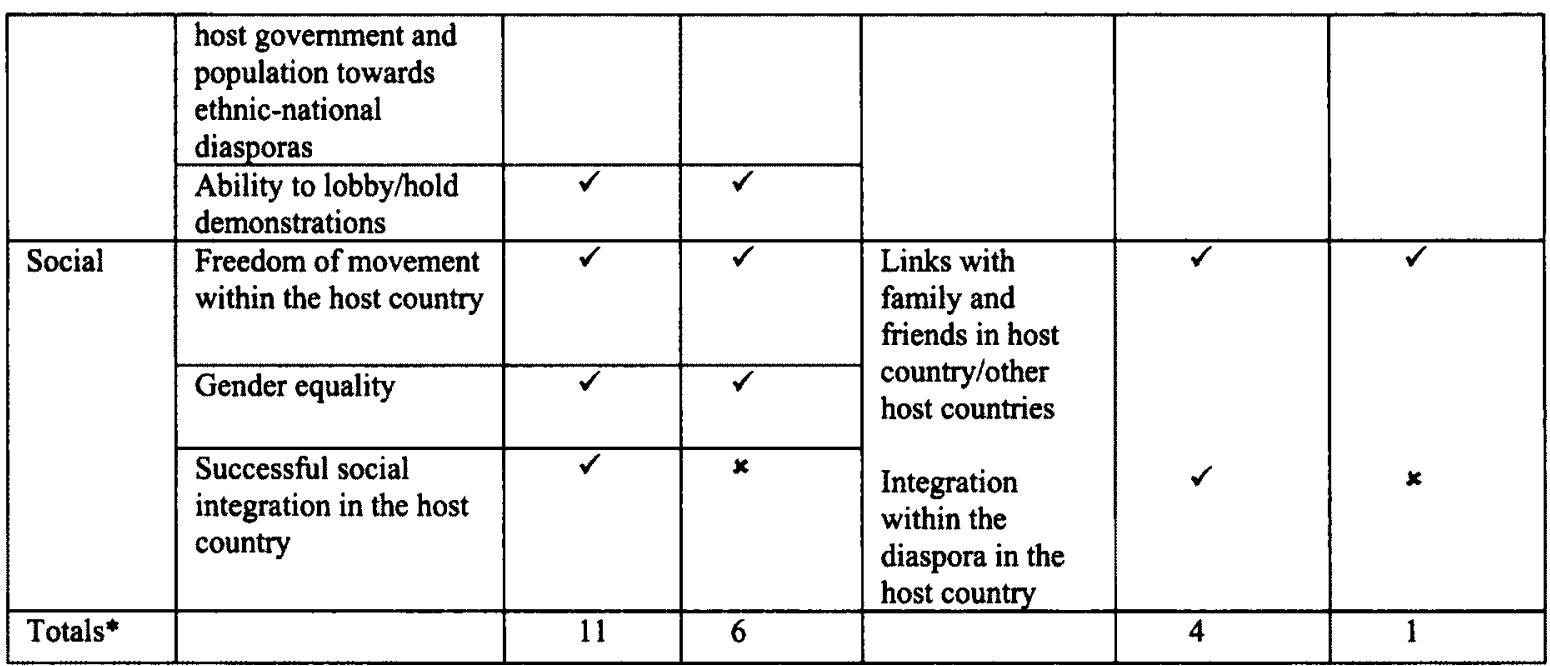

*Totals were listed simply to allow a quick comparison between host countries

The information presented in Table 13 indicates that, similar to the differentiation between host countries in terms of integration, Canada and Kenya have different degrees of access to opportunity structures across the economic, political, and social spheres for South Sudanese diasporic communities living in those host countries. The data suggests that diasporas in Canada should experience higher levels of capacity and motivation to act--both components indicated in the literature review to be foundational to decision making processes. Further insight into the factors that support or constrain opportunity can be noted from the qualitative data.

\subsubsection{Supporting Transnational Capability}

Diasporas in Canada point to several supports of transnational capability, or of the ability to make contributions to South Sudan. The most commonly reported is the ability to speak or write much more openly than in South Sudan. "Usually there is freedom of press--people can talk and suggest things and can oppose, can criticize things and it is safe--there is no fear of that" (Participant 8, Canada). In Kenya, freedom of speech was not as widely indicated. While several participants noted that access to more liberal media is helpful in raising awareness of events in South Sudan and as a forum for 
critiquing decisions, two participants indicated that the proximity to South Sudan did not allow for open communication about thoughts and concerns, particularly if the concerns underlined perceived failures of the government; such action would elicit threats or violence from affiliates of the GoSS. Most participants mentioned access to information from home as a benefit of residence in Kenya.

"If you are in South Sudan the news will not reach you because it only goes into big towns. There are some that get blacked out and you don't know anything about what is going on in the country. So if you are here you know--you are almost updated every day.... It is very easy to know what is going on at home." (Participant 5, Kenya)

The most commonly cited advantage of residence in Kenya was education. Although participants pointed to the challenge of securing funds to attend university in Kenya, they noted that education is a tool that can help build South Sudan. For example, the accumulation of human capital will allow individuals to return to South Sudan and invest in government or private initiatives, strengthening the country. Another example frequently mentioned is that through altering the mindset or worldview of individuals, one can alter the state of affairs at home. "The most important thing in getting your education--education helps you see things in a different perspective and to contribute to change" (Participant 11, Kenya). This latter advantage to residence in Kenya was presented in both the context of moving away from traditional livelihood practices such as cattle rearing and that of viewing inter-tribal relationships differently.

\subsubsection{Barriers to Transnational Capability}

A common theme in the Canadian participant responses in relation to their capacity to contribute to South Sudan in economic or political ways was the difficulty in balancing life in Canada with the time required in support or promotion of South Sudanese needs. 
"One of the challenges we have is that everybody is struggling to make ends meet. So there is a survival based on Maslov's hierarchy of needs, where people are looking for food, clothing and shelter. And people are really kept focused on that and are carried away from engaging as a community in bringing some of the concerns of the people of South Sudan to bear on the decisions of policy makers in Canada." (Participant 7, Canada)

"Life in Canada is very hard. You work, you have bills and there is no way that you can easily support financially ... at some point there is the realization that yes, you have made it, you can work hard and realize your potential but there are tremendous barriers in the way and that is actually a key point for the South Sudanese here.... Some of them have been here for fifteen years or ten years and there is no remarkable change in their lives. (Participant 9, Canada)

"If you come here, you have your mortgage to pay, you have your bills to pay, so that gets in the way also. People think that because you are in the West you have money--you made it--and that is not always true. I think those things get in the way. They are things you have to contend with." (Participant 1, Canada)

These remarks illustrate the idea that in the struggle to "make it" in Canada, South

Sudanese are distracted from transnational activities. If diasporas were not as preoccupied with subsistence activities within the host country, we might see a higher level of remittance behaviours. This finding challenges the arguments made in Chapter 1. Although Cioffi-Revilla and Starr (1995) and Al-Ali, Black and Koser (2001a) suggest that access to opportunity structures in the host country is a significant determinant of support or constraint to diasporic action, it appears based on the findings presented here that the presence of opportunity structures alone is not sufficient to support transnational capabilities. The focus on day-to-day life within a host country may limit the time and energy diasporas have for engaging in transnational activities. This finding does, however, support Brinkerhoff (2009) who suggests that diasporas increasingly shift focus from the activities of a home country to improvement of quality of life in the host country and that diasporic communities that are blocked from receiving certain rights tend to focus on fighting for and defending rights within the host country. Brinkerhoff argues this 
will detract from a focus on issues in the country of origin. As we can see, several of the Canadian diasporas indicated that they experienced challenges integrating and struggle to make ends meet. Much of their attention is directed towards those concerns as a result.

Similar barriers were mentioned by a small number of South Sudanese in Kenya. This was particularly the case in regard to finances, as many diasporas in Kenya rely on funds from relatives in either South Sudan or from the diaspora to fund their education. A lack of funds for education and the struggle to find sufficient funds to attend university were cited as barriers to contributing to South Sudan.

"Lack of school fees becomes a barrier because they want to learn and go back to South Sudan and contribute... Without that support there are children here who cannot afford to go to school, so that will become a barrier for them to be productive in South Sudan." (Participant 1, Kenya)

Time spent focusing on studies was also mentioned as a barrier because it limits the time that could be directed towards activities related to improving the country.

"Because I am in Kenya for school, education, struggling to pay my fees, and I have to ask people to help. So sometimes most of my time is covered up by school, so what time do I have for other activities?" (Participant 2, Kenya)

Given the importance placed on gaining skills and knowledge that would improve South Sudan, it appears that the barrier caused by time spent in class and studying is only temporary and perceived to be necessary, as an investment towards future contributions.

Continuing lack of unity between tribal groups was also indicated to be a barrier to capacity to contribute to South Sudan. "I think the effort of communities is weak in a way because . . the community is divided--some regional or tribal issues--and that affects the work of the community as an umbrella entirely" (Participant 14, Canada). Conversely, in Kenya, participants indicated that removal from the structures of South Sudan led to community unity, which allowed for inter-tribal dialogue, strategizing, and ultimately, the 
accrual of social capital. This will be discussed further in Chapter Six.

\subsubsection{Conclusion}

In conclusion, the evidence suggests that the linkage between capability and transnational activities, or remittances, as outlined in Chapter 1 may not be as strong as I anticipated. As stated earlier, Al-Ali, Black, and Koser (2001a, 2001b) argue that the capability of individuals, families, and communities to become involved depends on the skills and resources available to them, which, in turn, rest on the opportunity structures in their countries of destination. To determine whether this relationship does, in fact, hold true, the table of factors constructed by Al-Ali, Black, and Koser was evaluated against the data collected here. As we have seen, in both the Kenyan and the Canadian cases the evidence does not strongly support as robust a relationship as the literature describes. In the Canadian case, we would expect to see a high degree of access to opportunity structures. What we in fact see is that there are barriers that may constrain the capability of diasporas to remit. Similarly, evidence from the Kenyan case demonstrates that there are elements that I did not anticipate that may in fact support remittance behaviours. The literature reviewed in Chapters One and Two did not anticipate that the opportunity to build inter-ethnic relationships may present in a host country. Here that finding is interesting because it occurs in the host country where integration is low - Kenya. Such factors may result in a different outcome than hypothesized. This is further examined in the following section as I test the hypotheses posited here.

\subsection{Testing the Hypotheses}

At the end of Chapter Two, three hypotheses were presented. Now that we are familiar with some of the data that speaks to these hypotheses, we are in a good position 
to explore whether the data confirms those hypotheses or not. This section will review each hypothesis and present the analysis completed on the data.

\subsubsection{Hypothesis One}

In Chapter Two, the following hypothesis was posed:

Hypothesis 1: If a diasporic community experiences high levels of integration then that community will demonstrate high levels of remittance activities.

To test this hypothesis, first the data collected in each host country was analyzed to determine the correlation between host country and level of remittance. Remittance behaviours were divided into political, social, and economic based on the categories presented in Appendix $1 .{ }^{52}$ At this stage, only two values for integration--yes or no--were used, allowing the independent variable to be dummied. Similarly, the presence of each remittance behaviour was input as one of two values--1 or $2^{53}$--to allow for a simple correlation to be run. Results of this analysis are presented in Table 14.

Table 14: Correlation between host country and remittance behaviours

\begin{tabular}{|c|c|c|c|c|c|c|c|c|}
\hline & & $\begin{array}{c}\text { Integration } \\
\text { by Host } \\
\text { Country }\end{array}$ & $\begin{array}{c}\text { Remittance } \\
\text { behaviour } \\
\text { (political) }\end{array}$ & $\begin{array}{c}\text { Remittance } \\
\text { behaviour } \\
\text { (financial) }\end{array}$ & $\begin{array}{c}\text { Remittance } \\
\text { behaviour } \\
\text { (social) }\end{array}$ & $\begin{array}{l}\text { Integration } \\
\text { As reported }\end{array}$ & $\begin{array}{l}\text { Presence } \\
\text { of trans- } \\
\text { national } \\
\text { linkages }\end{array}$ & $\begin{array}{c}\text { Presence } \\
\text { of social } \\
\text { capital }\end{array}$ \\
\hline \multirow{5}{*}{$\begin{array}{l}\text { Integration } \\
\text { by Host } \\
\text { Country }\end{array}$} & $\begin{array}{l}\text { Pearson } \\
\text { Correlation }\end{array}$ & 1 & -.136 & $.593^{\circ *}$ & -.056 & $.655^{* *}$ & $-.655^{* * *}$ & $-.271^{*}$ \\
\hline & Sig. (2-tailed) & & .294 & .000 & .664 & .000 & .000 & .033 \\
\hline & $\begin{array}{l}\text { Sum of } \\
\text { Squares and } \\
\text { Cross-products }\end{array}$ & 15.484 & -1.710 & 8.871 & -.710 & 10.065 & -4.500 & -2.065 \\
\hline & Covariance & .254 & -.028 & .145 & -.012 & .165 & -.155 & -.034 \\
\hline & $\mathbf{N}$ & 62 & 62 & 62 & 62 & 62 & 30 & 62 \\
\hline $\begin{array}{l}\text { Remittance } \\
\text { behaviour }\end{array}$ & $\begin{array}{l}\text { Pearson } \\
\text { Correlation }\end{array}$ & -.136 & 1 & .149 & $.805^{* *}$ & -.053 & $.385^{*}$ & $.349^{* *}$ \\
\hline (political) & Sig. (2-tailed) & .294 & & .246 & .000 & .683 & .036 & .005 \\
\hline
\end{tabular}

\footnotetext{
52 To create aggregate responses in each category, each case (individual) had to demonstrate a majority of the remittance behaviours in the category. The exception to this was economic remittances; financial remittances were taken as evidence of economic remittance behaviours as very limited numbers of diasporas in either host country invest in South Sudan or send items other than money home.

${ }^{53}$ For example, within social remittance, the presence of social remittances was coded as 2 , and the absence of social remittances was coded as 1 . The same coding was used for financial and political remittances.
} 


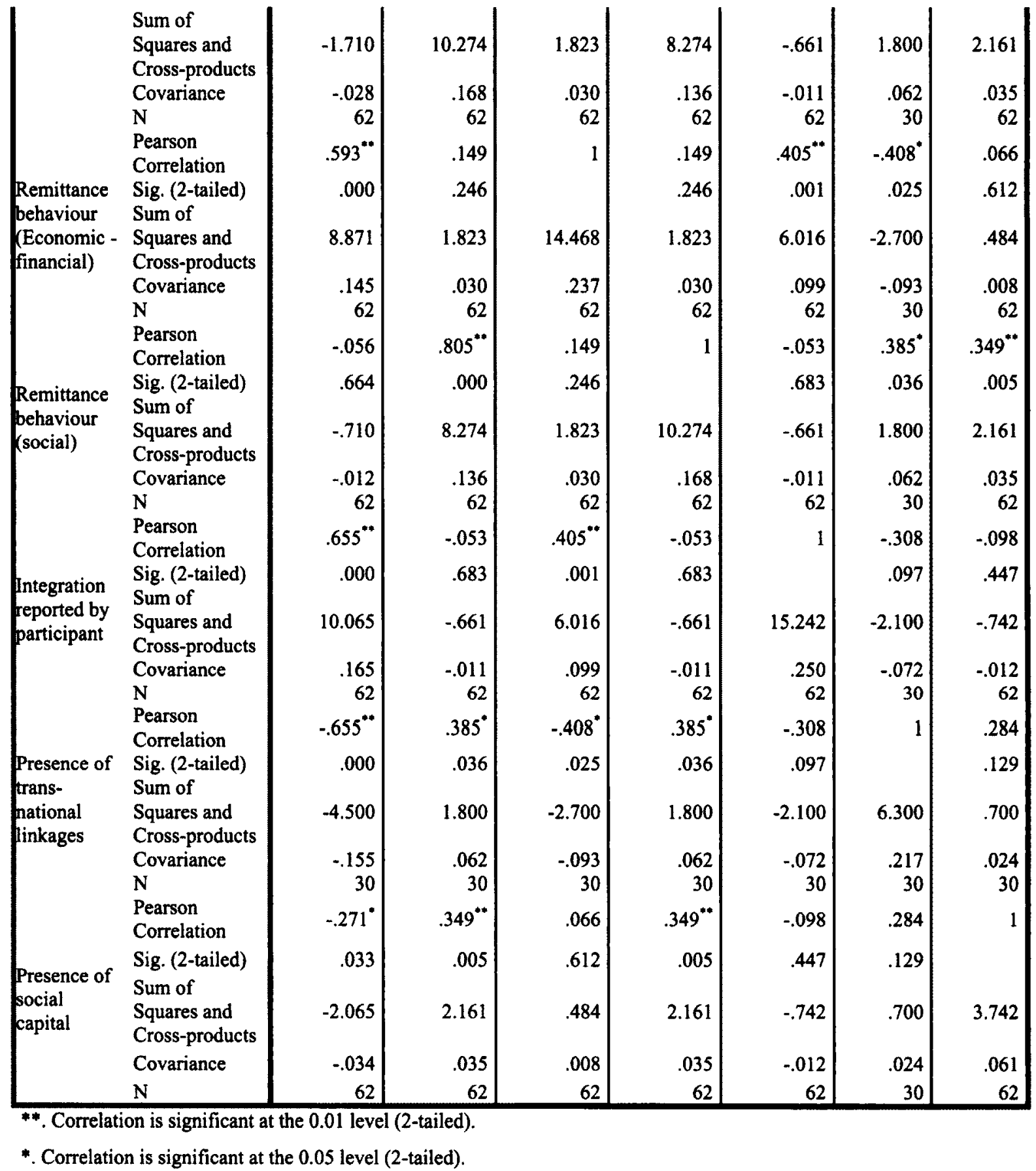

As we can see, the only remittance behaviour that appears to be affected by integration by host country is economic remittance. The relationship between integration and financial remittance makes sense in light of the differences in access to employment between cases. It is likely that that difference led to this result. The fact that a relationship was determined in only one remittance type does not fully support Hypothesis 1, and 
suggests that the presence of un-anticipated factors within host country environments, such as transnational linkages and social capital, may play a role in determining social and political remittance behaviours. This is more fully explored in Chapter Six, which builds on the relationships we see in Table 14 between those variables.

As discussed in Section 5.1, data collected on an individual level allow us to consider personal experiences of integration within each diasporic community. It cannot be assumed that every individual within a diasporic community is integrated based on the host country itself; diasporic communities are not internally homogeneous. Because individual experiences of integration may lead some diasporas in a host country to be active and others inactive due to differential access to opportunity structures statistical analysis was performed to evaluate whether a correlation existed between reported integration and remittance activity. When this correlation was run the correlation between integration and economic remittance decreased to 0.405 , as seen in Table $14 .^{54}$

To provide further detail on the remittance behaviours of these diasporic communities we turn to more specific responses to the survey and interview questions. For diasporas in Canada, the frequency of economic remittances was monthly, twice annually, or annually with the majority of diasporas remitting approximately $\$ 500$ per year. Only one respondent indicated giving to a charity and, other than providing money for families, no other destination for funds was indicated. Interview respondents followed a similar pattern. Only two of the fifteen interviewed participants from the South Sudanese diaspora in Kenya mentioned financial remittances; the remainder indicated

\footnotetext{
54 Multivariate tests were also conducted but the results are not presented within the body of this study because the relationships did not prove sufficiently strong. These results are available upon request. To provide variation on the dependent variable social, political and economic remittances were assigned a value of $1-4$ depending on the strength of the remittance behaviour. For example, 1=none, $2=$ little, 3=moderate, $4=$ high.
} 
that they receive financial support from family members either back at home or in countries in the West. This finding was similar to that of the survey. When asked about financial remittances, fourteen of the seventeen respondents indicated receiving support from family at home or abroad while two indicated that they send small amounts of money home twice a year. This result is not surprising given the fact that the diaspora in Kenya speaks unequivocally about the near impossibility of working in Kenya and, instead, invests time in increasing human capital through education until a return to South Sudan can occur.

What became evident from the data is that the majority of South Sudanese in Kenya remit socially and politically. ${ }^{55}$ The community presents as quite active in both of these areas. Political remittances tend to be both direct and indirect. All interviewed South Sudanese in Kenya voted in the last elections in South Sudan and seven participants indicated that they either write letters to members of the GoSS or speak with them when visiting home. Six participants indicated that they frequently use online media sources to present concerns and critique the handling of things:

"I write, and I write from an objective point of view and I see that I am changing people's minds and I am making a contribution, and that is what I need to continue to make--to contribute positively and get to tell people to think differently." (Participant 12, Kenya)

Diasporas also come together to demonstrate when pressing issues arise; members attend community forums that address concerns about occurrences in South Sudan, attempt to reach solutions, and lobby other diasporas online. Dialogue was the most frequent tool used to encourage political activity. Many respondents expressed frustration that their

\footnotetext{
${ }^{55}$ Several tables have been produced that detail the type and frequency of political, social and political remittance behaviour in each case, as indicated by interview participants. These tables are available upon request.
} 
words often fall on deaf ears in South Sudan: "The problem is that they just don't listen" (Participant 3, Kenya). Because their efforts to engage with members of the leadership in South Sudan are often unsuccessful, the South Sudanese diaspora in Kenya notes that other tactics must be employed to enact change in South Sudan. The focus has become grassroots peacebuilding and targeted programming within South Sudan, to change the perceived combative culture of the villages. Another recently considered tactic is, given the lessening of animosity in the Kenyan environment to the presence of South Sudanese immigrants or refugees, lobbying the host country government or even the international community to pressure the GoSS to address issues of governance.

"The South Sudanese community is politically active, but they cannot do anything based on the strength of political ideologies in South Sudan. ... Maybe if they come through a different government. Because our government will listen more to another government than an individual or group. So I think we could be effective in that way." (Participant 3, Kenya)

The diasporic community in Canada is similarly engaged in high levels of political remittance activity, although they spoke of their political attachment less vigorously than did the diasporas in Kenya. The tendency to be politically involved in South Sudanese concerns was considered somewhat ingrained in the South Sudanese diaspora. Several Canadian diasporas spoke directly to that:

"Our whole existence here is political. Even the fact that we are here is political, and the fact that we are sending money back home because they can't support themselves is political. ... There is formal politics, but that aspect of just being here is political and just engaged with people back home--with phone calls, with the money--that's political also." (Participant 1, Canada)

"Our community is a really political community by nature." (Participant 14 , Canada)

Many South Sudanese respondents in Canada spoke about the need for greater connectivity between the South Sudanese community and the Canadian government. 
"We need to work with MPs to send messages to the Canadian government to ensure that promises they made earlier can be pursued. Things need to change from lobbying the Canadian government so it goes through a higher level. The Canadian government has to be pushed to lobby the international community" (Participant 15, Canada).

Finally, regarding social remittances, the community in Kenya is very closely linked to South Sudan, helped, no doubt, by the short distance to travel to return home. Visits home are frequent and contact is maintained almost daily. Likewise, despite the distance necessary to return home, numerous respondents in Canada--11 of the 30 who completed surveys or interviews--have visited home within the last three years. In addition, 20 of the 30 participants in Canada are in contact with people at home more frequently than once a week. In both host countries diasporas indicated that the most meaningful and productive contribution they could provide is the expertise they have garnered through education and exposure to other systems of governance, health, education and investment. Social capital as a form of social remittance appears to be widespread in both Canada and Kenya. This will be further discussed in Chapter 5 .

In sum, Hypothesis 1 is not fully supported based on the statistical analysis. The only remittance behaviour that appears to differ between the two cases is financial remittances. Diasporas in both cases remit politically and socially. This finding indicates that the relationship between the host country environment, integration, opportunity structures and transnational activities is complex. In addition, the lack of support of this hypothesis could potentially be overcome with different cases, more variation on the DV or variation over time. These factors provide points of departure for future research.

\subsubsection{Hypothesis Two}

The second hypothesis posited was: 
Hypothesis 2: The level of integration experienced by diasporas will not have an affect on the desire or motivation of diasporas to engage in remittance activities.

Section 1.5 reviewed the literature on motivations of diasporic activity and introduced common motivations: kinship, empathy, personal gain and obligation. It was argued that since many of the motivations supporting desire or willingness arise internally to a diaspora (negotiation of identity, obligation, reciprocity) or from pressures from the country of origin, the differences in desire or motivation between diaspora groups based on degree of integration will be insignificant. In Chapter 2, I suggested that a difference between integrated and non-integrated diasporic communities would suggest a strong constraining effect of capacity on desire.

All individuals surveyed and interviewed indicated that they felt encouraged or obligated to contribute to South Sudan. Responses between the two host cases were very similar. In the survey, the question about motivation was posed as follows: "Do you agree with this statement: It is important for South Sudanese living in Kenya to contribute to development and peacebuilding in South Sudan?" All respondents in both host countries answered yes to this question. Respondents were also asked whether they were encouraged or pressured to contribute, and all but two in Canada indicated the former rather than the latter. The answers provided during interviews support this, confirming that the responses garnered were not as a result of the wording. Interview participants were asked some form of the following questions: "Do you feel that it is important to make contributions to South Sudan? What motivates you to make contributions (if you do)?" Responses indicate the presence of a strong motivation to contribute to South Sudan and to be actively involved in political and social spheres in both cases. 
When coding for motivation, the following three points were considered:

1. Did the participant express strong motivation to engage with South Sudan?

2. Was this motivation driven by pressure or coercion to contribute?

3. Was this motivation driven by empathy or concern for individuals who remained in South Sudan?

All thirty interviews, fifteen in each host country, exhibited enough enthusiasm to gain an affirmative evaluation for the first question. Regarding the second, it was rare (two cases) that interview participants indicated feeling coercion. The remaining 28 participants provided responses that indicated that empathy or concern was a strong factor in their motivation. This finding supports findings presented in Section 1.5, where studies by Mohan (2006), Shane (2000) and Al-Ali, Black and Koser (2001a) found that kinship and empathy are motivations prompting transnational activity. Obligation was also a key motivation; in fact the word 'obligation' was the most commonly used term in response to this question during the interviews. Participants indicated feeling obligated towards family that lives in South Sudan, obligated to those who fought for and won independence, and obligation to be involved in shaping a country to be proud of in the international community. The following quotes drawn from interviews in each host country demonstrate this:

"This year, 2012, is a critical year for us. If things are not handled well, things can get out of hand in the government. Because the groups still have this war attitude." (Participant 4, Kenya)

"I love my country and I want to be proud of it. I want to be in my country and I want someone else to be able to come to my country the way that I can go to their countries, and see things work. And who is able to do that work if not me?" (Participant 2, Kenya)

"It is our responsibility to go back and address those issues." (Participant 6, Kenya)

"You know South Sudan is backward in many development indices today, I feel very bad to see my own country lagging behind like that, I want my nation to be 
like any other nation in Africa or the developed world." (Participant 11, Kenya)

"I really feel like I need to contribute. I wasn't there during the war, so this is the time to actually contribute." (Participant 12, Canada)

"It is an obligation to change things and make things better." (Participant 15, Canada)

Given the finding here that Canadian diasporas struggle to make ends meet within Canada while contributing to South Sudan further supports Mohan's work which suggests that this obligation is sometimes a burden on already strained individuals.

It is important to note that in spite of the strength of response regarding the motivation to contribute, two Canadian participants mentioned that they perceived the diaspora community as lacking sufficient motivation to provide an effective contribution to South Sudan. "The only problem I now have with the community in the diaspora is that they have become weak and lazy" (Participant 14, Canada). This response leads me to consider that a bias may reside in questions regarding motivation to contribute.

Participants may be unlikely to express ambivalence about participating if they feel that it is an obligation that is wrong to neglect. In addition, participants may report more transnational activity that they actually engage in for the same reason. This is important to keep in mind in considering the validity of the results.

In sum, the finding that all participants indicated strong motivation to support South Sudan provides evidence in support of hypothesis 2. Different levels of structural integration and different individual experiences of integration do not appear to have resulted in different motivation levels between cases. This, paired with the relatively high degree of transnational activity exhibited in diasporic communities in both host countries, may indicate that motivation, or desire, has a stronger effect on behaviour than does 
capacity.

\subsubsection{Hypothesis Three}

The third hypothesis posed was:

Hypothesis 3: If strong transnational linkages are present in a diaspora, the difference between the remittance levels in diasporic communities in different host countries will be small.

It was argued that if, as suggested in Chapter 2, transnational linkages provide avenues for diasporic activity to take place regardless of the host country, we will see a limited effect of integration on remittance activities. This limited effect will be demonstrated when an insignificant difference between diaspora groups in different host country environments exists. To determine the correctness of this hypothesis, diasporas that were interviewed were asked whether, to their knowledge, transnational networks are present linking South Sudanese diasporas around the world. Participants were also asked whether they personally have links to South Sudanese in other parts of the world. Table 15 provides an indication of the number of diasporas in each host country who answered in the affirmative in each case.

Table 15: Indicated presence of transnational networks by host country

\begin{tabular}{|l|l|l|}
\hline & Canada & Kenya \\
\hline Presence of transnational networks & 10 & 15 \\
\hline Part of a transnational network & 9 & 15 \\
\hline
\end{tabular}

These results indicate that a majority of participants in both countries indicated that transnational networks are present. These networks link South Sudanese diasporas in the host countries studied with co-nationals in other host countries. This is particularly the case for Kenyan respondents. The following quote demonstrates a common sentiment in the diasporas in Kenya. This participant expressed that members of the diaspora can best support South Sudan by: 
“...going back, and number two by creating a linkage between the people at home and themselves wherever they are. If you don't have a link with people, how will you communicate with them? And how will you pass whatever you want to change the country to them if you don't know them. So people should be visiting them and creating a linkage with them, wherever we are." (Participant 6, Kenya)

Most commonly, connections are maintained with dispersed diaspora around the world through social media. Updates are shared and views are presented and discussed. Online forums serve as virtual conference spaces where many individuals can contribute to debates on events and decisions in South Sudan. Plans are launched and literature is compiled to pressure either the South Sudanese government or the international community to take action.

Participants in Canada also indicated that transnational linkages are present, although with less frequency than participants in Kenya. One participant remarked:

"People from South Sudan write on the discussions boards, people from Australia, UK, US, everywhere. So you have a little bit of a sense of community outside South Sudan." (Participant 12, Canada)

It is possible that the low level of integration experienced, on the whole, by diasporas in Kenya contributes to the heightened awareness of transnational linkages of participants in Kenya, and thus a greater tendency to have linkages with diasporas in other countries. Limited access to opportunity structures, as a result of low integration, in Kenya may force or encourage South Sudanese to seek out other avenues to work through. In fact, several interview comments regarding the existence of transnational linkages indicates that they are utilized for political purposes. One Canadian respondent indicated that:

"Those in the States, South Sudanese in Canada, the States and Europe and Africa, that is what we are doing. To put pressure on them [the government of South Sudan] and also to mobilize the international community." (Participant 13, Canada)

This finding is interesting because these linkages may temper constraints on capacity, 
supporting Hypothesis 3 . If these linkages help diasporic communities overcome constraints to their activity, this could be a critical pathway to study, particularly given the increasing ease with which people travel and communicate. The statistical finding that low integration is correlated with a high presence of remittance levels, as indicated in Table 14, provides some evidence that transnational linkages are formed to aid capacity. In sum, the data collected indicate support for Hypothesis 3 . This hypothesis is supported by three findings: that transnational linkages are present, that a significant number of South Sudanese diasporas are part of a transnational network, and the insignificant difference between cases on remittance activities.

\subsubsection{Conclusion}

In conclusion, I have evaluated the data and used the results to test the hypotheses posed. Concerning Hypothesis 1 , increased levels of integration only appears to correlate with higher levels of financial remittance behaviours. Increasing the number of participants in future studies may result in a more robust finding across other remittance categories. The choice of different cases might also change this finding. It may also be the case that other factors are at work in this system of diasporic activity that circumvent host country structures and allow activities to take place where they may otherwise be restrained. Evidence supports Hypothesis 2. Host country environments differ in integration levels experienced, but they do not produce different levels of motivation as a result. This supports the hypothesis that motivation is not affected by integration into a host country. This finding is significant because it provides an explanation for the remittance levels of South Sudanese diasporas. When motivation levels are high, individuals may find ways to contribute where they can. Although South Sudanese 
diasporas in Kenya are not able to remit financially, they can, and do, find ways to remit socially and politically. Finally, in considering Hypothesis 3, evidence supports a connection between transnational linkages and increased remittance behaviour. This suggests that transnational linkages may aid diasporas increase capacity. Further research must be conducted to ascertain the strength of this relationship.

\subsection{Conclusions}

This chapter has demonstrated several results. First, it has provided a detailed account of the integration experiences of South Sudanese diasporas residing within the two host countries where data was collected for this study. A clear understanding of integration in each case is an important part of this study as integration served as the dependent variable against which the primary outcome of interest--remittance behaviours, or transnational activities, was measured. This chapter also described the results of a statistical analysis that was conducted on the data collected and applied these results to the hypotheses posed, allowing us to evaluate each hypothesis. In regard to Hypothesis 1, evidence does not firmly confirm nor oppose the null hypothesis; a higher level of integration only appears to increase financial remittances. The finding that there was a significant amount of variation in perceived integration by individual diasporas in each case, as indicated in Section 5.1, may have impacted this result. Further influences are explored in Chapter Six. Some support was indicated for Hypothesis 2. Diasporas in both cases were strongly motivated to remit. As indicated by the scholars in Section 1.5, empathy, kinship and obligation were strong motivators for remittance behaviours. As we will see in Chapter Six, the desire to create a stable country to return to was also a motivating factor, supporting findings by Shane and Barth $(2003 ; 2008)$. Finally, support 
was also indicated for Hypothesis 3. This is an important finding because of the implications for transnational studies as well as diaspora studies. The finding of strong transnational networks between diasporas in host countries around the world and contacts back in South Sudan indicates support for transnational scholars who, as presented in Section 2.5 , prompt us to re-think the affect of localities on identity and behaviour (Faist, 2010; Bruneau, 2010; Dahinden, 2010). This finding also supports Phalet and Swyngedouw's (2003) suggestion that transnationalism may compete with integration.

Further research must be done to build on the findings presented here to determine whether the addition of more data would affect the results. It is likely that the addition of participants would provide more robust results. As mentioned above, the lack of support for Hypothesis 1 could also be the result of the cases chosen here. Future research could apply this model to other cases to test it further.

In evaluating the relationships presented here and the overall experience and behaviour profiles of the diasporic communities in Canada and Kenya, the qualitative data collected were of great value. Individuals provided detailed information relevant to the inquiries, which would have been missed, had only quantitative data been collected. Although the time commitment necessary to locate interview participants, conduct interviews, transcribe the interview tapes, and code the data both quantitatively and qualitatively was quite large, and prohibited me from collecting more data, it proved valuable for gaining insight into and understanding of diasporic behaviour. 


\section{CHAPTER SIX: Discussion}

In this chapter, I elaborate some of the ideas presented in the previous chapter. I will also address the research questions posed at the outset of this study and provide answers to these research questions based on the data collected in each host country. Qualitative data will be utilized to provide insights into the answers to these questions. First, I outline some of the themes that arose during qualitative evaluation of the interview responses. Themes that arose in participant responses help us understand the findings presented in the last chapter, particularly why the expected relationship between integration and remittance behaviours was not found. Second, I review the research questions posed at the outset of this study, and present answers gained from this study. Finally, I conclude with implications for further research.

\subsection{Emergent Themes}

In the previous chapter, the hypotheses were evaluated against the data collected. Further evaluation of the data provides valuable information on the factors that contribute to transnational capabilities and activities and gives further insight into the findings presented in Chapter 5.

In a thematic analysis of the qualitative data, several themes emerged: strong connectedness to South Sudan in both host countries; concerns regarding intra-state conflict and poor governance; and, most significantly, the transnational transitway for information, ideas, and values between host and home country. These themes help us to understand diasporic communities, their experiences and their actions in general, and the diasporic community under consideration, in particular.

\subsubsection{Connectedness to South Sudan}


A sense of connection remains between the diasporic community and South Sudan in both Kenya and Canada. This connection supports the maintenance of strong social ties and promotes social remittance transfer. This connection also underpins the strong feeling of obligation or necessity to contribute. We may also infer a sense of connection from the frequency with which participants and respondents maintain contact with those at home, the regularity with which they use forms of media to keep abreast of events in South Sudan, and the frequency with which they visit South Sudan.

For many participants, this connection is so strong that it acts against full integration into a host country environment. All diasporas in Kenya indicated that they intend to return to live in South Sudan whenever possible. However, the community in Canada was not as clear about this. Only one participant indicated outright that he intended to move back. Nine remarked that they might, and five indicated that they would not return. Ongoing concerns about the lack of infrastructure, particularly health and education facilities, limited access to employment, and political instability stand in the way of a return for many. Those in Kenya intending to return home indicated the same factors as concerns. ${ }^{56}$

Survey respondents were also asked whether they intend to return to South Sudan. I compared responses across both cases and found that the majority of respondents indicated that they do intend to return home. ${ }^{57}$ In the Kenyan case, 16 of 17 respondents affirmed they would return home. In the Canadian case, 12 of 15 respondents indicated they would return home. Temporary return is a commonplace occurrence for the Canadian diaspora. Many people use these trips as a way of determining whether it may

\footnotetext{
${ }^{56} \mathrm{~A}$ summary of the responses of participants from both host countries is available upon request.

${ }^{57}$ A country comparison based on survey responses is available upon request.
} 
be possible to return on a permanent basis, or to maintain a link while they are too tied to the host country to make a permanent return. Although diasporas in both host countries expressed a desire to return to South Sudan (stating reasons from obligation to the desire to return home where they feel they belong), common to both diasporic communities was the challenge of re-integration into South Sudan. Little infrastructure exists, and in the main cities (particularly Juba), where one may look for work, accommodation is scarce. Prices are high, and the job market is limited. Several participants noted that the only real employer at this time is the government, where nepotism is rampant. Unless one has familial or social connections to someone in the GoSS, the chance of finding a job is low.

The strength of the connection of participants is consistent with the connection suggested by the theory on conflict generated diasporas. The South Sudanese communities in both Canada and Kenya originated as a result of war and, accordingly, we expect maintenance of strong connections to the country of origin, high levels of remittance activities, and engagement in actions that perpetuate conflict in South Sudan. These cases demonstrate a strong connection to South Sudan and high levels of remittance activities. They also support the argument of Lyons (2009), namely that diasporas forced to leave a country of origin often make little attempt to integrate into a host society, considering themselves citizens of a home to which they will return as soon as circumstances allow.

Significantly, the South Sudanese diaspora also departs from the theory regarding conflict-generated diaspora and political activity in its remittance behaviour. As will be discussed below, these diasporic communities do not support the continuation or 
resurgence of conflict. ${ }^{58}$ One of the most commonly used words in interviews was "peace," and the need for peace was repeated over and over by respondents in both cases. The only participant who provided an "anti-peace" response was from Canada and expressed strong frustration with the current GoSS. This participant indicated that he or she wants to mobilize individuals in many host countries to force change in the governance of South Sudan. Extreme corruption, nepotism, and restrictions of freedom in South Sudan were cited as reasons for this mobilization. This respondent indicated that if these changes did not occur, the government must be removed.

Underlying the connections maintained with South Sudan, and the desire to remit, is a concern for the country. Diasporas want to see their country succeed, both as a point of pride and to provide for future generations.

\subsubsection{Concerns with the State of Affairs in South Sudan}

Two chief concerns for South Sudan emerged in the interview responses:

1. Concern about inter-tribal conflict ${ }^{59}$

2. Concern with governance--corruption and nepotism

In Canada, five participants referenced inter-tribal conflicts as a concern; in Kenya, ten participants referred to this concern. For example, one respondent stated:

"My major concern is the security in South Sudan in terms of inter-tribal conflict. The government needs to act swiftly or else there is going to be a lot of genocide, of massacre, a lot of abuse of human rights in South Sudan." (Participant 11, Kenya)

Other responses addressed "internal security," which also points to a concern regarding

\footnotetext{
${ }^{58}$ Lyons (2008) states that "due to the nature of their attachment to the homeland, many in the diaspora have framed conflicts categorically and have supported the most militant and uncompromising leaders back home. The Ethiopian diaspora, therefore, has the capacity to make conflict resolution more difficult and the conflict more protracted" (p. 594). Koinova (2009) states that the distress behind the displacement becomes fixed in the memories of such diasporas and limits their ability to see the conflict in interactive terms or to desire a resolution of the conflict (see also Shain, 2002; Adamson, 2006). The evidence here suggests that these assumptions may not be accurate for all diasporas.

${ }^{59}$ The terminology used here was the term used by participants.
} 
inter-tribal conflict. Taking these responses into consideration, internal security was the chief concern among participants. ${ }^{60}$

Canadian respondents overwhelmingly stated that few other concerns, such as development, investment, or the conflict with Sudan could be addressed without first curbing inter-tribal conflict. One participant stated:

"I think if we can deal with internal security, that is the first priority. If we can get everyone together there is no insurgencies disturbing the peace, we can pull together and address the security between the North and South.... The first thing should be within the South. These people are not peaceful--everyone carries a gun and they can just go around and do anything. First we have to deal with our internal security." (Participant 4, Canada)

Poor governance was also indicated as a concern in both cases. Nearly every participant mentioned the need to change corruption and nepotism during interviews. The link between democracy, peace, and development was often acknowledged and participants indicated that to ensure safety, the GoSS must become more democratic and allow inclusion of representatives from ethnic groups other than those of the governing body. To this effect, one participant indicated:

"We want to see democracy take root. If there is peace, then there is respect for human rights. If there is respect for human rights, then there is freedom to express your opinions and therefore development will take place." (Participant 2, Canada)

Five participants presented governance (largely conceived) as a concern, nine participants mentioned corruption and four participants in Canada spoke of nepotism. In Kenya, four participants indicated governance; three indicated corruption, and none specifically mentioned nepotism. From the Kenyan responses, it became evident that many of the needs mentioned for South Sudan include reference to governance, leading us to believe that even when governance was not explicitly mentioned as a concern, it

${ }^{60} \mathrm{This}$ is also true of survey participants. 
remains as a concern. ${ }^{61}$

Even given these concerns, a significant number of participants expressed patience in waiting for changes to come, rather than indicating a desire for quick reaction to the lack of democracy in governance. "We are already being patient ... We are tired of war" (Participant 5, Canada). Participants expressed a focus on the future generation to develop governance in South Sudan now that the work of winning the new country has been done by the current generation. The remaining task of the current generation in leadership is to provide the foundation from which the upcoming generation can build.

"We at least have to give those who are just born or the new generation a chance to go to school so that one day they will build the country." (Participant 5 , Canada)

One respondent attributed patience to living in Canada and learning from processes here:

"I think one of the things that I have really learned in Canada is that change happens slowly. And always you have to think positive ... people have to advocate for change slowly and peacefully." (Participant 12, Canada)

As we will see below, this process of learning and transmitting values to the country of origin was the number one point of discussion of participants in both Canada and Kenya. I would also argue it is one of the most valuable findings of this study.

\subsubsection{Transmission of Ideas and Values}

The third theme emerging from the qualitative data concerns the transmissions of ideas and values. A high proportion of respondents indicated that the diaspora has a role to play in supporting peace within South Sudan and in developing the new country. The ability of the diaspora to help in meaningful ways to restore and maintain peace was presented in several ways. The first step many participants indicated is the

\footnotetext{
${ }^{61}$ A table summarizing interview responses related to concerns for South Sudan is available upon request.
} 
encouragement of dialogue within the diaspora--with the aim of changing the

relationships between different tribal communities within the host country. The majority of respondents indicated that greater unity could be seen in the diaspora than within South Sudan. This was particularly true of the South Sudanese diaspora in Kenya, where 11 of 15 interview participants stated that the community in Kenya is more united than those in South Sudan. One participant credited the foundation of this unity to life in the refugee camp:

"That bond of togetherness is what kept the South Sudanese together all along. ... We are in our minds and values, being a community is one of the keys. I think that is what made us succeed against all the things we have faced." (Participant 1 , Kenya)

On the other hand, in Canada participants expressed the presence of rifts, suggesting that unity may be somewhat tenuous and may fracture, depending on events between ethnic communities in South Sudan. There was an equal split between those who suggest that divisions are present in Canada and those who indicate that the community in Canada is more unified and progressing even further in that direction. Seven participants indicated each was true, and one did not address this point. ${ }^{62}$

Overcoming animosity and moving forward as a collective were expressed as important first steps in both host countries. These steps were described as preliminary to making direct contributions in South Sudan as well as to contributing indirectly by becoming a strong front for lobbying.

"I think we really need to begin to think collectively as a community ... we really need to begin to break the way people think in silos. One of the things that has kept us behind in so many ways is those ethnic groupings." (Participant 5, Canada)

\footnotetext{
${ }^{62} \mathrm{~A}$ table summarizing interview responses that address commonalities in responses, such as unity within the diaspora, the role that the diaspora should take, and elements in the host country that diasporas transmit is available upon request.
} 
"If there is a strong commitment, it can be done ... we are still a fractured society. Even though we are South Sudanese we still think in terms of 'my tribe' . .. it is the Achilles heel for our community." (Participant 12, Canada)

As we can see from these quotations, the community wants to move beyond the divisions that separate ethnic communities. This is seen as a strategy for becoming a stronger lobbying force within Canada, as well as for becoming more effective at promoting intertribal peace in South Sudan.

"For the community to be viable you have to speak in one voice ... by dividing your voices you effectively have erased yourself from contributing to either your community welfare or shaping the community that you live in." (Participant 9, Canada)

Dialogue was cited to be a crucial entry point for diasporas to engage with contacts at home. Participants indicated that the intent of dialogue is to influence how people back home think about peace, how inter-tribal relationships are negotiated, and how conflict resolution is approached.

"We need to stop tribalism in Canada--the same things can be able to impact people back home. We need to create that here. And not divide ourselves so we are able to go home and show them that this is what we are doing in Canada... we need to be an example for them." (Participant 10, Canada)

Many participants credited exposure to values, ideas, and strategies within the host country to opening their eyes to alternative methods of conflict resolution than those employed in South Sudan. Participants indicated frustration that conflict is most commonly resolved with violence in South Sudan. As a result of exposure to other forms of resolution, through dialogue for example, diasporas have a desire to promote this in South Sudan.

Diasporas see this sort of transmission of ideas and values as central to their contribution to their new country. 
"Our country has been born in a time where we do not have to do a lot of research on things that are happening around the globe--you just have to copy and paste, and we are grateful for that. So, looking into this, I personally see that a lot of ideas that we have are useful for home." (Participant 14, Canada)

"I think living in Toronto and seeing some things--having seen how the government works, how the civil service is maintained and operated ... there is a contribution of my experiences here to how I view South Sudan." (Participant 6, Canada)

"Canada is not built by one family, it is built across the whole country... I I think the system of governance in Canada is good in terms of the federal system, inclusiveness, and that is what we want to see in South Sudan." (Participant 4, Canada)

"Let us learn from this place.... Why don't we take an example? If the change has got to come back home, we have got to bring them the example from here." (Participant 15, Canada)

Similarly to the Canadian case, In Kenya exposure to members of different tribal

groups on a frequent basis has allowed for negative stereotypes and grudges to diminish.

"In Kenya I have interacted with Nuer and have the best close friends who are Nuer. They are good. So you see being outside has exposed me to them and I have learned many things. They are good people, intelligent people, who I appreciate. And because I have been outside I see what my traditional opinion said to me was not true. And so being outside here makes some bonds. We have learned together." (Participant 1, Kenya)

As much as exposure to more democratic processes and strategies of governance were cited as important points to learn, within the Kenyan participants it was indicated that Kenya also possessed qualities that they would not want to export to South Sudan. The first was corruption within the government. Several respondents indicated that corruption in the current government may have even come from Kenya, where officials learned how to profit from their positions. "We got the seed in Kenya and it has been planted there in Sudan" (Participant 7, Kenya). In these cases, respondents underscored the opportunity to learn from the mistakes of others and to take what works well, leaving 
behind that which will not.

The strong linkages to South Sudan provide an avenue for the transmission of ideas and values from host countries to South Sudan. Diasporas observe and participate in host countries and what they see and experience influences the fashion in which they engage with South Sudan and that which they promote through remittance activities. This avenue is one to which host countries could give more credit. Rather than limiting access of diasporas to structures through which to act, host governments could encourage greater participation in host societies to aid the accumulation of this knowledge. As it stands now, in both host countries, but perhaps particularly in the case of Kenya, limited access to official channels has encouraged diasporas to engage in activities at a different, more grassroots, level.

\subsubsection{Community Level Work}

Many participants indicated that they engage in transnational activities that do not depend on access to formal structures. This was particularly true among Kenyan respondents, where the data indicates that these individuals also experience barriers in their host country. Six participants expressed either participation in or organizational roles in development or peace initiatives in South Sudan. These individuals either initiated charitable organizations or led workshops and conferences during trips home. Ten participants indicated that they engaged in dialogue with people at home on issues of import to the country and often arranged community gatherings to facilitate this dialogue.$^{63}$ Such activities circumvent official structures and allow diasporas to engage

\footnotetext{
${ }^{63}$ The numbers in comparison for Canadian participants were lower. Six participants expressly stated that they were involved in community meetings regarding South Sudanese directed initiatives, two were involved in organizations working to support peace or development in South Sudan, and five were engaged in community level dialogue.
} 
through other channels.

As discussed earlier, in a study of Kurdish diasporas Natali (2007) concluded that the more access diasporas have to a national political system, the more diasporic activities are channeled into that system. She also concluded that diasporas linked to legitimate leaders and organizations are more likely to pursue strategies of negotiation than are diasporas that are delegitimized in the international arena. While the South Sudanese diaspora has not been delegitimized, it has had challenges accessing formal national channels to act through. Consistent with Natali's finding, it has turned outside national systems in its involvement with South Sudan. However, in contrast with Natali's conclusions, the actions of the diaspora are not confrontational. The unofficial channels were indicated to be potentially de-stabilizing in only two cases in Canada.

It is important to note that the government in South Sudan is not receptive to advise or other forms of input from the diaspora in South Sudan. This means that South Sudanese diasporas are not able to work through official channels in South Sudan. This suggests that any meaningful contributions towards peacebuilding or development by the diaspora can only come about at a community level.

\subsubsection{Conclusion}

In sum, the analysis presented here has provided further insight into the motivations and activities of South Sudanese diasporas in Canada and Kenya. Canadian respondents discuss values and processes in Canada that they want to see happening in South Sudan whereas the Kenyan respondents are more likely to state that they want to return to South Sudan and already commonly spend time moving in and out of the country, encouraging dialogue and peaceful interaction. In this latter case, diasporas in 
Kenya are finding ways to contribute to peacebuilding and development in South Sudan even in the absence of formal channels to work through.

Now that the hypotheses have been evaluated using quantitative analyses, and the qualitative data collected through interviews has been analyzed to draw out themes that contribute to our understanding of the system at work in determining why diasporas act the way they do, I will answer the research questions posed at the outset of this paper. The following section will address the research questions and evaluate them against the findings presented here.

\subsection{Research Questions: Asked and Answered}

The overarching question that directed this study was: Does integration into a host country affect the remittance behaviour of diasporas? Within this question, a more specific research question was asked: Does access to political, economic, and social opportunity structures increase or decrease the remittance behaviours of conflict generated diasporas? The literature reviewed in Chapter One suggests that I should receive positive responses to these questions. For example, Al-Ali, Black and Koser (2001a; 2001b) argued for the particular importance of capacity and access to opportunity structures in a host country in prompting behaviour. Cioffi-Revilla and Starr (1995) also argued that the opportunity to act is constrained or allowed depending on the structural context. On this basis, I argued that capacity (environmental factors creating possibilities and constraints, i.e., the structural context) and desire (the motivation behind choices) are the two critical components of the decision making process for diasporas.

However, based on the findings of this study I would argue that integration is not a strong predictor of remittance behaviours and that while access to political, social and 
economic opportunity structures in a host country may significantly help or hinder the transnational capabilities of diasporas, other factors present in the system limit the effect of these structures. A potential reason for this finding, which sits in opposition to CioffiRevilla and Starr (1995) and Al-Ali, Black and Koser (2001a; 2001b), may be that in the last decade technology has opened previously limited access to transportation and communication, contributing to the formation of stronger transnational networks. The host country environment as a determinant of diaspora behaviour may be something of the past. This study has not provided conclusive evidence to support or refute this claim, but does reveal the need for further research. While both the capacity of diasporas and their motivations are still important in understanding why diasporas act in certain ways and in predicting how they may act, what constitutes capacity may include factors previously not considered.

As discussed above, three additional factors that affect transnational acts of a diaspora must be considered. First, I must examine whether integration into a host country facilitates the transfer of social remittances. Second, I will explore whether the presence of social capital creates avenues through which diasporas can engage with a country of origin independently of their levels of integration into a host society. Finally, I investigate whether integration affects whether diasporas act in a peace supporting or peace wrecking capacity.

From the data presented here, social remittances emerge as a significant activity of South Sudanese diasporas. Following Levitt's (2008) definition of social remittances as the behaviours, ideas, values, identities, and social capital that flow from countries receiving a diaspora to those sending it, clearly the South Sudanese diasporic community 
is active in this sense. ${ }^{64}$ As suggested by Levitt, these remittances are a potential community development aid. We can see evidence here of each of the three types of social remittances Levitt identified: (a) normative structures (ideas, values, and beliefs); (b) systems of practice (actions based on normative structures: religious practices, patterns of civil and political participation, leadership styles and strategies); and (c) social capital. Social capital becomes an important avenue through which the remittance behaviours of diasporas can take place. Marrow (2005) clarifies that even when a host country creates barriers to formal participation in political processes, other institutions such as labour unions, churches, and voluntary organizations create skills that enable active participation.

This accumulation of skills, or "social capital" appears for South Sudanese diasporas in both host countries and, as suggested by Marrow (2005), may allow diasporas an increased ability to act from within a host country where barriers may be present in formal structures. It may also facilitate more effective remittance transfer from diasporas to people in the country of origin. Social capital may be why we see comparable levels of political and social remittance levels across Canadian and Kenyan communities. Social capital may in fact support transnational activity that may not be possible based on the levels of integration into a host society. Significantly, as we can see from Table 14, the presence of political remittance behaviours and the presence of social remittance behaviours was the strongest correlation found among all the variables

\footnotetext{
64 This finding is important because transmission of social remittances has been discussed as a significant method of changing norms (Levitt, 2008), which is particularly relevant in diaspora remittance behaviours. Social remittances then provide a critical window of opportunity for a host country to affect diasporic behaviours that can either promote or frustrate peace building in countries of origin.
} 
investigated. ${ }^{65}$ The presence of social capital might facilitate other forms of remittance behaviours. This link is one that should certainly be studied further.

In considering whether integration, or lack thereof, facilitates remittance behaviours that either promote or block peace in a country of origin, I found no evidence of a relationship. Diasporas in Kenya did not voice anything to suggest that they are more, or less, militant in their action than those in Canada. Respondents that indicate feeling exclusion from the host country rather than integration did not say anything that suggested they were more likely to engage in de-stabilizing activities. The only participant who exhibited more aggressive inclinations towards South Sudan, in this case towards the government, came from Canada. This participant reported feeling integrated.

In conclusion, the presence of social capital accumulation in the South Sudanese diaspora is a finding that provides insight into the relationship between the host country environment and remittance behaviours--which is not the relationship I expected to find. The potential of social capital to facilitate transnational capacity, and through that, transnational activity, is a critical point for future research.

\subsection{Conclusion}

"The best thing is to lobby among themselves and form some association that will really work for peace. First of all, they amongst themselves should have peace before they go and encourage people in South Sudan to have peace. The South Sudanese in Kenya are a composition of the different tribes in South Sudan and if they are united in Kenya they will be able to convince the South Sudanese to live peacefully and cooperate amongst themselves." (Participant 11, Kenya)

In this chapter I delved into the content of the interviews and through analysis of commonalities in responses, presented themes that emerged. These themes clarified the findings of the quantitative analysis and, in combination with those results, answered the

\footnotetext{
${ }^{65}$ The correlation found was 0.805 , significant at the 0.001 level.
} 
research questions. Themes presented here include the strong connection South Sudanese diasporas have to South Sudan, the overall peaceful attitude of this conflict-generated diaspora - significant as this is not the norm for conflicted-generated diaspora, and the presence of social remittances. The latter is important because social remittances are argued to be a key method for changing norms, particularly relevant because of the potential for such changes to impact peace perspectives and conflict issues (Levitt, 2008). Social remittances, and the potential of transmitted ideas to influence the actions of people in a host country, is crucial in the case of South Sudan where ethnic conflict is a constant danger. One of the strongest themes to emerge in the data was that diasporas in both host countries are collecting ideas and strategies for improving South Sudan, and in many cases these strategies revolve around creating peace and unity between ethnic groups. For example, one respondent has said:

"While in the village before I left South Sudan I knew that everyone keeps cows. While I have been in Kenya I have seen that people are living better lives without cows. ... I have a belief that people living in South Sudan can live without cows-there are other ways that they can live better." (Participant 1, Kenya)

Exposure to an existence that did not rely on cattle in Kenya encouraged at least one participant to think differently about reliance on cattle. Cattle-raiding is one of the greatest forms of instability in South Sudan because it prompts violent conflict between ethnic communities. This internalization and transmission of values and strategies for securing peace provides opportunity for a host country to affect diasporic behaviours that can either promote or frustrate peace building in countries of origin.

An answer to the central research question asked in this study-whether integration into a host country affects the remittance behaviour of diasporas-was presented. A statistical analysis of the data indicated that the only relationship between integration and 
remittance behaviours is financial remittances. Through the qualitative findings presented in this chapter, we are able to see the complexity of the factors contributing transnational activity. The discussion here of several of the factors that arose in the data, namely transnational linkages, social capital and the use of informal channels to engage in transnational activities, points us to interesting new areas of research.

Three future avenues for research are recommended: first, one might study the affect of transnational linkages of diasporic activity; second, one might examine the potential of social capital in facilitating transnational activities that might otherwise be constrained due to lack of access to opportunity structures. The latter is of particular interest when considering the relationship between social and political remittances. This relationship is one that must be further investigated. Third, investigating whether diasporas are utilizing informal structures to engage in activities in the country of origin, and tracing those structures will provide insight into activities that are occurring under the radar of official channels. The fact that South Sudanese diasporas in Kenya are involved in grass-roots peacebuilding activities suggests that other diasporas may be doing the same. Whether those activities are positive, as suggested here, or dangerous, as suggested by Natali (2007) warrants further investigation. 


\section{CHAPTER SEVEN: Conclusions}

"We should look at the common things that bring us together, not the differences that pull us apart. It is high time that we focus on peace and unity, that we can live in harmony, because if you talk about ethnicity it can be taken negatively or positively.... We look at each other as warring parties because we have had conflict before.... Now is high time that we stop all of those conflicts and move forward. It is up to us now. To remove this negative thing about ethnicity and try now speaking to our people in a way that will educate them." (Participant 7 , Kenya)

As this study makes evident, because of the complexity of factors that underpin opportunity and desire, understanding diaspora behaviour is a challenge. The host country, country of origin, and the broader international environment all contribute to a system of diasporic activity, and each factor can support or constrain that activity. The objectives of this study were threefold: to create a model that describes diaspora behaviour while delving into how integration into a host country contributes to engagement with the country of origin, as evidenced by the presence of remittance activities; to collect data on diaspora behaviour in two different host environments, one that has allowed diaspora integration, and another that has not; and to identify whether host country policy affects the engagement of diasporas with their country of origin. Each of these objectives has been met and in this chapter, I will review my conclusions, acknowledge the limitations and contributions of the study, and briefly indicate the implications of my findings for further research and policy.

\subsection{Summary of Findings}

Initially, based on a review of pertinent literature, I argued that one cannot overlook the importance of the role of structures in a host country in contributing to diaspora capacity and desire. In particular, I selected the proposition that access (or its lack) to 
political, economic, or social structures in a host country significantly enables or constrains the action of a diaspora for further study. I adopted the factors suggested by Al-Ali, Black, and Koser (2001a; 2001b) as constructs that determine the capability profile of a country of origin. After a review of the literature, involving an investigation of the pathways indicated by theorists and researchers, I developed a model of diasporic behaviour, satisfying the first objective of this study.

In Chapter 2, I considered the relationship between integration and diaspora remittance activities. Pérez-Armendáriz and Crow (2010), for example, found that the process of becoming integrated in a host country gave Mexican immigrants in the US skills to become more politically active in Mexico. Brinkerhoff (2009) argues that diasporic communities that are not given an opportunity to integrate into a host country and which are, therefore, blocked from receiving certain rights within that country, tend to focus on fighting for and defending rights within the host country. This will inevitably detract from a focus on issues in the country of origin. Finally, Guarinzo et al. (2003) and Van Hear, Pieke and Vertovec (2004) suggest that the longer a diaspora is in a host country and the more integrated the diaspora becomes, the more likely it is actively to engage with the country of origin. Three hypotheses were developed as a result of the addition of the integration literature and the arguments made by these scholars.

In Chapter 3, I outlined the methodology used in this study. I adopted a comparative framework in which I analyzed opportunity structures for diasporas in Canada and Kenya to provide indications of the consequences these structures have in disparate host country environments. The use of this framework advances and refines what is known about factors that contribute to diaspora action. This study is unique in 
research on diasporic communities as it provides empirical data on the affect of

integration on action directed towards a country of origin. The multi-strategy research

design chosen allowed for the collection of both qualitative data (which shows the

general perspectives of subjects) and quantitative data (which explores specific issues).

Utilizing this research strategy allows one to appreciate the advice of King, Keohane, and

Verba (1994), who argue that most social research does not fit clearly into one category

(quantitative or qualitative) alone and that the best research combines elements of each.

Indeed, this research strategy allowed an appreciation of the reasons behind the outcomes

observed and proved valuable when exploring previously unaddressed relationships.

In Chapter 5, I presented the results of data collection and analysis and tested the

hypotheses based on data analysis. The results are summarized in Table 16.

Table 16: Summary of hypotheses and results

\begin{tabular}{|l|l|l|}
\hline Hypothesis & Result & Evidence \\
\hline $\begin{array}{l}\text { Hypothesis 1: If a diasporic community } \\
\text { experiences high levels of integration then } \\
\text { that community will demonstrate high } \\
\text { levels of remittance activities. }\end{array}$ & $\begin{array}{l}\text { Null may be true - but not } \\
\text { across all remittance } \\
\text { behaviours }\end{array}$ & $\begin{array}{l}\text { A correlation between integration and } \\
\text { remittance behaviours was not found } \\
\text { across social and political remittances. } \\
\text { Economic remittances, specifically } \\
\text { financial, produced a significant } \\
\text { correlation. }\end{array}$ \\
\hline $\begin{array}{l}\text { Hypothesis 2: The level of integration } \\
\text { experienced by diasporas will not have an } \\
\text { affect on the desire or motivation of } \\
\text { diasporas to engage in remittance activities. }\end{array}$ & $\begin{array}{l}\text { Null does not appear to be } \\
\text { true. }\end{array}$ & $\begin{array}{l}\text { Motivation levels between host countries } \\
\text { did not differ--no variation on this } \\
\text { variable was found. All participants } \\
\text { noted strong motivation to contribute to } \\
\text { the country of origin. Different levels of } \\
\text { structural integration and different } \\
\text { individual experiences of integration do } \\
\text { not appear to have altered motivation } \\
\text { levels. This lack, paired with the } \\
\text { relatively high degree of transnational } \\
\text { activity exhibited in diasporic } \\
\text { communities in both host countries, may } \\
\text { indicate that motivation has a stronger } \\
\text { effect on behaviour than has capacity. }\end{array}$ \\
\hline $\begin{array}{l}\text { Hypothesis 3: If strong transnational } \\
\text { linkages are present in a diaspora, the } \\
\text { difference between the remittance levels in } \\
\text { countries will be small. }\end{array}$ & true. & $\begin{array}{l}\text { Participants, particularly those in Kenya, } \\
\text { indicate a strong presence of } \\
\text { transnational linkages. Utilizing these } \\
\text { linkages may have circumvented limits } \\
\text { to activity caused by lack of access to } \\
\text { opportunity structures in Kenya. }\end{array}$ \\
\hline
\end{tabular}


Hypotheses 2 and 3 are supported by this study. Future studies may need to increase the subject pool to determine whether the null hypothesis is proved or not in the case of the Hypothesis 1. Integration may facilitate access to the political, economic and social structures in a host society, however, the level of access alone does not necessarily constrain or promote remittance behaviours. It would also appear that the absence of capacity may not restrain diasporas from acting in ways they wish when high levels of desire are present, evidenced by the high degree of political and social remittance behaviours of the South Sudanese diaspora in Kenya. Several explanations for this unexpected finding were presented: the presence of transnational linkages and the presence of social capital. These factors may stand in place of opportunity structures and provide platforms to enact motivation.

Finally, Chapter 6 elaborated on the content of the interviews and presented themes that emerged. Themes presented here include the strong connection South Sudanese diasporas have to South Sudan, the overall peaceful attitude of this conflict-generated diaspora-significant as this is not the norm for conflicted-generated diaspora, and the presence of social remittances.

\subsection{Limitations and Contributions of this Study}

Although the methodology employed here resulted in the collection of a rich data set, some limitations arise. Here, I review the limitations of this study and consider the contributions made by it.

\subsubsection{Limitations of this study}

The objective of this research was to provide a descriptive and exploratory analysis of the transnational activities of the South Sudanese diaspora in two different host 
country environments. Since little prior research on the topic was available, the use of questionnaires and interviews as research methods was appropriate. Nonetheless, research using questionnaires and interviews have certain inherent limitations, which means that results should be interpreted with some caution. Specifically, results from this research may not be representative of all South Sudanese diasporas in either Canada or Kenya because the sampling design was not random in nature. Most respondents were recruited through the snowball technique and, thus, the pool of respondents had some degree of contact with one another; as a result, they may have had some common characteristics, for example, a proclivity towards political activity. Attempts were made to reach a variety of respondents, but this was not always possible.

Another significant limitation to the research was time constraints, which had implications for the amount of data collected. Due to the time required to (a) build relationships with South Sudanese communities in two countries, (b) establish trust, (c) interview those willing to participate (which often included rescheduling missed interview sessions), (d) transcribe the interview tapes, and (e) code the data, there was a limit to the number of participants that could be included. This limitation resulted in a small sample size, perhaps limiting my ability to find significant relationships.

Finally, the methodologies used mean that the findings are not truly generalizable. An important point that emerges from the research is the range of experiences of South Sudanese diasporas; the range of experiences does not allow that the findings presented here are the final word regarding the linkages between a host country environment and remittance behaviours. I do argue, however, that the benefits of the methodologies used outweigh the limitations. I gained insights into factors that I may have otherwise missed. 
As a result, this study makes several important contributions.

\subsubsection{Contributions of this Study}

The point of the work presented here was to gain a better understanding of the systems at work in diaspora behaviour and, in particular, in transnational activities or remittance behaviours. The broader context that shapes this behaviour is very complex. The study conducted here allows us to tease out some of the meaningful linkages within this context. If we conceptualize the system within which diasporas act as consisting of three spheres of influence--the country of origin, the factors intrinsic to individual diasporas, and the conditions within a host country-- this study contributes an exploration of the last of these spheres of influence. This study opens the door for further work that may either take up one of the other spheres, or focus on the intricacies of chains of influence within any of the three.

This study has made contributions in several areas. First, it provides insight into ways in which policy may be augmented or constructed to support and utilize Canada's rich diasporic population; second, it provides insight into the activities and concerns of a particular diasporic community; and, finally, it provides a foundation for further research.

\subsection{Implications of this Research}

As conflicts continue around the world, the international community, academics and policy makers must consider the influence of diaspora populations on those conflicts. Before design of policy for engaging with diasporas, a better understanding must be found regarding what motivates and enables diasporas to act. More work must be done on evaluating the factors that lead some diasporas to undermine peaceful resolution of homeland conflict while leading others to contribute to it. 


\subsubsection{Implications for Further Research}

"It is impossible to generalize about the African diaspora, let alone their roles in conflict. What we can do is conduct useful case studies from which to draw out wider lessons." (Koser, 2007, 239)

The linkages studied here have only recently begun to be explored and are not yet well understood. If transnational linkages in fact help disadvantaged diasporic communities overcome constraints to their activity, these linkages could be a critical pathway to study. Further, if, as suggested here, social capital is an avenue through which remittance behaviours of diasporas can take place, despite barriers to formal participation in political processes created by a host country or home country, it is important to explore social capital more explicitly. South Sudanese diaspora are involved in both local, international, and virtual organizations, which may allow the development of skills that enable active participation, as argued by Marrow (2005). If this accumulation of skills, or social capital facilitates more effective remittance transfer from diasporas to people in the country of origin, it may change the way that diasporas are studied. Research may move away from the study of localized structural and national factors towards connections that may be more important. The relationship between transnational linkages, which may facilitate transnational activity, and social capital, which may allow people to become active and make effective use of those channels, would be an interesting one to explore. Finally, the finding, consistent with Natali (2007), that the South Sudanese diaspora in Kenya has turned outside national systems in its involvement with South Sudan, and began to work through informal channels is provoking. This, combined with the fact that, in contrast with Natali's conclusions, the actions of the diaspora are not confrontational speaks to a final avenue for further inquiry. In closing, as these last two findings were not 
intended to be a focus of this study, a lesson revealed is that sometimes the questions that an investigator takes as incidental to a project produce the most interesting findings.

\subsubsection{Implications for Policy}

"Once they get this education they will go with a new democratic mentality. They will, and that will be a very big contribution." (Participant 3 , Kenya)

Mohamoud and Osman (2008) argue, in the context of the African diaspora, that the connection between a diaspora's activities and a conflict in their homelands has been largely overlooked in research and policy analysis, despite its critical significance.

Mohamoud and Osman (ibid, p. 44) state:

African diaspora organizations, groups and individuals occupy an inimitable space, as they live in two cultures, or between two cultures. This gives them the advantage of intimate knowledge about different social situations, local conditions and networks and cultural experiences in Africa to a far greater degree than people with only a western background.

Mohamoud and Osman suggest that due to the continued connection between diasporas and a country of origin, diasporas retain knowledge of how to work within local systems. Their knowledge allows diasporas to act in effective ways and it places a diaspora in a position as valuable advisor on conflict and development issues in their country of origin.

Evidence suggests that the South Sudanese diasporic communities in both Canada and Kenya are motivated to contribute to South Sudan and that they are willing to do what they can to see their country, the newest country in the world, succeed. This points to the fact that these populations are a reservoir of expertise about South Sudan that can be utilized to ensure that humanitarian and development support is directed to the right avenues. They also could ensure that investments are made in the right areas and that necessary support is directed towards building capacity in governance and rule of law. Tracing the capacities and intentions of the actions of diasporas can lend insight into 
policy prescriptions for host countries that can support positive outcomes.

It has been argued that policy interventions can make a difference to the role played by diasporas in conflict, specifically to reduce negative engagements and to encourage constructive contributions (Koser, 2007). The African Diaspora Policy Centre (2006), for example, argues that many domestic conflicts in African countries have not only been regionalized, but that they are also largely internationalized through the activities of diaspora groups. The African Diaspora Policy Centre also noted that generally, in policy discussions on conflict in Africa, diaspora are mentioned only in passing remarks and without further substantiation as negative agents in the processes of conflict. However, long-distance diaspora activities have both positive and negative consequences on conflict dynamics in their homelands. This reality makes it imperative to assign some priority to diaspora activities in policy and proposals designed to promote peace and security, political stability, and good governance in Africa.

Evidence indicates that foreign governments can encourage positive interventions by diaspora communities by giving them access to legitimate channels for engagement, such as including them in policy dialogues. Significantly, Natali (2007) discusses the way in which the United States government encouraged peacemakers to be created within Kurdish communities using this technique. Natali also suggests that by including the Iraqi Kurdish homeland elite and representatives living in the United States in wartime planning, the United States created a willingness of the local Kurdish diaspora community to work with, not against, international institutions and foreign governments. This suggests that the Canadian government may be missing an opportunity to engage the Sudanese diaspora to promote peace and stability in Sudan. The possibility remains that 
through the encouragement of dialogue to reconcile differences, the provision of support for non-violent conflict resolution, and the advocacy of remittances for the reconstruction of war-torn or severely under-developed areas, much could be done.

In sum, the quality of Canada's foreign policy may be enhanced through more systematic inclusion of inputs from transnational Canadians. An important way for the Government of Canada to support the Sudanese diaspora would be to provide support for community-based organizations that focus on building unity in the community and promoting unity and peace in South Sudan. Canada has committed a significant pool of resources to Sudan- $-\$ 760$ million in contributions to humanitarian objectives during the past four and a half years (Canadian Internat ional Development Agency, 2012). Peace is a necessary pre-requisite for the success of this investment.

One community-based organization existed in Toronto until recently, funded through Citizenship and Immigration Canada, but was closed when funding was withdrawn. If the government wanted to support the South Sudanese community in Canada without including the diaspora in foreign policy, or in the absence of a formal policy of diaspora engagement, supporting such organizations is a key strategy. Umbrella organizations provide a point of entry for providing formal skills in organizing, research, conflict-resolution, or alliance-building, which would greatly benefit the South Sudanese diaspora. We can see from the findings here that supporting cohesion will help lessen the ethnic divisions that persist both in the diaspora and more strongly in South Sudan. In addition, skills provided to the diaspora will find their way into South Sudan. A small investment can go a long way. 


\section{References}

Abu-Laban, B., Derwing, T., Krahn, H., Mulder, M., \& Wilkinson, L. (1999). The Settlement Experiences of Refugees in Alberta. Study Prepared for Citizenship and Immigration Canada, University of Alberta, Prairie Centre of Excellence for Research on Immigration and Integration.

Adamson, F. (2006). Crossing borders: International migration and national security. International Security, 31 (1), 165-199.

Al-Ali, N., Black, R., \& Koser, K. (2001a). Refugees and transnationalism: The experience of Bosnians and Eritreans in Europe. Journal of Ethnic and Migration Studies, 27 (4).

Al-Ali, N., Black, R., \& Koser, K. (2001b). The limits to 'transnationalism': Bosnian and Eritrean refugees in Europe as emerging transnational communities . Ethnic and Racial Studies, 24 (4), 578-600.

Ataca, B., \& Berry, J. W. (2002). Psychological, Sociocultural, and Marital Adaptation of Turkish Immigrant Couples in Canada. International Journal of Psychology, 37 (1), 13-26.

Barth, F. (1969). Ethnic Groups and Boundaries: The social organization of culture difference. (p. 153). London: Allen \& Unwin.

Benesova, S. (2004). Southern Sudanese Women in the Diaspora. The Osprey Journal of Ideas and Inquiry, 79.

Boulding, K. (1962). Conflict and Defense. New York: Harper \& Row.

Brinkerhoff, J. (2009). Diasporas and Conflict Societies: Conflict Entrepeneurs, Competing Interests or Contributors ro Stability and Development. Global Effects and Local Dynamics of Intrastate Conflicts International Workshop .

Bruneau, M. (2010). Diasporas, transnational spaces and communities. In R. Baubock, \& T. Faist (Eds.), Diaspora and Transnationalism: Concepts, Theories and Methods (pp. 35-50). Amsterdam: Amsterdam University Press.

Bryman, A., \& Teevan, J. (2005). Social Research Methods. Ontario, Canada: Oxford University Press.

Campbell, E. H. (2005). Formalizing the informal economy: Somali refugee and migrant trade networks in Nairobi. Binghamton University. Geneva: Global Commission on International Migration.

Cioffi-Revilla, C., \& Starr, H. (1995). Opportunity, Willingness and Political Uncertainty. Journal of Theoetical Politics, 7 (4), 447-476.

Cochrane, F. (2006). The Power of the Diaspora: Lessons from Irish-America in building Constituencies for Peace. DIASPORAS AND PEACE BUILDING (pp. 38-81). Toronto: University for Peace.

Coleman, J. S. (1988). Social Capital in the Creation of Human Capital. The American Journal of Sociology, 94, S95-S120.

Collier, P. (2006). Economic Causes of Civil Conflict and their Implications for Policy.

Collier, P. (2001). Economic causes of civil war and their implications for policy. In F. O. Chester A. Crocker (Ed.), Turbulent Peace: The Challenges of Managing International Conflict. United States Institute of Peace Press.

Collier, P., \& Hoeffler, A. (2001). Greed and Grievance in Civil War. Washington, DC: The World Bank. 
Collier, P., \& Hoeffler, A. (2000). Greed and Grievances in Civil War. Washington, DC: World Bank.

Davis, D., \& Moore, W. (1997). Ethnicity Matters: Transnational Ethnic Alliances and Foreign Policy Power. International Studies Quarterly, 41, 171-184.

de Costa, R. (2006). Rights of Refugees in the Context of Integration: Legal Standards and Recommendations. Retrieved March 13, 2012 from UNHCR: http://www.unhcr.org/refworld/pdfid/44bb9b684.pdf

Demmers, J. (2007). New wars and diasporas: suggestions for research and policy. Journal of Peace Conflict \& Development, 11, 4-26.

Denzin, N., \& Lincoln, Y. (2000). Introduction: The Discipline and Practice of Qualitative Research. In N. Denzin, \& Y. Lincoln, Handbook of Qualitative Research (pp. 1-28). Thousand Oaks, CA, USA: Sage Publications.

Diamond, B. (2000). For the benefit of all: Challenges of community economic development. Journal of Aboriginal Economic Development , 1 (2), 3-6.

Diverse Hamilton. (n.d.). Sudanese Community. Retrieved May 6, 2012 from Diverse Hamilton: http://www.diversehamilton.ca/africanCommunity/sudanese.html

Fair, C. (2007). The Sri Lankan Tamil Diaspora. In H. Smith, \& P. Stares (Eds.), Diasporas in Conflict (pp. 172-195). United Nations University.

Faist, T. (2010). Diaspora and transnationalism: What kind of dance partners? In R. Bauböck, \& T. Faist (Eds.), Diaspora and Transnationalism: Concepts, Theories and Methods (pp. 9-34). Amsterdam: Amsterdam University Press.

Fukuyama, F. (1995). Social Capital and the Global Economy. Foreign Affairs , 74 (5), 89-103.

Fukuyama, F. (2001). Social Capital, Civil Society and Development. Third World Quarterly, 22 (1), 7-20.

Ghedi, A. J. (2007). Diaspora Contribution to Innovative Sectors: The Horn of Africa's Experience. In U. J. Dahre (Ed.), The Role of Diasporas in Peace, Democracy and Development in the Horn of Africa (Research Report in Social Anthropology I ed.). Lund, Sweden: Media-Tryck Sociologen.

Gitari, A. (2000). Refugee Consortium Kenya. 8, 35-36.

Glaeser, E., Laibson, D., \& Sacerdote, B. (2002). An Economic Approach to Social Capital. The Economic Journal, 112, 437-458.

Glaeser, E., Laibson, D., Scheinkman, J., \& Soutter, C. (2000). Measuring Trust. Quarterly Journal of Economics, 65 (2), 811-846.

Government of Canada. (2011). Canada's Engagement in Sudan: Priorities and Objectives. Retrieved March 11, 2012 from Government of Canada - Sudan: http://www.canadainternational.gc.ca/sudansoudan/engagement.aspx?lang $=$ eng\&view $=\mathrm{d}$

Griffiths, D., Sigona, N., \& Zetter, R. (2005). Refugee Community Organisations and Dispersal Networks, Resources and Social Capital. Bristol: Polity Press.

Gurzu, A. (2011). How Diaspora Politics are Beginning to Drive Canada'a Foreign Policy. Retrieved September 13, 2011 from Embassy Magazine: http://embassymag.ca/page/printpage/ethnic-03-16-2011

Hassan, A. I. (2002). Refugees in Kenye and the Constitutional Review Process: The way forward. Retrieved October 12, 2011 from Constitution of Kenya Review Commission: http://www.commonlii.org/ke/other/KECKRC/2002/12.html 
International Crisis Group. (2010). Preventing Implosion in Sudan. Retrieved February 18, 2011 from International Crisis Group: Key Issues:

http://www.crisisgroup.org/en/key-issues/preventing-implosion-in-sudan.aspx

International Crisis Group. (2010). The Sri Lankan Tamil Diaspora after the LTTE. International Crisis Group. ICG.

Ionescu, D. (2005). Engaging Diasporas as Development Partners, For Home and Destination Countries. Workshop on the National Strategy for Migration . International Organization on Migration.

Jaji, R. (2009). Refugee Women and the Experiences of Local Integration in Nairobi, Kenya. doctoral dissertation, Bayreuth University, Harare.

Kibreab, G. (2007). The Eritrean Diaspora, the War of Independence, Post-Conflict (Re)construction and Democratisation. In U. J. Dahre (Ed.), The Role of Diasporas in Peace, Democracy and Development in the Horn of Africa (pp. 97-122). Lund, Sweden.

King, C., \& Melvin, N. J. (2000). Diaspora Politics: Ethnic Linkages, Foreign Policy, and Security in Eurasia. International Security, 24 (3), 108-138.

King, G., Keohane, R., \& Verba, S. (1994). Designing Social Inquiry: Scientific Interference in Qualitative Research. Princeton, NJ, USA: Princeton University Press.

Koch, K. (2006). Capacity Building for Peace and Development: The Afghan Diaspora in Toronto. Capacity Building for Peace and Development: Roles of Diaspora (pp. 155). Toronto: University for Peace.

Koinova, M. (2009). Conditions and timing of moderate radical diaspora mobilization: Evidence from confli. Working Paper, George Mason University, Centre for Global Studies.

Koser, K. (2007). International Migration: A Very Short Introduction. UK: Oxford University Press.

Krippendorff, K. (1980). Content Analysis. Beverly Hills, California: Sage Publications.

Kruk, M. E., Rockers, P. C., Varpilah, S. T., \& Macauley, R. (2011). Which doctor?: Determinants of utilization of formal and informal health care in postconflict liberia. Med Care , 49 (6), 585-591.

Kuhlman, T. (1991). The Economic Integration of Refugees in Developing Countries: A Research Model. Journal of Refugee Studies , 4 (1), 1-20.

Kunz, E. F. (1973). The Refugee in Flight: Kinetic Models and Forms of Displacement. International Migration Review , 7, 127-140.

Lemke, D. (1996). Why So Much Peace? Interstate War in Africa. Annual Meeting of the American Political Science Association. San Francisco, California.

Levin, S., \& Sidanius, J. (1999). Social Dominance and Social Identity in the United States and Israel: Ingroup Favoritism or Outgroup Derogation? Political Psychology, 20 (1), 99-126.

Levitt, P. (1998). Social Remittances: Migration Driven Local-Level Forms of Cultural Diffusion. International Migration Review, 32 (4), 926-948.

Lieber, M. (2008). National Institutions for a World Polity: Transnational Mirant Diasporas, Political Remittances and State Responses. 2008 Annual Conference of the International Studies Association. San Francisco. 
Lyons, T. (2006). Conflict-Generated Diasporas and Peacebuilding: A Conceptual Overview and Ethiopian Case Study. Capacity Building for Peace and Development: Roles of Diasporas (pp. 117-152). Toronto: University for Peace.

Lyons, T. (2006). Diasporas and Homeland Conflict. In B. Walter, \& M. Kahler (Eds.), Globalization, Territoriality, and Conflict. Cambridge: Cambridge University Press.

Lyons, T. (2008). Ethipoia's Convergence of Crises. Current History, 154-160.

Lyons, T. (2009). The Ethiopian Diaspora and Homeland Conflict. In S. Ege, H. Aspen, B. Teferra, \& S. Bekele (Ed.), Proceedings of the 16th International Conference of Ethiopian Studies. Trondheim.

Marrow, H. B. (2005). New Destinations and Immigrant Incorporation. Perspectives on Politics, 3 (4), 781-799.

McGown, R. B. (1999). Muslims in the Diaspora: The Somali Communicties of London and Toronto. Toronto, Ontario, Canada: University of Toronto Press.

Merriam, S. (2009). Qualitative Research: A Guide to Design and Implementation. San Fransisco, USA: Jossey-Bass.

Moghissi, H., Rahnema, S., \& Goodman, M. J. (2009). Diaspora by Design: Muslim Immigrants in Canada and Beyond. Toronto, Ontario, Canada: University of Toronto Press.

Mohamoud, A., \& Osman, S. (2008). The African Diaspora as Agents of Peace on the Continent. Conflict Trends, 4, 38-44.

Mohan, G. (2006). Embedded Cosmopolitanism and the Politics of ObligationL The Ghanian Diasporas and Development. Environment and Planning A , 38 (5), 867883.

Nagel, J. (1994). Constructing Ethnicity: Creating and Recreating Ethnic Identity and Culture. Social Problems, 41 (1), 152-176.

Nagel, J., \& Olzak, S. (1982). Ethnic Mobilization in New and Old States: An Extension of the Competition Model. Social Problems, 30 (2), 127-143.

Natali, D. (2007). Kurdish Interventions in the Iraq War. In H. Smith, \& P. Stares (Eds.), Diasporas in Conflict. New York: United Nations Press.

Neuendorf, K. (2002). The Content Analysis Guidebook. Thousand Oaks, California: Sage Publications.

Newland, K., \& Patrick, E. (2004). Beyond Remittances: The Role of Diaspora in Poverty Reduction in their Countries of Origin. A Scoping Study, Migration Policy Institute, Department of International Development, Washington.

Newland, K., Terrazas, A., \& Munster, R. (2010). Diaspora Philanthropy: Private Giving and Public Policy. Diasporas \& Development policy project, Migration Policy Institute.

Njanga, C. (2011). Giving Hope to Refugees: Celebrating World Refugee Day. Retrieved September 12, 2011 from Refugee Consotrtium of Kenya: http://www.rckkenya.org/index.php/component/content/article/43-blogs/463giving-hope-to-refugees-celebrating-world-refugee-day.html

Orjuela, C. (2006). Distant Warriors, Distant Peace Workers? Multiple Diaspora Roles in Sri Lanka's Violent Conflict. Capacity Building for Peace and Development: Roles of Diaspora (pp. 217-244). University for Peace. 
Parekh, B. (2003). Cosmopolitanism and global citizenship. Review of International Studies, 29, 3-17.

Patton, M. (2002). Qualitative Research and Evaluation Methods (3rd Edition ed.). Thousand Oaks, CA: Sage.

Pérez-Armendáriz, C., \& Crow, D. (2010). Do Migrants Remit Democracy? International Migration, Political Beliefs, and Behavior in Mexico. Comparative Political Studies, 43 (119).

Phalet, K., \& Swyngedouw, M. (2003). Measuring Immigrant Integration: The Case of Belgium. Migration Studies, 152, pp. 773-803.

Pieterse, J. N. (2003). Social capital and migration. Ethnicities , 3 (1), 5-34.

Portes, A. (1998). Social Capital: Its Origins and Applications in Modern Sociology. Annual Review of Sociology, 24, 1-24.

Putnam, R. D. (1993). Making democracy work: Civic traditions in modern Italy. Princeton: Princeton University Press.

Rea, L. M., \& Parker, R. A. (1992). Designing and Conducting Survey Research: A Comprehensive Guide. San Francisco, California, USA: Jossey-Bass Inc.

Refugee Consortium Of Kenya. (2005). Self Settled Refugees in Nairobi: A Close Look at their Coping Strategies. Information and Research Programme, Nairobi.

Refugees International. (2008). Kenya: National Registration Processes Leave Minorities on the Edge of Statelessness. Retrieved September 15, 2011 from Refugees International: http://www.refugeesinternational.org/policy/field-report/kenyanational-registration-processes-leave-minorities-edge-statelessness

Sanders, J. M. (2002). Ethnic Boundaries and Identity in Plural Societies. Annual Review of Sociology, 28, 327-357.

Schiller, N. G. (2010). A global perspective on transnational migration: Theorising migration without methodological nationalism. In R. Bauböck, \& T. Faist (Eds.), Diaspora and Transnationalism: Concepts, Theories and Methods (pp. 109-130). Amsterdam: Amsterdam University Press.

Shain, Y. (2007). Kinship and Diasporas in International Affairs. Ann Arbor, Michigan: University of Michigan Press.

Shain, Y. (2000). The Mexican-American Diaspora's Impact on Mexico. Political Science Quarterly, 114 (4), 661-691.

Shain, Y., \& Barth, A. (2003). Diasporas and International Relations Theory. International Organization, 57, 449-479.

Shain, Y., \& Bristman, B. (2002). Diaspora, Kinship and Loyalty: The Renewal of Jewish National Security. International Affairs, 78 (1), 69-95.

Shandy, D. J. (2007). Nuer Passages: Globalizing Sudanese Migration. Florida: University Press of Florida.

Sheffer, Gabriel. (2003). Diaspora Politics: At Home Abroad. Cambridge: Cambridge University Press.

Siverson, R., \& Starr, H. (1990). Opportunity, Willingess and the Diffusion of War. The American Political Science Review, 84 (1), 47-67.

Smith, H. (2007). Diasporas in International Conflict. In H. Smith, \& P. Stares (Eds.), Diasporas in Conflict: Peace Makers or Peace Wreckers? (pp. 3-16). New York: United Nations University Press. 
Spear, J. (2006). The Potential of Diaspora Groups to Contribute to Peace Building: A Scoping Paper. International Studies Association. San Diego.

Starr, H. (2000). Opportunity, Willingness and Geographic Information Systems (GIS): Reconceptualizing Borders in International Relations. New Methodologies of the Social Sciences: The Develpment and Application of Spatial Analysis for Political Methodology. Boulder, Colorado: University of Colorado.

Starr, H., \& Most, B. A. (1976). The Substance and Study of Borders in International Relations Research. International Studies Quarterly, 20 (4), 581-620.

Statistics Canada. (2010). 2006 Census of Population. Retrieved November 11, 2010 from http://www12.statcan.gc.ca/census-recensement/2006/dp-pd/tbt/Rpeng.cfm? $\mathrm{LANG}=\mathrm{E} \& \mathrm{APATH}=3 \& \mathrm{DETAIL}=0 \& \mathrm{DIM}=0 \& \mathrm{FL}=\mathrm{A} \& \mathrm{FREE}=0 \& \mathrm{GC}=0 \&$ $\mathrm{GID}=0 \& \mathrm{GK}=0 \& \mathrm{GRP}=1 \& \mathrm{PID}=99016 \& \mathrm{PRID}=0 \& \mathrm{PTYPE}=88971,97154 \& \mathrm{~S}=0 \& \mathrm{SH}$ OWALL $=0 \&$ SUB $=0 \&$ Temporal $=2006 \&$ THEME $=70 \& \mathrm{VID}=0 \& \mathrm{VNAMEE}=\& \mathrm{VNA}$ $\mathrm{MEF}=$

Statistics Canada. (2003). Longitudinal Survey of Immigrants to Canada: Process, progress and prospects . Housing, Family and Social Statistics Division. Minister of Industry.

Statistics Canada. (2006). Topic Based Tabulations. Retrieved December 8, 2011 from Stats Canada: http://www12.statcan.gc.ca/census-recensement/2006/dp-pd/tbt/Rpeng.cfm? $\mathrm{LANG}=\mathrm{E} \& \mathrm{APATH}=3 \& \mathrm{DETAIL}=0 \& \mathrm{DIM}=0 \& \mathrm{FL}=\mathrm{A} \& \mathrm{FREE}=0 \& \mathrm{GC}=0 \&$ $\mathrm{GID}=0 \& \mathrm{GK}=0 \& \mathrm{GRP}=1 \& \mathrm{PID}=92333 \& \mathrm{PRID}=0 \& \mathrm{PTYPE}=88971,97154 \& \mathrm{~S}=0 \& \mathrm{SH}$ OWALL $=0 \&$ SUB $=801 \&$ Temporal $=2006 \&$ THEME $=80 \& V I D=0 \& V N A M E E=\& V$ NAMEF

Tölölyan, K. (1991). The Nation-State and Its Others: In Lieu of a Preface. Diaspora: A Journal of Transnational Studies, 1 (1), 3-7.

The Mosaic Institute. (2009). Profile of a Community: A "Smart Map" of the Sudanese Diaspora in Canada. Retrieved February 12, 2011 from http://www.mosaicinstitute.ca/uploaded/tiny_mce/File/Sudanese_Report.pdf

The Mosaic Institute. (2010). Sudanese-Canadians and the Future of Sudan. Retrieved October 22, 2011 from http://www.mosaicinstitute.ca/uploaded/tiny_mce/File/FINALConferenceReportOc tober27_2010.pdf

Turner, M. (2008). Three Discourses on Diasporas and Peacebuilding. Paper, University of Bradford, UK, Department of Peace Studies.

UNHCR. (2011). 2011 UNHCR country operations profile - Kenya. Retrieved September 4, 2011 from UNHCR - The UN Refugee Agency: http://www.unhcr.org/cgi$\mathrm{bin} / \mathrm{texis} / \mathrm{vtx} /$ page?page $=49 \mathrm{e} 483 \mathrm{al} 6$

Van Hear, N., Pieke, F., \& Vertovec, S. (2004). The Contribution of UK-Based Diasporas to Development and Poverty Reduction. University of Oxford, ESRC Centre on Migration, Policy and Society (COMPAS).

Vertovec, S. (2004). Migrant transnationalism and modes of transformation. International Migration Review, 38 (2), 970-1001.

Vertovec, S. (2002). The Political Importance of Diasporas. In M. Glasius, \& M. Kaldor, Global Civil Society Yearbook (pp. 3-34). Oxford: Oxford University Press. 
Wahlbeck, Ö. (1998). Transnationalism and Diasporas: The Kurdish Example. International Sociological Association XIV World Congress of Sociology. Montreal, Canada.

Wayland, S. (2004). Ethnonationalist Networks and Transnational Opportunities: The Sri Lankan Tamil Diaspora. Review of International Studies, 30, 405-426.

Weber, R. (1990). Basic Content Analysis. Newbury Park, California: Sage Publications. Williams, J. (2006). Global Migration. Finance and Development , 43(3). Retrieved March 16, 2012 from http://www.imf.org/external/pubs/ft/fandd/2006/09/williams.htm

Wimmer, A. (2008). The Making and Unmaking of Ethnic Boundaries: A Multilevel Process Theory. American Journal of Sociology, 113 (4), 970-1022.

Yang, P. Q. (1994). Immigrant Naturalization. International Migration Review, 28 (3), 449-477.

Yeung, Henry Wai-chung. (1997). Critical realism and realist research in human geography: a method or a philosophy in search of a method? Progress in Human Geography 21: 51-67.

Zunzer, W. (2004). Diaspora Communities and Civil Conflict Transformation. Berghof Research Center for Constructive Conflict Management. 


\section{APPENDIX 1}

\section{Categorization of Diasporic Remittance Activities}

\begin{tabular}{|c|c|c|}
\hline & Activity & Examples \\
\hline Economic Remittances & $\begin{array}{l}\text { - Financial remittances } \\
\text { - Other remittances (e.g. } \\
\text { medicine, clothes) } \\
\text { - Investments } \\
\text { - Charitable donations } \\
\text { (Philanthropy) } \\
\text { - Taxes }\end{array}$ & $\begin{array}{l}\text { - Globally, migrants sent US\$ } 80 \text { billion in remittances to } \\
\text { developing countries in } 2002 \text {. Compared to } 33.1 \text { billion in } \\
\text { 1991, remittances more than doubled in that decade. } \\
\text { - In Albania, remittances account for } 12 \%-23 \% \text { of GDP. } \\
\text { International Monetary Fund, Bank of Albania, and The } \\
\text { World Bank reports indicate that remittances have been a } \\
\text { major factor in the financial stability of Albania. } \\
\text { Remittances exceed foreign direct investment and foreign } \\
\text { aid and are more stable. } \\
\text { - In Tajikistan, } 50 \% \text { of households are dependent on } \\
\text { remittance income, according to the International } \\
\text { Organization for Migration. } \\
\text { - The African Diaspora consists of approximately } 20 \text { to } 30 \\
\text { million adults who send about US\$ } 40 \text { billion annually to } \\
\text { their families and local communities. For the region as a } \\
\text { whole, this represents } 50 \% \text { more than net official } \\
\text { development assistance from all sources, and, for most } \\
\text { countries, the amount also exceeds foreign direct } \\
\text { investment). In several fragile states, remittances are } \\
\text { estimated to exceed } 50 \% \text { of GDP. }{ }^{69} \\
\text { - Nigeria is the top remittance recipient in Africa, } \\
\text { accounting for US\$ } 10 \text { billion in } 2010, \text { a slight increase } \\
\text { over the previous year (US\$ } 9.6 \text { billion). Other top } \\
\text { recipients include Sudan (US } \$ 3.2 \text { billion), Kenya (US\$ } \\
1.8 \text { billion), Senegal (US\$ } 1.2 \text { billion) and South Africa } \\
\text { (US\$ } 1.0 \text { billion). } \\
\text { - During the height of the insurgency, the LTTE had an } \\
\text { annual income that included US\$ } 60 \text { million from the } \\
\text { diaspora. These funds were obtained through voluntary } \\
\text { and coerced contributions. }\end{array}$ \\
\hline Political Remittances & $\begin{array}{l}\text { - Participation in } \\
\text { elections } \\
\text { - Membership in political } \\
\text { parties } \\
\text { - Indirect lobbying of } \\
\text { host country } \\
\text { government }\end{array}$ & $\begin{array}{l}\text { - The Croatian diaspora reportedly provided US\$ } 4 \text { million } \\
\text { in contributions to the electoral campaign of Franjo } \\
\text { Tudjman and was rewarded with } 12 \text { of the } 120 \\
\text { parliamentary seats in recognition of their role. A similar } \\
\text { outcome occurred in the election of President Sirileaf in } \\
\text { Liberia, whose campaign was supported and funded by } \\
\text { Liberian diasporas. } \\
\text { - In Mexico, financial remittances "pull" politicians to court } \\
\text { diasporas. The financial remittances of diasporas, which } \\
\text { are critical to many economies,are translated into political } \\
\text { rights that allow diasporas to act in country of origin } \\
\text { politics. } \\
\text { - International migrants are agents of democratic diffusion. } \\
\text { A study of Mexican diasporas found that they spread }\end{array}$ \\
\hline
\end{tabular}

${ }^{66}$ World Bank Global Development Finance Report (2003).

${ }^{67}$ Etleva Germenji (2005).

${ }^{68}$ Newland and Patrick (2004).

${ }^{69}$ World Bank Report (2003).

${ }^{70}$ Mohapatra, Ratha, and Silwal (2010).

${ }^{71}$ Fair (2007).

${ }^{72}$ Spear (2006).

${ }^{73}$ Lieber (2008). 


\begin{tabular}{|c|c|c|}
\hline & & $\begin{array}{l}\text { attitudes and behaviours from democratic host countries to } \\
\text { less democratic home countries by way of migrant returns, } \\
\text { cross-border communication between migrants still abroad } \\
\text { and their friends and family back home, and migrant } \\
\text { information networks in high-volume migration-producing } \\
\text { communities. }{ }^{74} \\
\text { - The Turkish diaspora lobbied US government agencies, } \\
\text { conducted demonstrations, media campaigns, television } \\
\text { and radio interviews, rallies, and conferences to push the } \\
\text { US to respect their national claims in post-Saddam Iraq. } \\
\text { The LTTE used its global networks to develop and } \\
\text { maintain political support from host countries. Lobbying } \\
\text { efforts were successful in creating state support for its } \\
\text { movements during the } 1980 \text { s and } 1990 \text { s. }^{76}\end{array}$ \\
\hline Social Remittances & $\begin{array}{l}\text { - Visits to friends and } \\
\text { family } \\
\text { - Social contacts } \\
\text { - 'Social capital' (values, } \\
\text { norms, access to } \\
\text { transactions facilitated } \\
\text { by relationships) } \\
\text { - Contributions to } \\
\text { newspapers circulated } \\
\text { in home country }\end{array}$ & $\begin{array}{l}\text { - Diasporas from the Dominican Republic living in the US } \\
\text { frequently travel back and forth and communicate with } \\
\text { people at home. Diasporas indicate that during such } \\
\text { meetings or conversations they would tell people at home } \\
\text { everything about the US--the rules, the laws, and the } \\
\text { customs. Various changes occurred in the Dominican } \\
\text { Republic as a result, including changes in notions of } \\
\text { gender identity and government practices. In addition, } \\
\text { status or prestige acquired in the US helped to gamer } \\
\text { favours or advantages for family members or friends at } \\
\text { home. } \\
\text { - Funding for Tamil websites and newspapers, abroad and at } \\
\text { home, came from diaspora donations. In addition, many } \\
\text { diasporas write articles posted in these media sources. }\end{array}$ \\
\hline
\end{tabular}

\footnotetext{
${ }_{74}^{74}$ Pérez-Armendáriz and Crow (2010).

75 Natali (2007).

${ }^{76}$ Fair (2007).

${ }^{77}$ Levitt (1998).

${ }^{78}$ Wayland (2004).
} 


\section{APPENDIX 2}

\section{Model of Diaspora Behaviour}

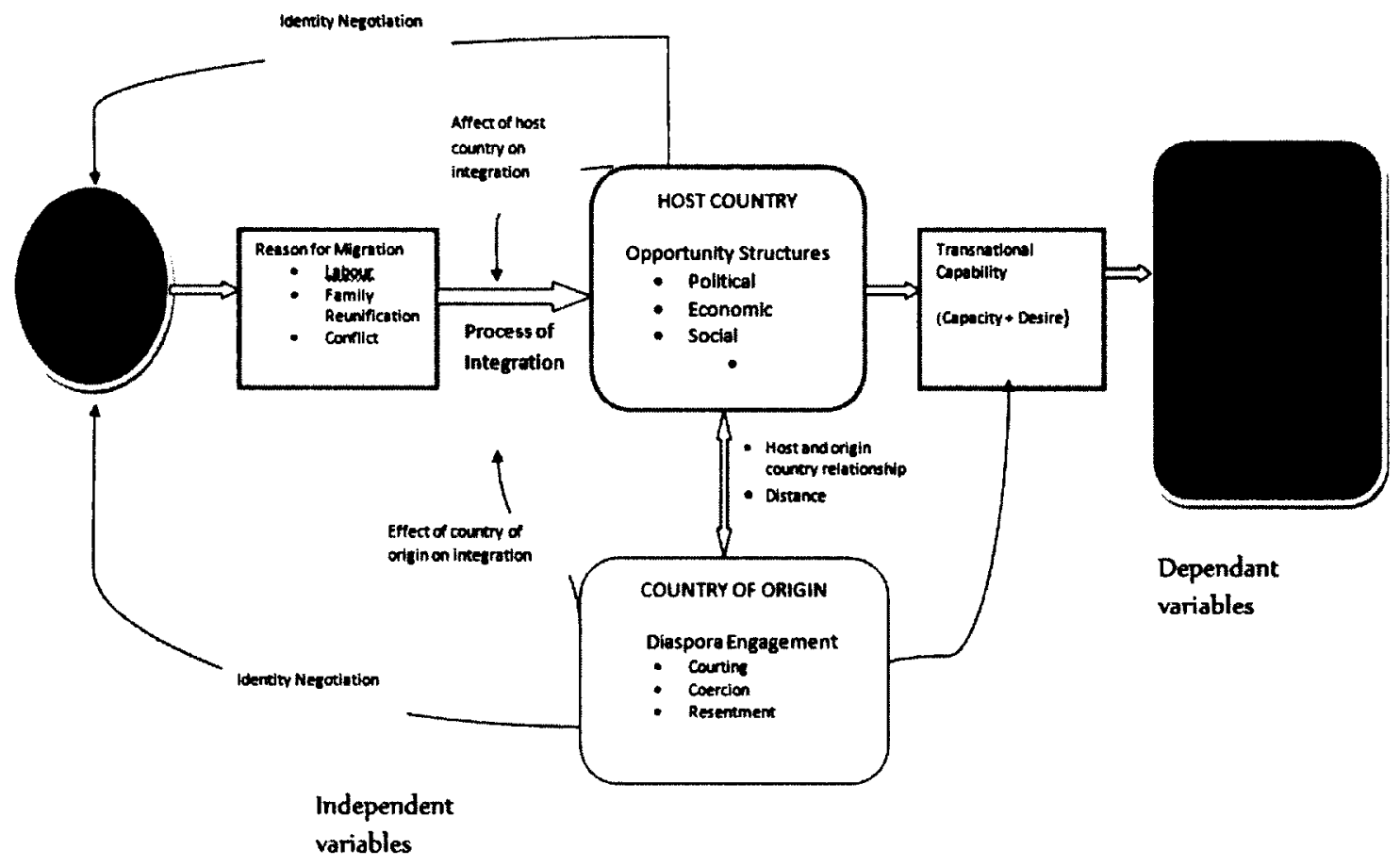




\section{APPENDIX 3}

\section{Survey}

Part A: Demographic Information

Age:

Gender:

Citizenship:

Year of first arrival in Canada/Kenya:

Languages Spoken:

Employment Status: (Please put a check mark beside your response)

\begin{tabular}{|l|l|}
\hline Unemployed & \\
\hline Employed - part time & \\
\hline Employed - full time & \\
\hline Student & \\
\hline
\end{tabular}

Education: (Please put a check mark beside the level you have completed)

Primary school

High school

Some college or university

Undergraduate degree

Graduate degree

Doctoral degree

How many of your close family members (spouse, siblings, children, parents) live in Kenya?

Proportion of family still in South Sudan: (Please put a check mark beside the appropriate response)

Only a few family members

The majority of family members

Where were you from in South Sudan?

\section{Part B: Contact with South Sudan}

1. How often do you visit South Sudan? (Please check the appropriate box) 


\begin{tabular}{|l|l|}
\hline Once a year or more & \\
\hline Once every one to three years & \\
\hline Every three to five years & \\
\hline Every five to ten years & \\
\hline Never & \\
\hline
\end{tabular}

2. Do you intend to permanently return to South Sudan? (Please circle) Yes No

3. How often are you in contact with friends or family in South Sudan? (Please check the appropriate box)

\begin{tabular}{|l|l|}
\hline Once a day & \\
\hline Once per week or more & \\
\hline Once every two weeks & \\
\hline Once per month & \\
\hline Less than once per month & \\
\hline
\end{tabular}

4. Do you access media (newspapers, websites, radio stations, etc.) from South Sudan? If so, which ones do you access?

\begin{tabular}{|l|l|}
\hline Newspapers & \\
\hline Online newspapers & \\
\hline Online or satellite television news sources & \\
\hline Radio & \\
\hline
\end{tabular}

Other:

5. How often do you access media from South Sudan?

\begin{tabular}{|l|l|}
\hline Once a day & \\
\hline Once per week or more & \\
\hline Once every two weeks & \\
\hline Once per month & \\
\hline Less than once per month & \\
\hline
\end{tabular}

6. How quickly do you receive news from South Sudan?

\begin{tabular}{|l|l|}
\hline Right away & \\
\hline After a few days & \\
\hline After a few weeks & \\
\hline After a few months & \\
\hline I do not receive news from South Sudan & \\
\hline
\end{tabular}

Part C: Experience in Kenya

1. Do you feel well integrated in Canada/Kenya?

$$
\text { Yes No }
$$

2. Is there anything that makes it difficult to integrate into Canadian/Kenyan society for you? If so, what makes it difficult? 
3. Do you participate in Canadian/Kenyan politics by doing any of the following? (Please check any/all that apply)

\begin{tabular}{|l|l|}
\hline Vote & \\
\hline Pay attention to media coverage of political issues in the newspaper or on the news & \\
\hline Attend rallies or marches related to Kenyan issues & \\
\hline Lobby for or against particular issues & \\
\hline Act in the government & \\
\hline Hold membership in a particular political party & \\
\hline
\end{tabular}

4. Is your participation in Canadian/Kenyan politics driven by your interest in Canada/Kenya's policies towards South Sudan? (Please circle)

Yes No I do not participate in Canadian/Kenyan politics

5. Do you feel that the Canadian/Kenyan government has been supportive of the reconstruction and development effort in South Sudan?

Yes $\quad$ No

6. Do you feel that there is more that the Canadian/Kenyan government should do to support South Sudan?

Yes $\quad$ No

7. Generally speaking, would you say that: (Please check one)

\begin{tabular}{|l|l|}
\hline Most people can be trusted & \\
\hline You need to be careful who you trust & \\
\hline
\end{tabular}

8. Which tribal group do you come from?

$\underline{\text { Part D - Relationship with South Sudan }}$

9. Do you send money to South Sudan? (Please circle)

Yes No

10. If you do send money, who do you send money to? (Please check all that apply)

\begin{tabular}{|l|l|}
\hline Family & \\
\hline Charities & \\
\hline Non-government funded community Organizations & \\
\hline Government run/political organizations & \\
\hline
\end{tabular}

Other:

11. If you do send money, how often do you send money to South Sudan?

Once per month 


\begin{tabular}{|l|l|}
\hline Every $1-3$ months & \\
\hline Every 3-6 months & \\
\hline Every 6-12 months & \\
\hline Very rarely or never & \\
\hline
\end{tabular}

12. How much money do you send to South Sudan, on average, per month? (Please check the appropriate box)

\begin{tabular}{|l|l|}
\hline $0-\$ 100 / 0-500 \mathrm{KSH}$ & \\
\hline$\$ 100-\$ 200 / 500-800 \mathrm{KSH}$ & \\
\hline$\$ 200-\$ 300 / 800-1000 \mathrm{KSH}$ & \\
\hline$\$ 300$ or more / $1000 \mathrm{KSH}$ or more & \\
\hline
\end{tabular}

13. Do you receive money from family members or friends that live in South Sudan?

Yes No

14. In what ways, if any, are you involved in the politics of South Sudan? (Please check all that apply)

\begin{tabular}{|l|l|}
\hline Vote in elections & \\
\hline Voted in the referendum & \\
\hline Have personal contact with members of the Government of South Sudan & \\
\hline Hold membership in a particular political party & \\
\hline
\end{tabular}

15. If there were a rally, march or demonstration taking place in Canada/Kenya about South Sudan would you attend? (Please circle)

$$
\text { Yes } \quad \text { No }
$$

16. How frequently do you discuss social or political activities occurring in South Sudan with other people from South Sudan that live in Kenya? (Please check the appropriate box)

\begin{tabular}{|l|l|}
\hline Never & \\
\hline Occasionally & \\
\hline Often & \\
\hline Very often & \\
\hline
\end{tabular}

17. Are you a member of any South Sudanese organizations in Kenya? If so, which ones?

18. If there were an issue that was important to you about South Sudan would you participate in any of the following activities in Kenya to raise awareness or encourage action by the Kenyan government? (Please check any/all that apply)

\begin{tabular}{|l|l|}
\hline Attend a rally, march or demonstration related to South Sudanese issues & \\
\hline Lobby the government for or against issues & \\
\hline Create or sign a petition & \\
\hline Communicate with the local, provincial or federal government & \\
\hline
\end{tabular}

19. Do you agree with this statement: It is important for South Sudanese living in Kenya to contribute to development and peacebuilding in South Sudan? (Please circle)

$$
\text { Yes No }
$$


20. Please indicate whether you agree or disagree with the following statements:

\begin{tabular}{|l|l|l|}
\hline $\begin{array}{l}\text { I support development in South Sudan because I want the country to be a better } \\
\text { place for my family and friends }\end{array}$ & Agree & Disagree \\
\hline $\begin{array}{l}\text { South Sudanese living outside South Sudan are encouraged to contribute in the } \\
\text { development effort in South Sudan }\end{array}$ & & \\
\hline $\begin{array}{l}\text { Family members encourage those living outside South Sudan to contribute to } \\
\text { development or reconstruction efforts }\end{array}$ & & \\
\hline $\begin{array}{l}\text { The government of South Sudan encourages those living outside South Sudan } \\
\text { to contribute }\end{array}$ & & \\
\hline People living outside South Sudan feel pressured to contribute & & \\
\hline
\end{tabular}

21. In your opinion, what are the most crucial issues in South Sudan right now? (Please number from 1 to 5 in order of importance with 1 being the most critical issue)

\begin{tabular}{|l|l|}
\hline Security along the border region & \\
\hline Economic Development & \\
\hline Governance & \\
\hline Lack of infrastructure & \\
\hline Risk of intertribal conflict & \\
\hline
\end{tabular}

\section{Interview Questions}

(After receiving consent the questions will be asked, not necessarily in this order nor with this precise phrasing).

1. How long have you lived in Canada/Kenya?

2. Do you feel well integrated into Canada/Kenya?

3. Did you experience any difficulty integrating?

4. Do you think that diasporas can contribute more to development and reconstruction in South Sudan by remaining in Canada or returning to South Sudan?

5. Do you have plans to either permanently or temporarily return to South Sudan? Why/why not?

6. What, if any, concerns do you have for the future of South Sudan?

7. What actions do you think South Sudanese people living outside of South Sudan should take now that South Sudan has gained independence?

8. Do you feel that it is important to make contributions to South Sudan?

9. Are you in close contact with people in South Sudan? How often are you in contact?

10. Do you ever send money home to South Sudan? 
11. Are you politically active in regards to South Sudan?

12. Do you feel that you contribute to peacebuilding, post-conflict reconstruction or development in South Sudan? In what ways?

13. What motivates you to make contributions (if you do)?

14. Do you think that experiences you have had in Canada/Kenya have influenced any of the ways that you contribute to South Sudan or the reasons why you contribute?

15. Is there anything about living here in Canada/Kenya that helps you to make these contributions? (if the person interviewed does contribute)

16. Are there any barriers to making contributions to peace building, development or reconstruction in South Sudan?

17. How best can the Canadian/Kenyan government support you in making positive contributions? (or those that do, if the individual interviewed personally does not)

18. What groups or organizations are you a part of in Canada/Kenya (if any)? Are any of these specifically focused on issues in South Sudan?

19. What role do South Sudanese organizations in Canada/Kenya currently play in the social or political climate in South Sudan?

20. Do you tend to most of your time with South Sudanese people in Canada/Kenya?

21. Do you have connections with South Sudanese living in other parts of the world?

22. Is it common that South Sudanese diaspora in different countries to be connected or communicate?

23. Do you think that the South Sudanese diasporas in Canada/Kenya are united in their vision for South Sudan, or are there different goals or efforts coming from different groups? 


\section{APPENDIX 4}

\section{Coding Schedule}

\section{Section One - Demographics}

1. Is the respondent living in Canada or Kenya? $(0=$ Canada, $1=$ Kenya $)$

2. Is the respondent male or female? $(0=$ male, $1=$ female $)$

3. How long has the respondent been in the host country? $(0-10$ years $=0,10-20$ years $=1)$

4. What age is the respondent? $(0-30=0,30+=1$, unknown=9)

5. Did the respondent leave South Sudan due to conflict? (no=0, yes=1)

\section{Section Two - Rationale}

6. Did the respondent indicate that they are concerned with the current political situation South Sudan? (no=0, yes $=1$ )

7. Did the respondent indicate that they are concerned with security in South Sudan? (no=0, yes $=1$ )

8. Did the respondent indicate concern for the development status of South Sudan? (no=0, yes $=1$ )

9. Did the respondent express concern that tribal clashed may lead to civil conflict in South Sudan? (no $=0$, yes $=1$ )

10. Did the respondent indicate concern that the relationship between Sudan and South Sudan would lead to renewed conflict? (no $=0$, yes $=1$ )

\section{Section Three - Integration}

11. Did this respondent indicate feeling integrated into their host country? (no=0, yes $=1$ )

12. How integrated does this diaspora seem, based on their discussion of his/her experience of integration in the host country?

1- only a little integrated

2- moderately integrated

3- very integrated

13. Does the respondent intend to return to South $\operatorname{Sudan}$ ? $(\mathrm{no}=0$, yes $=1$ )

14. Did the respondent express discontent with life in the host country? (no $=0$, yes $=1$ )

15. Did the participant sound as though they had made an effort to integrate into the host country environment? (no=0, yes $=1$ )

\section{Section Four - Transnational Capabilities}

Motivation/Desire

16. Did the participant express strong motivation to engage with South Sudan? (no=0, yes $=1$ )

17. Was this motivation driven by pressure or coercion to contribute? (no $=0$, yes $=1$ )

18. Was this motivation driven by empathy or concern for individuals that remained in South Sudan? $($ no $=0$, yes $=1)$

Ability

19. Did the respondent express access to employment, or mention having a job? (no=0, yes $=1$ ) 
20. Did the respondent indicate citizenship to the host country? (no $=0$, yes $=1$, did not mention=9)

21. Did the respondent indicate feelings of insecurity about their status in the host country? (no=0, yes=1)

22. Did the respondent indicate that they engaged in political activity (voting, lobbying, membership in a political party, etc.) in the host country? (no=0, yes=1)

23. Did the respondent indicate feelings of exclusion in the host country? (no=0, yes=1)

24. Did the respondent mention feeling/experiencing a lack of freedom within the host country? (no $=0$, yes $=1)$

\section{Section Five - Transnational Activities}

25. Overall, does the respondent seem very connected to the homeland, as evidenced by the degree and frequency of contact with South Sudan?

Financial Remittances

26. Did the respondent mention remitting financially? $(\mathrm{no}=0$, yes $=1$ )

27 . Did the respondent mention sending any other items home? $(n o=0, y e s=1)$

28 . Did the respondent mention having had invested in the country of origin? (no=0, yes=1)

Political Remittances

29. Does the respondent vote in elections in South Sudan? (no=0, yes=1)

30. Does the respondent hold membership in a political party in South $S u d a n$ ? (no=0, yes=1)

31. Does the respondent indirectly affect the politics of South Sudan through actions in the host country? For example, lobbying the host government, petitioning the government, working with the government to affect foreign policy etc. (no=0, yes $=1$ )

32. Does the respondent seem very knowledgeable about the political occurrences in South Sudan? (no=0, yes $=1$ )

Social Remittances

33. Does the respondent frequently visit family and friends in South Sudan? (Frequently = more than once per three years). (no $=0$, yes $=1$ )

34. Does the respondent maintain frequent contact with friends/family in South Sudan? (Frequent $=$ more than once per week). $($ no $=0$, yes $=1)$

35. Does the respondent spend most of his/her time with other South Sudanese individuals in the host country? (no=0, yes $=1$ )

36. Does the respondent contribute to newspapers or online media that are accessed by people in South Sudan? $(\mathrm{no}=0$, yes $=1)$

\section{Section Six - Social Capital and Transnational Linkages}

\section{Social Capital}

37. Did the respondent discuss the existence of networks that exist between diasporas that suggest that the presence of informal networks? $(\mathrm{no}=0$, yes $=1)$

38. Do the connections discussed between the respondent and other South Sudanese diasporas suggest the presence of trust/reciprocity? ( $\mathrm{no}=0$, yes $=1$, unanswerable $=9$ )

39. Is the respondent a member of any South Sudanese organizations within the host country? Transnational Linkages

40. Did the respondent indicate the presence of linkages between diasporas in multiple countries?

41. Does the respondent have contact with other South Sudanese diasporas outside of Canada/South Sudan? (no=0, yes $=1$ ) 